\title{
APPROACHES FOR THE OPTIMISATION OF DOUBLE SAMPLING FOR STRATIFICATION IN REPEATED FOREST INVENTORIES
}

\author{
Dissertation \\ zur Erlangung des Doktorgrades \\ der Fakultät für Forstwissenschaften und Waldökologie \\ der Georg-August-Universität Göttingen
}

\author{
vorgelegt von \\ Nikolas von Lüpke \\ geboren in Göttingen
}

Göttingen, 2013 
1. Referee: Prof. Dr. Joachim Saborowski

2. Referee: Prof. Dr. Jürgen Nagel

Day of oral examination: 26.03 .2013 


\section{Acknowledgements}

This thesis is the result of my work at the Department of Ecoinformatics, Biometrics and Forest Growth of the Büsgen Institute of the University of Göttingen between September 2009 and November 2012. It would not have been possible without the support of the following persons, whom I thank herewith.

- Prof. Dr. Joachim Saborowski gave me great support where- and whenever necessary.

- Prof. Dr. Jürgen Nagel acts as a Co-Referee.

- Michael Henke, Robert S. Nuske, Tim Ritter, Dr. Rainer Schulz and Jan C. Thiele enriched my work through fruitful discussions, proofreading and technical support.

- Jan Hansen helped me when problems with the program WaldPlaner 2.0 occured.

- Marco Bender and Jonas Ide helped me through the development of an optimisation algorithm for clustering of sampling points.

- The (former) colleagues at the Department of Ecoinformatics, Biometrics and Forest Growth, PD Dr. Wilfried Hakes, Reinhard Hemmerling, Prof. Dr. Winfried Kurth, Dr. Irina Kuzyakova, Dr. Reinhold Meyer, Yongzhi Ong, Sebastian Schoneberg, Prof. Dr. Dr. h.c. Branislav Sloboda, Dr. Katarína Smoleňová and Ilona Watteler-Spang always helped me and provided a nice atmosphere, which made me enjoying the work.

- The colleagues from the departments of Ecosystem Modelling, Forest Economics and Forest Utilization, Silviculture and Forest Ecology of the Temperate Zones, and Forest Inventory and Remote Sensing made my coming to work gladly.

- My family and friends. 



\section{Contents}

1 Introduction 1

2 Zusammengesetzte Schätzer für periodische Waldinventuren 7

2.1 Hintergrund . . . . . . . . . . . . . . . . . . 9 9

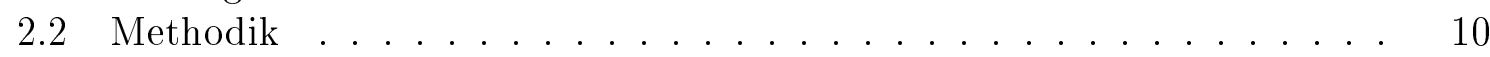

2.3 Modellstudie . . . . . . . . . . . . . . . . . 12

3 A three-phase sampling procedure for continuous forest inventory with partial re-measurement and updating of terrestrial sample plots $\quad 17$

3.1 Introduction . . . . . . . . . . . . . . . . 19

3.2 A three-phase estimator for stratification and regression . . . . . . . 21

3.3 Case Study . . . . . . . . . . . . . . . . . . 25

3.4 Conclusions . . . . . . . . . . . . . . . . . . . . 33

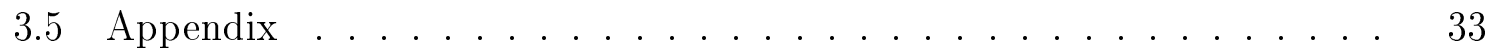

4 Combining double sampling for stratification and cluster sampling to a three-phase sampling design for continuous forest inventories $\quad 37$

4.1 Introduction . . . . . . . . . . . . . . . . . 39

4.2 An estimator for cluster subsampling of double sampling for stratification 40

4.3 Case Study . . . . . . . . . . . . . . . . . . . 44

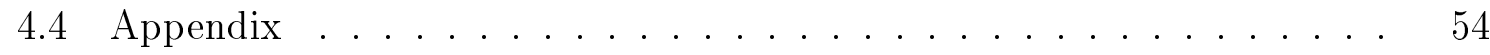

5 Clustering existing sample points in resource inventories 55

5.1 Introduction . . . . . . . . . . . . . . . 57

5.2 Methods . . . . . . . . . . . . . . . . . 59

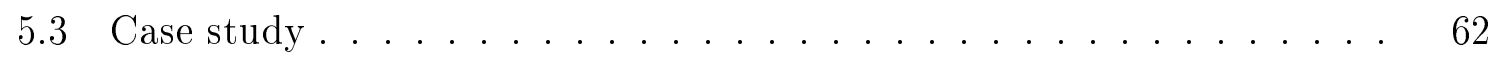

6 General Discussion $\quad 71$

$\begin{array}{lll}7 & \text { Summary } & 75\end{array}$

8 Zusammenfassung $\quad 77$

$\begin{array}{ll}\text { Bibliography } & 79\end{array}$ 



\section{Chapter 1}

\section{Introduction}

Since von Carlowitz (1713) introduced the principle of sustainability to forestry, it plays a central role in there, and over the last centuries it has been further developed and extended. To achieve and maintain sustainability in its different specifications (Speidel, 1984; Schanz, 1996) can be seen as one of the main goals or even the main goal of forestry. A prerequisite for such a sustainable forestry is information on the forest resources, their conditions and changes. This information is usually gained through forest inventories.

The first ancestors of modern forest inventory might be seen in the visual assessments that were carried out in Central Europe since the end of the Middle Ages (Loetsch \& Haller, 1973; Gabler \& Schadauer, 2007). At this time, information on the growing stock was demanded for forests close to towns and mines. There the first wood shortages occurred and made forest planning necessary. Maps of these forests were created and the growing stock was visually estimated per stand. Afterwards, these estimates were aligned with the yields from fellings and estimates for management units like forest districts where obtained by summarising the corresponding stand-level information. Due to their simplicity and cheapness these visual assessments were applied for a long time, e.g. until the 1940s in the state forest of Saxony (Loetsch \& Haller, 1973).

Based on the developments in sampling theory, the first approaches of sample-based forest inventories were presented in the 19th century; Examples are known from Germany and Sweden (Loetsch \& Haller, 1973; Gabler \& Schadauer, 2007). Around 1920 the first sample-based National Forest Inventories (NFIs) were introduced in Scandinavia (Gabler \& Schadauer, 2007; Tomppo et al., 2010b). Since then, such samplebased NFIs were set up in most European and North American countries (Tomppo et al., 2010b). With increasing statistical knowledge, technological progress and the advances in information technology, inventory methods have become more and more sophisticated, and still this development proceeds. Today, a plethora of sampling schemes exists (Cochran, 1977; de Vries, 1986; Schreuder et al., 1993; Shiver \& Borders, 1996; Särndal et al., 2003; Kangas \& Maltamo, 2006; Scheaffer et al., 2006; Gregoire \& Valentine, 2008; Mandallaz, 2008) and usually these methods are evaluated regarding their efficiency. Either the highest precision should be achieved with predefined inventory costs or a predefined precision should be achieved with minimal inventory costs.

Progress in the development of sampling schemes is especially important for largescale forest inventories. Due to their high costs, an increase of efficiency may lead to remarkable savings. A closer look on several NFIs (Lawrence et al., 2010; Tomppo et al., 2010a) reveals that their sampling schemes change frequently, likely because of 
an expected increase of efficiency. Moreover, the requirements for forest inventories increased and made changes necessary (McRoberts et al., 2010b). Besides information on growing stock, further information on biodiversity or carbon storage are required from such inventories today, e.g. for reporting for international conventions such as the Kyoto Protocol or the United Nations Framework Convention on Climate Change. Following McRoberts \& Tomppo (2007), information on 100-400 variables are collected in typical European NFIs. Despite all development, sampling schemes and definitions are still different across different countries (Gabler \& Schadauer, 2007; Tomppo et al., 2010a), making a common reporting for international conventions difficult. Therefore, currently efforts are made to harmonise these NFIs (McRoberts et al., 2009). The idea of harmonisation implies that it is not wanted to change existing sampling schemes substantially, once they have been established successfully. Rather, methods for making the results of different inventories comparable should be found. Thus, harmonisation can be seen as a 'bottom-up-approach' (Köhl et al., 2000; McRoberts et al., 2010a). In contrast, standardisation, as a 'top-down-approach', would aim at setting up a common standard for all countries (Köhl et al., 2000; McRoberts et al., 2010a). Even though existing sampling schemes should be maintained, further increases of efficiency are desired from authorities. This wish can be seen as main driver for current research on forest inventory. Within this research area, progress is not only restricted to the development of new sampling designs and the incorporation of new data sources or techniques into existing designs. Rather, also advances in sampling theory, e.g. the infinite population approach (Mandallaz, 2008), are made and conclusions are included in existing methods (e.g. Saborowski et al., 2010).

Terrestrial sampling is very cost-intensive and therefore its (partial) replacement by cheaper techniques like remote sensing is tried to be achieved. Following Gabler \& Schadauer (2007), using aerial images has become especially important in countries with large forest areas, e.g. Canada or the USA. But, even though the results of remote sensing techniques become better and better, terrestrial sampling cannot be replaced completely yet (McRoberts \& Tomppo, 2007; McRoberts et al., 2010b). Demands for species-specific information or information on deadwood, lichens or soil carbon make terrestrial sampling inevitable (McRoberts et al., 2010b). Nevertheless, a strong incorporation of remote sensing techniques may raise the efficiency of forest inventory designs.

A method that often uses remote sensing techniques and that is known to be efficient (Brassel \& Köhl, 2001; Saborowski et al., 2010) is double sampling for stratification (2st) (Cochran, 1977; de Vries, 1986; Schreuder et al., 1993; Shiver \& Borders, 1996; Särndal et al., 2003; Scheaffer et al., 2006; Gregoire \& Valentine, 2008; Mandallaz, 2008). In the classical two-phase design (Figure 1.1), data are obtained from the target variable as well as from an auxiliary variable. This auxiliary variable is qualitative and its sampling is cheaper than the one of the target variable. Therefore it is obtained at all sampling units in the first phase. By means of this auxiliary variable the population is stratified into different strata, according to different rules. The variability within these strata should be small whereas it should be high between them. Afterwards (phase II), the target variable is sampled per stratum in a sub-sample of the first-phase units. Thereby, 


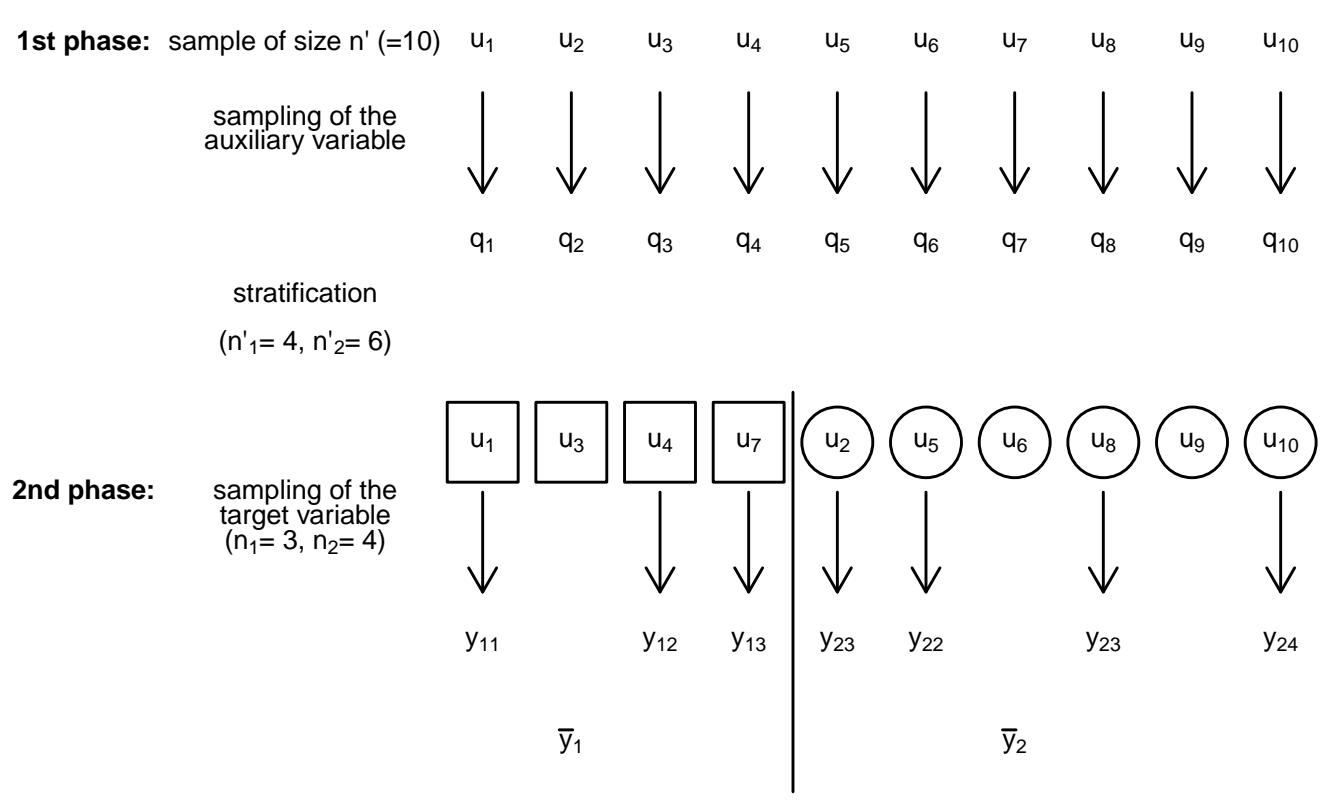

Figure 1.1: Sampling procedure of double sampling for stratification.

the sampling fraction, the ratio of the number of second- and first-phase plots, might be different across strata (Cochran, 1977).

The corresponding theory was given first by Neyman (1938). Since then this sampling scheme has constantly been further developed. In early literature, it was usually assumed that the second-phase sample size is fixed within a stratum. Sub-sampling procedures that are mathematically sound and free of this inconsistency were presented by Singh \& Singh (1965) and Rao (1973). Williams (2001) compared different estimators for sub-populations, and recently estimators for the mean and the variance have been presented, that are based on the infinite population approach in the first phase (Saborowski et al., 2010). Furthermore 2st has been expanded to designs with more than two phases (Frayer, 1979). Fattorini et al. (2006) expanded 2st by a further sub-stratification to a three-phase design, where the second-phase sampling units are further stratified.

Its high efficiency makes 2st attractive for forest inventories, and it is applied in the NFIs of Canada (Gillis et al., 2010) and Switzerland (Lanz et al., 2010) and different regional forest inventories in Italy (Gasparini et al., 2010). Another application of 2st is known from a private forest administration in Southern Germany (Nothdurft et al., 2009). Chojnacky (1998) describes an application in the Interior West of the USA. Also the forest administration of Lower Saxony, Germany, decided in favour of a 2st-design, when the Forest District Inventory was renewed in 1998 (Böckmann et al., 1998; Dahm \& Saborowski, 1998). Usually, CIR aerial images are taken and analysed in these forest inventory applications. The results of these analyses are then used as qualitative variables for the stratification. When designing strata, it has to be kept in 
mind that the allocation of sampling units to them can easily be done, trying to reduce the risk of misclassification. Therefore, the number of strata should be small. In several forest inventory applications only two strata, e.g. forest and non-forest area, are used. Despite the already high efficiency of this method, further cost reductions are desired from authorities.

Possibilities for such cost-reductions are in particular given for repeated inventories. For these inventories multiple designs and analysis procedures exist, e.g. the possibility to use data from a previous inventory occasion as additional data source is given (Scott et al., 1999). These data hold valuable information and often they are used in the context of Sampling with Partial Replacement (SPR) (Ware \& Cunia, 1962; Scott, 1984; Gregoire, 2005). Therein only a certain percentage of the units from the previous occasion are remeasured at a following occasion, the omitted units are replaced by new ones. Through regression the data from the previous occasion are then updated and incorporated into the overall estimation (Köhl, 1994). Thus it is possible to achieve on the one hand estimates of current status and on the other hand of changes between the two occasions. Bickford et al. (1963) presented a combination of 2st and SPR, and a corresponding three-phase design was given by Scott \& Köhl (1994). A further possibility for incorporating data from a previous inventory occasion is the so-called Mixed Estimation approach for Rotating Panel Systems (van Deusen, 1996). For this approach the sampling units are partitioned into equally sized sub-samples. Each year, one of these sub-samples is inventoried and updates are calculated for the rest of the sampling units. These updates are based on data from previous inventory occasions. Thus, the inventory-cycle is as long as the number of sub-samples. This procedure becomes advantageous through a constant sampling effort and thereby planning certainty per year.

Due to the rapid development of forest growth models and the increasing reliability of their results (Pretzsch \& Ďurský, 2001; Pretzsch, 2002, 2009; Schmid et al., 2006; Albrecht et al., 2009; Härkönen et al., 2010; Vospernik et al., 2010), it seems worthwhile to think of incorporating them instead of data from a previous occasion into forest inventory methods. But, this will only lead to good results if the growth model is parameterised for the inventory area, and if the time interval between inventory occasions is relatively small. Albrecht et al. (2011) presented methods for testing the transferability of forest growth models to other regions than the one used for parameterisation. They suggest starting with qualitative and quantitative evaluations, followed by adaption through e.g. re-parameterisation of model functions. Finally, test applications are recommended.

Another approach to reduce inventory costs is to create more efficient sampling designs for the execution of the terrestrial sampling. A sampling design, whose execution is usually assumed to be efficient, is cluster sampling (cl). In this design spatial clusters of sampling units are formed and afterwards a sub-sample of these clusters is inventoried (Cochran, 1977; Gregoire \& Valentine, 2008). Thereby a high variability within and a low variability between clusters is tried to be achieved. Furthermore, it is mostly desired to execute the field work per cluster during one working day (Kleinn, 1996), leading usually to clusters of homogenous size. Nevertheless, numerous different cluster-shapes 
such as triangle, cross or square exist. Clustering becomes especially advantageous in remote regions with bad infrastructure, where the costs for travelling between sampling units are high. Nevertheless, also applications from regions with a good infrastructure are known, e.g. the NFIs of Austria (Gschwantner et al., 2010), Finland (Tomppo \& Tuomainen, 2010) and Germany (Polley et al., 2010) follow cl-designs. Even though the precision of $\mathrm{cl}$ is always lower than that of Simple Random Sampling (SRS) with the same sample size, the costs might be lower than those of other designs. This is the case if a sufficiently high number of clusters can be sampled at lower costs than the sampling units of other schemes.

The present thesis aims to be part of the constantly ongoing process of designing 2 st more efficient, and in the following several approaches to achieve this goal are presented. All these approaches have been applied in case studies with data from the Forest District Inventory of Lower Saxony, Germany, that follows a 2st-design (Böckmann et al., 1998; Dahm \& Saborowski, 1998). In a cycle of approximately ten years all forest districts are subsequently inventoried and the first run has been executed between 1999 and 2008. The fact that meanwhile data from a second inventory occasion are available for several forest districts, offered the opportunity to compare the classical 2st-design with new designs that incorporate growth simulations in their estimations for these districts. These growth simulations have been carried out with the program WaldPlaner 2.0 (Hansen, 2006; Albert \& Hansen, 2007) that is based on the individual tree-growth model BWinPro (Nagel, 1996; Nagel et al., 2002, 2006; Nagel \& Schmidt, 2006). This model has been developed at the Northwest German Forest Research Station and was parameterised with data from Northern Germany, in particular from Lower Saxony and was assumed to provide the most reliable and precise growth predictions for the study area. In addition, the default settings follow the Federal State silvicultural program of Lower Saxony (LÖWE). One aim of this silvicultural program is to raise the proportion of mixed and broadleafed stands. Today, the forecasts of BWinPro are used in the planning process of Forest Service in Lower Saxony (Böckmann, 2004; Nagel, 2004; Nagel \& Schmidt, 2006). Based on BWinPro, the program WaldPlaner 2.0 was developed, and with this program it is possible to run large-scale simulations, as needed for the case studies.

In total, four approaches are presented in the following four chapters; each of them can be read independently from the others. Within these chapters background and methods of the respective approaches are thoroughly described, and results of the corresponding case studies are presented and discussed. A general discussion of the results of all four case studies can be found in chapter 6 .

In the first case study (chapter 2) an approach of combining current inventory data and growth model-based updates of the data from the previous inventory occasion in a Composite Estimator after Schaible (1978) is presented. Therein, the idea is to reduce the sample size of terrestrial sampling units and compensate for the following loss in precision through the incorporation of growth model-based updates. As the incurring additional costs of growth simulations are expected to be smaller than the savings through sample size reduction, a reduction of the overall costs might be achieved but is expected to be small or even irrelevant. An early approach of using a Composite 
Estimator in forest inventories was given by Green \& Strawderman (1986), who could show that its use can decrease the recommended sample size but did not use it in the context of repeated inventories.

A further approach for the combination of 2st and growth model-based updates is presented in chapter 3. 2st and double sampling for regression are combined to a three-phase sampling design, as described first by Saborowski (1994). In contrast to the Composite Estimator, this approach directly exploits the correlations between past or predicted and current inventory plot data, which are shown to be high. The designbased estimators are expanded under the infinite population approach in the first phase and applied in a case study. Besides the results of forest growth simulations, data from the preceding inventory occasion are used in this case study to assess the additional benefit of growth model-based predictions.

As described above, the execution of clustered sampling designs is often assumed to be more efficient than that of SRS-schemes. Therefore, the extension of 2 st by cluster sub-sampling to a three-phase design seems also promising for raising the efficiency of classical 2st. In chapter 4, such a 2st,cl-design, the corresponding estimators and an application in a case study are presented. Again, the infinite population approach is used for the first phase. Within the case study the general performance of the estimator, compared to 2st, is analysed as well as the effect of different cluster types on the variance of the estimator.

If existing sampling schemes should be converted into clustered schemes, like the 2st,cl-scheme in chapter 4, methods for building these clusters are needed. This is the reason for the research on cluster algorithms, as presented in chapter $\mathbf{5}$ that aims to find methods for building clusters of homogenous sizes. Furthermore, short within- and large between-cluster distances are required for reducing the time-consumption and thereby the costs of terrestrial sampling. Within the case study classical clustering algorithms as well as algorithms of the vehicle routing problem are used, and their results are compared. 


\section{Chapter 2}

\section{Zusammengesetzte Schätzer für periodische Waldinventuren}

Nikolas von Lüpke ${ }^{1}$ - Jürgen Nagel ${ }^{2}$ - Joachim Saborowski ${ }^{1,3}$

${ }^{1}$ Department of Ecoinformatics, Biometrics and Forest Growth,

University of Göttingen, Büsgenweg 4, 37077 Göttingen, Germany

${ }^{2}$ Northwest German Forest Research Station,

Grätzelstraße 2, 37079 Göttingen, Germany

${ }^{3}$ Department of Ecosystem Modelling,

University of Göttingen, Büsgenweg 4, 37077 Göttingen, Germany

Published in:

Deutscher Verband Forstlicher Forschungsanstalten, Sektion Forstliche Biometrie und Informatik - 22. Tagung, 13-21. 
- Jürgen Nagel supported the forest growth simulations.

- Joachim Saborowski supported the analysis of the results and the writing of the manuscript. 


\section{Summary}

Composite estimators are long established (Schaible, 1978). These estimators are a weighted mean of a direct and a synthetic estimator. Very important for the accuracy of the estimate is the choice of a correct weight. In this article we present a composite estimator, whose components are i) an actual double sample for stratification and ii) a simulation of growth and yield of the plot data measured at the former inventory. The direct estimator is based on a reduced forest district inventory in Lower Saxony, which follows a double sampling for stratification scheme since 1999 (Böckmann et al., 1998). The Forest growth simulations are carried out with the program WaldPlaner 2.0 of the Northwest German Forest Research Station (Albert \& Hansen, 2007; Hansen, 2006). First results show that it is possible to construct a composite estimator for this purpose. However, the differences between the results of the simulation and the second inventory are too big to reduce the sample size of the second inventory remarkably.

\section{Zusammenfassung}

Zusammengesetzte Schätzer sind seit langem bekannt (Schaible, 1978). Bei diesen Schätzern handelt es sich um einen gewichteten Mittelwert aus einem direkten und einem synthetischen Schätzer. Die Schätzgenauigkeit hängt dabei bedeutend von der Wahl des richtigen Gewichtes ab. In dieser Arbeit wird ein zusammengesetzter Schätzer vorgestellt, dessen zwei Komponenten aus i) einer aktuellen zweiphasigen Stichprobe zur Stratifizierung und ii) Fortschreibung der vorausgegangenen Inventur mit Hilfe von Waldwachstumsmodellen berechnet werden. Grundlage des direkten Schätzers ist eine reduzierte Betriebsinventur, wie sie in Niedersachsen seit 1999 als zweiphasige Stichprobe zur Stratifizierung durchgeführt wird (Böckmann et al., 1998). Die Waldwachstumssimulationen wurden mit dem Programm WaldPlaner 2.0 der Nordwestdeutschen Forstlichen Versuchsanstalt (Albert \& Hansen, 2007; Hansen, 2006) durchgeführt. Erste Ergebnisse zeigen, dass sich ein zusammengesetzter Schätzer für diesen Fall konstruieren lässt. Allerdings sind die Unterschiede zwischen den Daten der Fortschreibungen und denen des zweiten Inventurdurchgangs noch zu groß, um den Stichprobenumfang merklich zu reduzieren.

\subsection{Hintergrund}

Die Güte von Waldinventurverfahren wird häufig an ihrer Kosteneffizienz gemessen. Man erwartet entweder die größtmögliche Schätzgenauigkeit bei einem vorgegebenen Kostenrahmen oder die geringsten Kosten bei einer vorgegebenen Schätzgenauigkeit. Auch die Ausgangsfrage dieser Studie - Wie können periodische Inventurverfahren so verändert werden, dass i) die Aufnahmekosten verringert werden und ii) die Schätzgenauigkeit annähernd gleich bleibt? - fragt nach einer größeren Kosteneffizienz. Der in dieser Arbeit vorgestellt Lösungsansatz sieht vor, den Präzisionsverlust, der durch 
eine geringere Stichprobendichte entsteht, durch Nutzung von Informationen aus vorherigen Inventuren auszugleichen. Dabei sollen Wachstumsprognosen, basierend auf den Daten des ersten Inventurdurchgangs, erstellt und mit den Werten einer ausgedünnten Stichprobe beim zweiten Inventurdurchgang kombiniert werden.

\subsection{Methodik}

\subsubsection{Zusammengesetzter Schätzer}

Bei zusammengesetzten Schätzern $\left(\Theta_{z u s}\right)$ handelt es sich um einen gewichteten Mittelwert (Gleichung 2.1) aus einem direkten $\left(\Theta_{\text {dir }}\right)$ und einem synthetischen Schätzer $\left(\Theta_{\text {syn }}\right)$. Anwendung finden sie beispielsweise zur Schätzung von Durchmesserverteilungen (Bierer, 2008).

$$
\hat{\Theta}_{z u s}=\phi \hat{\Theta}_{d i r}+(1-\phi) \hat{\Theta}_{s y n}
$$

Entscheidend ist dabei die Wahl des richtigen Gewichts $(\phi)$, das Werte zwischen 0 und 1 annehmen kann (Gleichung 2.2).

$$
\phi^{*}=\frac{M S E\left(\hat{\Theta}_{d i r}\right)-E\left(\left(\hat{\Theta}_{d i r}-\Theta\right)\left(\hat{\Theta}_{s y n}-\Theta\right)\right)}{M S E\left(\hat{\Theta}_{d i r}\right)+M S E\left(\hat{\Theta}_{s y n}\right)-2 E\left(\left(\hat{\Theta}_{d i r}-\Theta\right)\left(\hat{\Theta}_{s y n}-\Theta\right)\right)}
$$

Nimmt man an, dass die Kovarianz im Verhältnis zum mittleren quadratischen Fehler (MSE) des synthetischen Schätzers relativ klein ist, kann das optimale Gewicht nach Schaible (1978) näherungsweise wie folgt berechnet werden.

$$
\phi_{a p p}^{*}=\frac{M S E\left(\hat{\Theta}_{d i r}\right)}{M S E\left(\hat{\Theta}_{d i r}\right)+M S E\left(\hat{\Theta}_{s y n}\right)}
$$

Schaible (1978) konnte zeigen, dass, bei Verwendung seiner Approximation, der MSE eines zusammengesetzten Schätzers höchstens so groß wie der größere MSE der beiden Schätzer ist, bei geschickter Wahl von $\phi$ aber sogar kleiner als der niedrigere MSE der beiden Schätzer sein kann (Abbildung 2.1).

Särndal et al. (2003) weisen darauf hin, dass der Anteil des direkten Schätzers mit steigender Anzahl von Stichprobenpunkten in der Fläche zunehmen sollte. Bei entsprechendem Stichprobendesign ist dieser im Gegensatz zum synthetischen Schätzer unverzerrt. Mit abnehmender Anzahl von Stichprobenpunkten in der Fläche sollte dagegen der Anteil des indirekten Schätzers zunehmen, da der direkte Schätzer dann eine hohe Varianz aufweist (Särndal et al., 2003). Um Aussagen über die Schätzgenauigkeit des zusammengesetzten Schätzers treffen zu können, kann der MSE desselbigen berechnet 

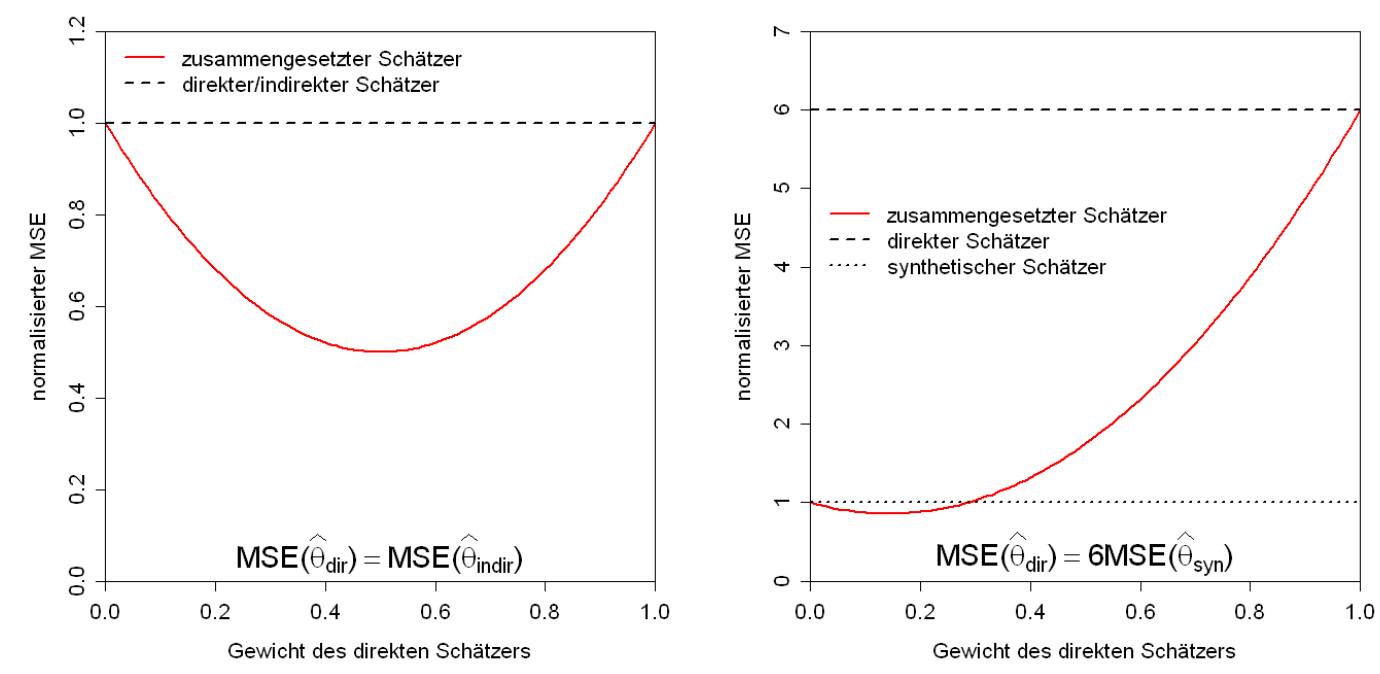

Abbildung 2.1: Der normalisierte MSE des zusammengesetzten Schätzers im Vergleich zum normalisierten MSE des direkten und synthetischen Schätzers bei unterschiedlichen Annahmen. Links: Der MSE des direkten Schätzers entspricht dem des synthetischen. Rechts: Der MSE des direkten Schätzers ist sechs Mal größer als der MSE des synthetischen Schätzers.

werden (Gleichung 2.4). Bei Annahme der Approximation nach Schaible (1978) findet die Kovarianz keine Berücksichtigung, der dritte Summand fällt weg.

$$
\begin{array}{r}
M S E\left(\hat{\Theta}_{z u s}\right)=\phi^{2} M S E\left(\hat{\Theta}_{d i r}\right)+(1-\phi)^{2} M S E\left(\hat{\Theta}_{s y n}\right)+ \\
2 \phi(1-\phi) E\left(\left(\hat{\Theta}_{d i r}-\Theta\right)\left(\hat{\Theta}_{\text {syn }}-\Theta\right)\right)
\end{array}
$$

\subsubsection{Die Betriebsinventur Niedersachsens}

Bei der Niedersächsischen Betriebsinventur handelt es sich seit 1999 um eine zweiphasige Stichprobe zur Stratifizierung (Böckmann et al., 1998). Diese wird in jedem Forstamt in einem 10-jährigen Turnus durchgeführt. Zunächst werden in der ersten Phase in einem $(100 \mathrm{~m} \times 100 \mathrm{~m})$-Raster Stichprobenpunkte ausgewiesen, an denen eine Luftbildinterpretation vorgenommen wird. Anhand des Luftbildes wird jeder Stichprobenpunkt einem von acht Straten zugewiesen; es wird zwischen zwei Baumartengruppen (Laubbzw. Nadelholz, LH bzw. NH) und 4 Altersgruppen (1: $\leq 40$ Jahre, 2: über 40 bis 80 Jahre, 3: über 80 bis 120 Jahre, 4: > 120 Jahre) unterschieden.

In der zweiten Phase dann wird in jedem Stratum ein bestimmter Anteil der Probepunkte der ersten Phase zufällig ausgewählt. An jedem dieser zufällig ausgewählten Probepunkte werden zwei konzentrische Probekreise (6 m bzw. $13 \mathrm{~m}$ Sollradius) eingemessen. Nähere Angaben zum Vorgehen bei der Betriebsinventur finden sich in der Aufnahmeanweisung (Niedersächsisches Forstplanungamt, 2001). 


\subsubsection{Direkter Schätzer}

Das mittlere Volumen einer Zielpopulation (Gleichung 2.5) und die dazugehörige Varianz (Gleichung 2.6) können nach Cochran (1977) geschätzt werden. Hierbei entspricht die Varianz dem MSE.

$$
\begin{gathered}
\hat{V}=\sum_{h=1}^{L} \frac{n_{h}^{\prime}}{n^{\prime}} \frac{1}{n_{h}} \sum_{i=1}^{n_{h}} \hat{V}_{h i}=\sum_{h=1}^{L} \frac{n_{h}^{\prime}}{n^{\prime}} \bar{V}_{h} \\
\widehat{\operatorname{var}}(\hat{V})=\frac{1}{n^{\prime}}\left(\sum_{h=1}^{L} \frac{n_{h}^{\prime}}{n^{\prime}} \frac{s_{h}^{2}}{\nu_{h}}+\sum_{h=1}^{L} n_{h}^{\prime} n^{\prime}\left(\hat{V}_{h}-\hat{V}\right)^{2}\right)
\end{gathered}
$$

Dabei bezeichnet $L$ die Anzahl der Straten, $n^{\prime} h$ die Anzahl von Stichprobenpunkten in Stratum $h$ in Phase I, $n^{\prime}$ den Stichprobenumfang in Phase I, $n_{h}$ die Anzahl von Stichprobenpunkten in Phase II, $V_{h i}$ das Volumen an Stichprobenpunkt $i$ in Stratum $h, \nu_{h}$ den Anteil terrestrischer Punkte in Stratum $h$ und $s_{h}^{2}$ die Varianz des Volumens innerhalb eines Stratums.

\subsubsection{Synthetischer Schätzer}

Die synthetische Schätzung erfolgt mittels des Programmes Waldplaner 2.0 der NWFVA (Albert \& Hansen, 2007; Hansen, 2006). Mit diesem Programm können Bestände und deren Entwicklung auf Basis der Inventurdaten simuliert werden. Auch die Fortschreibungen werden mit den Formeln des direkten Schätzers ausgewertet. Der MSE des synthetischen Schätzers lässt sich nach dem sogenannten Ordinary Approach wie folgt bestimmen (Rao, 2003).

$$
\widehat{M S E}\left(\hat{\Theta}_{s y n}\right)=\left\|\hat{\Theta}_{s y n}-\hat{\Theta}_{d i r}\right\|^{2}-\widehat{v a r}\left(\hat{\Theta}_{s y n}-\hat{\Theta}_{d i r}\right)+\widehat{v a r}\left(\hat{\Theta}_{s y n}\right)
$$

\subsection{Modellstudie}

\subsubsection{Datengrundlage}

Für die vier niedersächsischen Forstämter Liebenburg, Reinhausen, Grünenplan und Saupark liegen die Daten von zwei Inventurdurchgängen vor. Vor dem zweiten Inventurdurchgang wurden keine neuen Luftbilder aufgenommen und ausgewertet. Es wurden fast alle Punkte des ersten Inventurdurchgangs erneut aufgenommen. Insgesamt konnten so die Daten von 6.343 Stichprobenpunkten der Phase II in die Analyse einbezogen werden (Tabelle 2.1).

Da nicht die Werte aller Baumarten und Durchmesserklassen von Interesse sind, wurden 12 Zielpopulationen gebildet, für die die Berechnungen durchgeführt wurden (Tabelle 2.2). 
2. Zusammengesetzte Schätzer für periodische Waldinventuren

Tabelle 2.1: Die Anzahl der Stichprobenpunkte der Phase II in den unterschiedlichen Straten der vier Forstämter.

\begin{tabular}{lrrrrrrrrr}
\hline & LH1 & LH2 & LH3 & LH4 & NH1 & NH2 & NH3 & NH4 & Summe \\
\hline Liebenburg & 123 & 166 & 136 & 180 & 65 & 343 & 41 & 9 & 1063 \\
Reinhausen & 191 & 230 & 287 & 430 & 153 & 318 & 112 & 55 & 1776 \\
Grünenplan & 231 & 197 & 191 & 316 & 199 & 37 & 217 & 42 & 1769 \\
Saupark & 170 & 141 & 148 & 376 & 160 & 627 & 100 & 13 & 1735 \\
\hline
\end{tabular}

Tabelle 2.2: Die zwölf Zielpopulationen der Modellstudie.

\begin{tabular}{llll}
\hline \multicolumn{3}{c}{ BHD-Bereich $(\mathrm{cm})$} \\
\hline Buche & $<25$ & $25-50$ & $>50$ \\
Eiche & $<25$ & $25-50$ & $>50$ \\
Fichte & $<25$ & $25-35$ & $>35$ \\
Kiefer & $<25$ & $25-40$ & $>40$ \\
\hline
\end{tabular}

\subsubsection{Vorgehen}

Im Rahmen der Modellstudie wurden die Daten aller Probekreise des ersten Inventurdurchgangs mit dem WaldPlaner 2.0 fortgeschrieben und der dazugehörige MSE nach Gleichung 2.7 berechnet. Die Varianz des direkten Schätzers wurde modellhaft für alle Stichprobenumfänge zwischen 0 und 3000 nach Gleichung 2.6 bestimmt; variiert wurde dabei lediglich der Anteil terrestrischer Punkte je Stratum $\left(\nu_{h}\right)$. Diese 3000 MSE wurden mit dem MSE des synthetischen Schätzers nach Gleichung 2.4 kombiniert. Auf diese Weise kann die Schätzgenauigkeit des zusammengesetzten Schätzers bei verschiedenen Stichprobenumfängen beurteilt werden.

\subsubsection{Ergebnisse}

Im Folgenden werden die Ergebnisse beispielhaft an der Zielpopulation „Fichten $>35$ cm" für die Forstämter Reinhausen und Grünenplan dargestellt.

Es zeigt sich, dass die Simulationen zu brauchbaren Ergebnissen kommen (Abbildung 2.2). Der Korrelationskoeffizient nach Pearson zwischen den gemessenen und den simulierten Volumina liegt bei 0,75 bzw. 0.79. Auffällig sind die Probekreise, für die ein Volumen prognostiziert aber nicht gemessen wurde, bzw. die Plots, auf denen Volumina gemessen aber nicht simuliert wurden. Diese Probekreise verringern die Korrelation deutlich. Mögliche Gründe für die Unterschiede zwischen Simulation und Wirklichkeit sind Kalamitäten oder Nutzungen, es handelt sich nicht um systematische Fehler. Zudem ist zu berücksichtigen, dass bei der Berechnung der Korrelation auch die zahlreichen Probepunkte berücksichtigt werden, für die Volumina weder gemessen noch simuliert wurden. Diese Punkte erklären, dass die Korrelationskoeffizienten deutlich größer sind 

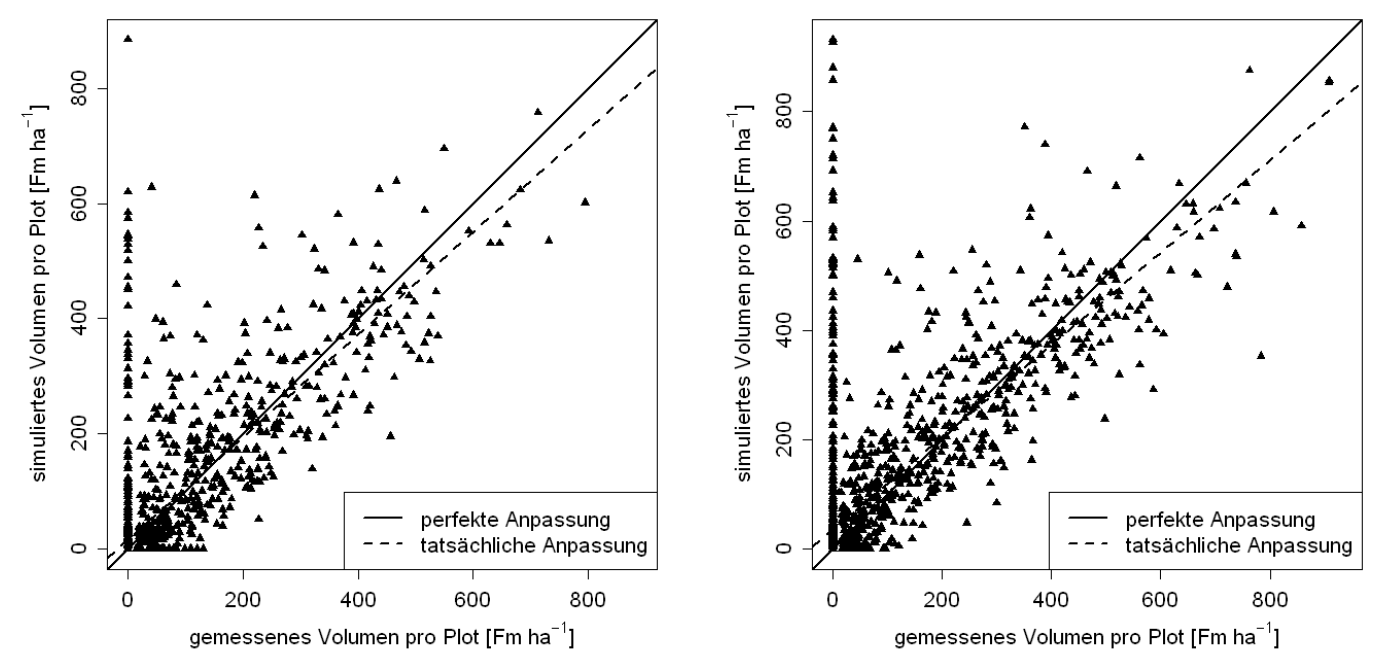

Abbildung 2.2: Vergleich der gemessenen und der simulierten Volumina je Plot der Fichten mit einem BHD $>35 \mathrm{~cm}$ in den Forstämtern Reinhausen (links) und Grünenplan (rechts)

als man anhand der Abbildungen vermuten würde. Der Unterschied zwischen den Fortschreibungen und den Messungen ist im Forstamt Reinhausen deutlich kleiner als im Forstamt Grünenplan.

Die Approximation nach Schaible (1978) führt zwar zu geringeren Fehlern (Abbildung 2.3) ist jedoch nicht ganz korrekt, da sowohl der synthetische als auch der direkte Schätzer die Punkte des zweiten Inventurdurchganges gemeinsam benutzen. Der Einfluss der Kovarianz ist allerdings relativ gering, sie führt zu einer Erhöhung des MSE um maximal etwa $8 \%$.

Durch die Kombination des synthetischen mit dem direkten Schätzer lässt sich der mittlere quadratische Fehler im Vergleich zum MSE des direkten Schätzers verkleinern (Abbildung 2.4). Dargestellt sind hier die Ergebnisse bei Berücksichtigung der Kovarianzen; eine Anwendung der Approximation nach Schaible würde die Ergebnisse noch einmal geringfügig verbessern, ist aber nicht korrekt. Der notwendige Stichprobenumfang der zweiten Phase kann jedoch nur in geringem Umfang verkleinert werden, da der MSE des synthetischen Schätzers für eine Vielzahl der Stichprobenumfänge der Phase II wesentlich größer als der MSE des direkten Schätzers ist. Es wird deutlich, dass der MSE der Simulationen fast ausschließlich durch die quadratische Differenz zwischen den beiden Volumenschätzungen bestimmt wird, die als Schätzung für den quadrierten Bias dient.

\subsubsection{Vorläufiges Fazit}

Zunächst einmal ist festzustellen, dass sich ein zusammengesetzter Schätzer für diesen Zweck konstruieren lässt. Allerdings erscheinen die Unterschiede zwischen den Werten der Fortschreibungen und denen der Wiederholungsaufnahme noch zu groß zu sein. 

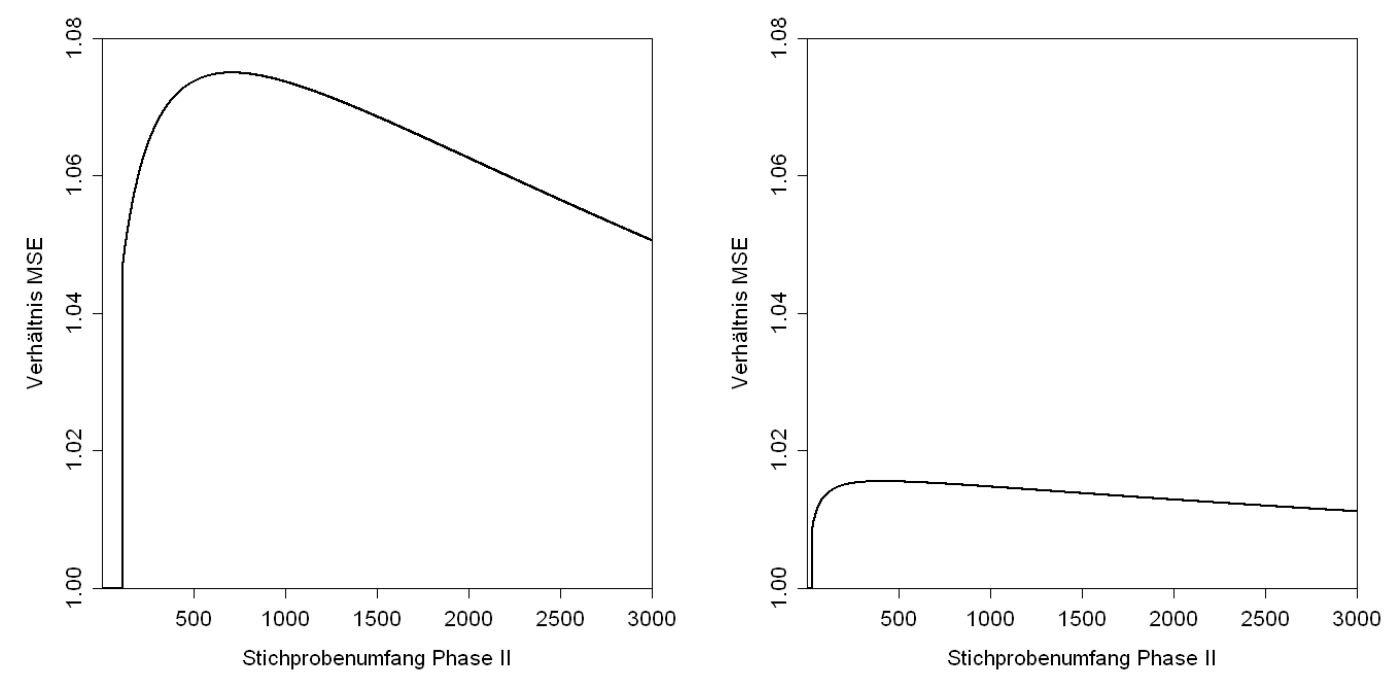

Abbildung 2.3: Das Verhältnis des korrekt berechneten MSE des zusammengesetzten Schätzers zum MSE, der nach der Approximation nach Schaible (1978) berechnet wurde, in Abhängigkeit vom Stichprobenumfang der zweiten Inventurphase. Links: Forstamt Reinhausen, Rechts: Forstamt Grünenplan.
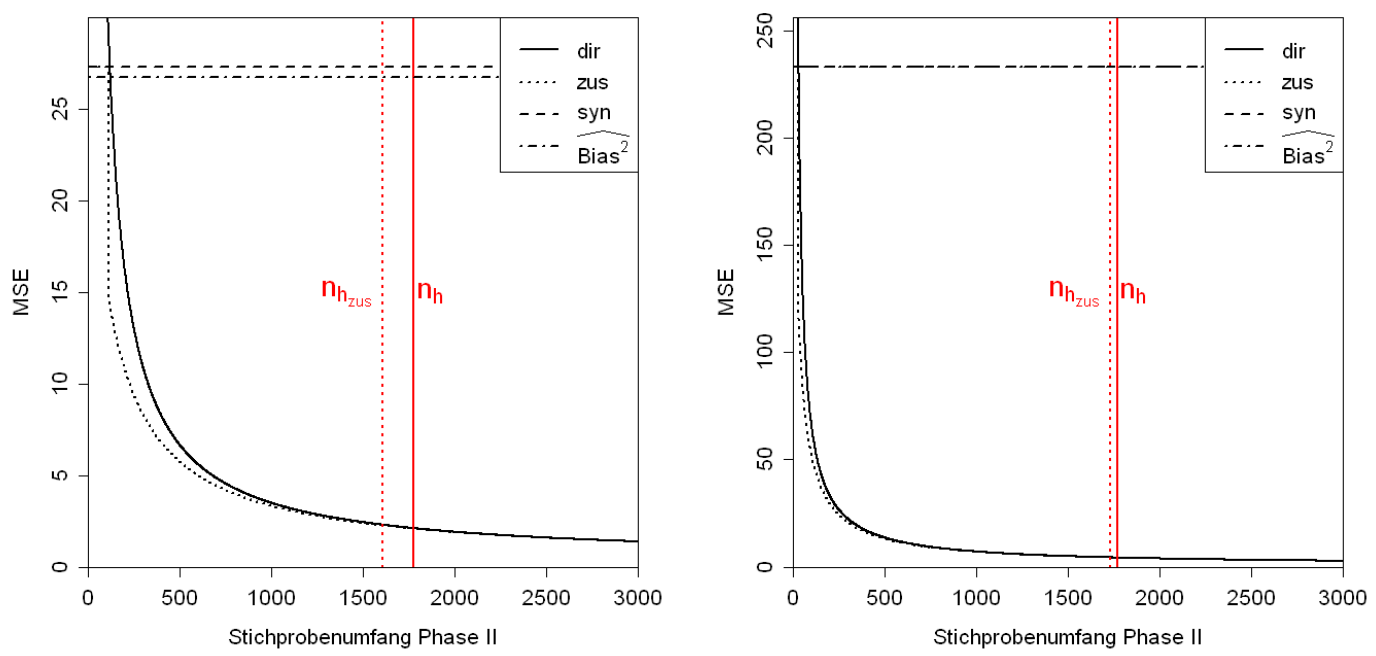

Abbildung 2.4: Die Mittleren quadratischen Fehler des direkten, des synthetischen und des kombinierten Schätzers, sowie der geschätzte quadrierte Bias in Abhängigkeit vom Stichprobenumfang in der zweiten Phase der Inventur. Links: Forstamt Reinhausen, Rechts: Forstamt Grünenplan. 
Bisher lässt sich anhand der hier vorgestellten Ergebnisse kein nennenswertes Einsparungspotenzial erkennen. Es muss an einer weiteren Verbesserung der Genauigkeit der Fortschreibungen durch den Waldplaner 2.0 gearbeitet werden.

\section{Danksagung}

Die Autoren danken der Deutschen Forschungsgemeinschaft, die dieses Projekt finanziell fördert (Sachbeihilfe SA 415/5-1). 


\section{Chapter 3}

\section{A three-phase sampling procedure for continuous forest inventory with partial re-measurement and updating of terrestrial sample plots}

Nikolas von Lüpke ${ }^{1}$ - Jan Hansen ${ }^{2}$ - Joachim Saborowski ${ }^{1,3}$

\footnotetext{
${ }^{1}$ Department of Ecoinformatics, Biometrics and Forest Growth,

University of Göttingen, Büsgenweg 4, 37077 Göttingen, Germany

${ }^{2}$ Northwest German Forest Research Station,

Grätzelstraße 2, 37079 Göttingen, Germany

${ }^{3}$ Department of Ecosystem Modelling,

University of Göttingen, Büsgenweg 4, 37077 Göttingen, Germany
}

Published in:

European Journal of Forest Research 131, 1979-1990.

(DOI: 10.1007/s10342-012-0648-z) 
- Jan Hansen supported the forest growth simulations.

- Joachim Saborowski developed the estimators for three-phase sampling for stratification and regression. Moreover, he supported the analysis of the results and the writing of the manuscript. 
3. A three-phase sampling procedure for continuous forest inventory with partial re-measurement and updating of terrestrial sample plots

\section{Abstract}

For a current inventory using double sampling for stratification with a reduced secondphase sample size, compared to a previous inventory, we develop a three-phase sampling procedure which exploits plot data from the previous inventory or their updates based on a growth model to increase precision. The three-phase procedure combines double sampling for stratification with a two-phase regression estimator within strata. We consider sampling from an infinite population in the first phase. The combined estimator is tested in a case study using data from two consecutive inventories in four State Forest Districts in Lower Saxony, Germany. Data from a reduced number of sample plots from the second occasion are combined with (1) volumes from the first occasion or (2) growth simulations on the sample plots from the first occasion. The data from the previous inventory or their updates serve as the auxiliary variable for the regression estimator of the strata means of the target variable. This case study indicates a remarkable increase in precision and thereby an enormous cost-saving potential for reduced intermediate inventories in a periodic inventory design with both types of auxiliary variables.

\section{keywords}

Continuous forest inventory - Double sampling for stratification - Double sampling for regression - Forest growth models

\subsection{Introduction}

Multipurpose resource inventories have to fulfil several demands (Lund, 1998) and their methods are usually evaluated regarding efficiency, which means that a required precision should be achieved with a minimum of inventory costs or that the maximum precision should be achieved with predefined inventory costs. Therefore, different sampling procedures have been developed over the last decades with the aim of cost-reduction in mind. An established approach is to use auxiliary variables, the inventory of which is cheaper than that of the target variables.

One such method is double sampling for stratification (2st). This is a well-known, widely used and efficient method (Cochran, 1977; de Vries, 1986; Schreuder et al., 1993; Köhl, 1994; Särndal et al., 2003; Gregoire \& Valentine, 2008; Mandallaz, 2008), which has recently been studied under the infinite population approach (Saborowski et al., 2010). Scott \& Köhl (1994) extended 2st by sampling with partial replacement (SPR). In the first phase of this procedure all sampling units are stratified according to specific rules with help of qualitative variables. Often this is done based on aerial images, which serve as a source of auxiliary variables. After the stratification, within-strata subsamples of the first-phase units are inventoried; in forest inventories it is common to do this with terrestrial sampling. Even though the costs of this sampling procedure are relatively low in comparison to other methods (Brassel \& Köhl, 2001; Saborowski et al., 2010), a further cost-reduction is desirable. 
A special opportunity to do so occurs when data from a previous inventory exist as is the case with periodic inventories. Saborowski et al. (2010) showed how 2st-sampling can be applied in periodic inventories with optimised allocation of second-phase units. In periodic inventories one may be willing to accept a slight loss of precision regularly on every second occasion, or at least temporarily on one occasion in times of small budgets, if that is accompanied by a remarkable cost reduction. Such "intermediate" low-cost inventories are known e.g. from forest disease inventories in Germany, where the regular square grid of $4 \mathrm{~km} \times 4 \mathrm{~km}$ was reduced to $8 \mathrm{~km} \times 8 \mathrm{~km}$ for intermediate occasions until 2005, when the $8 \mathrm{~km} \times 8 \mathrm{~km}$ grid became the regular grid.

Under a simple one-phase design for the periodic inventories, one might use double sampling for regression using the plot measurements from the previous inventory as an auxiliary variable (regressor) to compensate for the reduced sample size of the current inventory. Here, we want to deal with the generally more efficient 2st-design, which could be replaced temporarily, or in a fixed cycle on every second occasion, by a new three-phase design. The proposed design combines first-phase stratification as applied in the 2st-design and double sampling for regression (2lr) (Cochran, 1977; Särndal et al., 2003; Mandallaz, 2008) based on the finite number of second-phase plots within strata.

Moreover, we use not only the most recent preceding plot measurements as auxiliary variable, but also their updates predicted by a growth model which considers the current silvicultural policy, at least to a certain extent, and we compare the efficiency of both approaches.

The three-phase design is expected to account for different within-strata variances of the target variable, what particularly will occur in case of volume or basal area if age classes or species groups are used as strata, as well as for regression models varying among strata (Figure 3.1). Thus an integration of 2st and 2lr in a three-phase design seems to be a promising design, because it combines the strengths of both sampling schemes. The stratification helps to create more homogeneous subpopulations, whereas the regression includes additional information at low costs based on the preceding inventory.

A combination of current sample plot measurements and model-based updates of previous inventories was also suggested by van Deusen (1996) in a rotating panel context. The difference from our setting is that he had to deal with auxiliary data from a time series of previous inventories, where the target variable currently measured on a subsample of all plots has to be predicted based on data which were measured the furthest in the past. Sampling with partial replacement (Gregoire, 2005) is related to our approach, insofar as we choose a subsample to estimate the regression coefficients and omit the rest of the sampling units from the most recent occasion. But the omitted units are not replaced here by new ones, as it would be done with SPR, because we use subsampling as a measure for cost reduction.

Forest growth models have experienced a rapid development during the last years (Pretzsch \& Ďurský, 2001; Pretzsch, 2002, 2009; Schmid et al., 2006; Albrecht et al., 2009; Härkönen et al., 2010; Vospernik et al., 2010), and their forecasts have become more and more reliable. Therefore it should be possible to use the results of these growth 
3. A three-phase sampling procedure for continuous forest inventory with partial re-measurement and updating of terrestrial sample plots

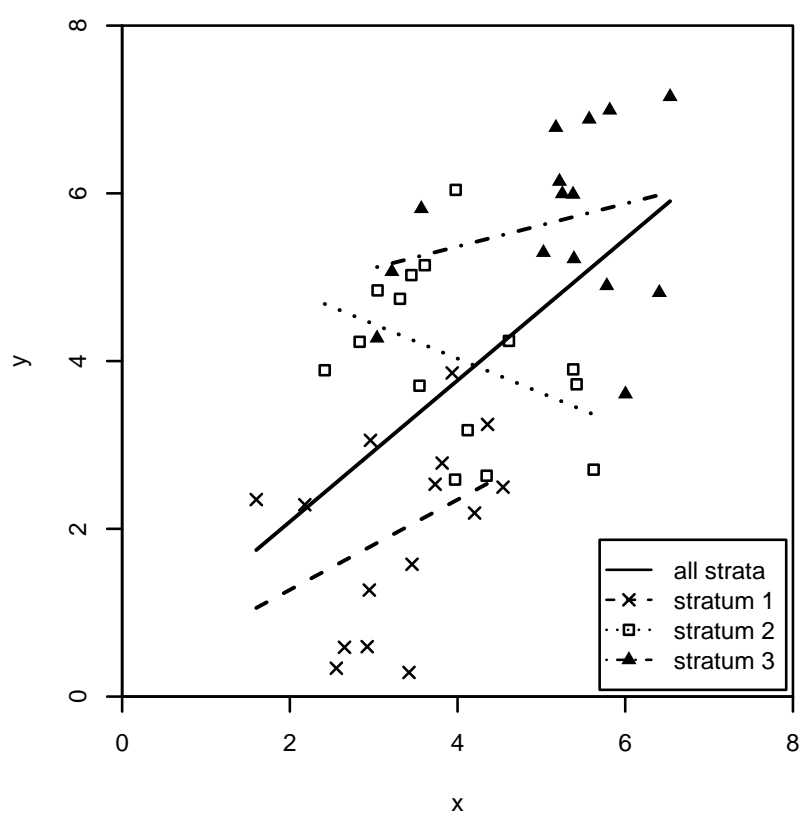

Figure 3.1: Three samples of size 15, showing different relationships between $\mathrm{x}$ and $\mathrm{y}$. The overall relationship misapplies these different relationships.

simulations in forest inventories. In a previous study (von Lüpke et al., 2011) 2st and growth model based updates have been combined in a composite estimator after Schaible (1978). The mean squared error (MSE) of this estimator - as a measure of precision - is calculated using the estimated bias of the simulation results. Due to the fact that this bias has been considerable high, this approach could not reduce the number of sample points remarkably. A regression estimator seems to be the more promising approach because it uses the correlations between previous and current inventories, which are expected to be high.

In the following article we present results which have been obtained for the threephase estimator that combines $2 \mathrm{lr}$ with 2 st. In the case study aerial images were used as auxiliary variable to identify strata and (updated) data from the previous inventory as volume predictors in a regression model.

\subsection{A three-phase estimator for stratification and regression}

Due to the fact that the estimator assumes the infinite population approach in the first phase, a short explanation of the approach seems appropriate. Whereas the finite population approach assumes that the study area consists of a finite number of nonoverlapping sampling units, the infinite population approach assumes point sampling in a given area. The local value of the target variable at a sample point is defined by the tree data within a sample plot assigned to the point. An obvious disadvantage of 
the first approach is that not all shapes of sampling units fulfil the assumptions. With circles for example it is impossible to sample the whole study area without overlaps. Therefore the infinite population approach is more realistic and preferable for forest inventory; a comprehensive theory with applications can be found in Mandallaz (2008).

For all the schemes presented here, simple random sampling (SRS) is assumed in the first phase. In practice, often only the first sample point is chosen randomly and from that starting point a systematic grid is constructed to find the rest. Generally unbiased variance-estimators do not exist in case of systematic sampling; therefore, often the SRS-estimators are applied. It can be justified by the fact that they lead to an overestimation in most cases and thus are assumed to be conservative estimators (Gregoire \& Valentine, 2008; Mandallaz, 2008).

\subsubsection{Double sampling for stratification}

Two phases can be distinguished in this sampling scheme. After stratification of the first-phase sample plots $\left(n^{\prime}\right)$, measurements only take place in a sub-sample $(n)$. To estimate the mean of the target variable (e.g. dbh, basal area or volume) the strata means $\left(\bar{y}_{h}\right)$ are weighted with the proportions of first-phase sample points per stratum $\left(n_{h}^{\prime} / n^{\prime}=w_{h}\right)$, as can be seen in Equation 3.1 (see e.g. Cochran, 1977).

$$
\widehat{\bar{Y}}_{2 s t}=\sum_{h=1}^{L} w_{h} \frac{1}{n_{h}} \sum_{i=1}^{n_{h}} y_{h i}=\sum_{h=1}^{L} w_{h} \bar{y}_{h}
$$

Equation 3.2 shows an unbiased estimator for the variance of this sampling proced-

ure under the infinite population approach (Saborowski et al., 2010), where $s_{h}^{2}$ is the estimator for the within-stratum variance of the target variable (Equation 3.3) and $\nu_{h}=n_{h} / n_{h}^{\prime}$ the proportion of terrestrial sample points per stratum.

$$
\begin{gathered}
\widehat{V}\left(\widehat{\bar{Y}}_{2 s t}\right)=\frac{1}{n^{\prime}-1}\left(\sum_{h=1}^{L} \frac{n_{h}^{\prime}-1}{n^{\prime}} \frac{s_{h}^{2}}{\nu_{h}}+\sum_{h=1}^{L} w_{h}\left(\bar{y}_{h}-\widehat{\bar{Y}}_{2 s t}\right)^{2}\right) \\
s_{h}^{2}=\frac{1}{n_{h}-1} \sum_{i=1}^{n_{h}}\left(y_{h i}-\bar{y}_{h}\right)^{2}
\end{gathered}
$$

\subsubsection{Double sampling for regression}

In this sampling procedure, which we will later use according to the finite population approach given the $n_{h}^{\prime}$ first-phase samples within strata, the auxiliary variable $(x)$ is sampled at all first-phase plots $\left(n^{\prime}\right)$. Again, the target variable $(y)$ is only measured in a sub-sample $(n)$. For the estimation of the mean of this target variable (Equation 3.4), the sample means of the auxiliary variable, calculated from the sample points of phases 
3. A three-phase sampling procedure for continuous forest inventory with partial re-measurement and updating of terrestrial sample plots

one $\left(\bar{x}^{\prime}\right)$ and two $(\bar{x})$, are required. Besides, the sample mean of the target variable $(\bar{y})$ and the estimated regression coefficient $b$ (Equation 3.5) are used (Cochran, 1977).

$$
\begin{gathered}
\widehat{\bar{Y}}_{2 l r}=\bar{y}+b\left(\bar{x}^{\prime}-\bar{x}\right) \\
b=\frac{\sum_{i=1}^{n}\left(y_{i}-\bar{y}\right)\left(x_{i}-\bar{x}\right)}{\sum_{i=1}^{n}\left(x_{i}-\bar{x}\right)^{2}}
\end{gathered}
$$

An estimator for the variance is given in Cochran (1977), formula (12.67), with the variance estimator of the target variable $s_{y}^{2}$ and $s_{y . x}^{2}$ being an unbiased estimator of $S^{2}\left(1-R^{2}\right)$, where $S^{2}$ is the true variance of $y$ and $R$ the correlation coefficient between $x$ and $y$. Here, $N$ stands for the total number of all possible sampling units in the study area. Since we will use 2lr in our three-phase estimator conditionally on the first-phase sample within each of the strata, the finite population approach is appropriate with $N$ replaced by $n_{h}^{\prime}, n^{\prime}$ by $n_{h}$ and $n$ by $n_{h}^{*}$ (see Equation 3.7 and Appendix 3.15).

$$
\widehat{V}\left(\widehat{\bar{Y}}_{2 l r}\right)=\frac{s_{y \cdot x}^{2}}{n}+\frac{s_{y}^{2}-s_{y \cdot x}^{2}}{n^{\prime}}-\frac{s_{y}^{2}}{N}
$$

\subsubsection{Three-phase sampling for stratification and regression}

The estimator used in this study was suggested by Saborowski (1994), who presented it together with a variance estimator under the finite population approach. In total, three phases can be distinguished in this procedure (Figure 3.2). In the first phase all sampling units $\left(n^{\prime}\right)$ are stratified into $L$ strata $\left(n^{\prime}=\sum_{h=1}^{L} n_{h}^{\prime}\right)$, and in the second phase measurements of an auxiliary variable $x$ are collected in a subsample of every stratum $\left(n_{h}=\nu_{h} n_{h}^{\prime}\right)$. Data of the target variable are finally measured in phase three in a further subsample of the second-phase sample per stratum $\left(n_{h}^{*}=\nu_{h}^{*} n_{h}\right)$. To estimate the mean of the target variable, the differences between the means of the auxiliary variable in the second and the third phase are used together with the mean of the target variable estimated from phase three.

The mean of the target variable can be estimated using Equation 3.7, where $\bar{y}_{h}^{*}$ denotes the sample mean of the target variable in a sub-sample of the second-phase sample with sample size $n_{h}^{*}$ in stratum $h . \bar{x}_{h}$ denotes the sample mean of the auxiliary variable in stratum $h$ (second-phase sample size $n_{h}$ ), and $\bar{x}_{h}^{*}$ stands for the mean of the auxiliary variable in stratum $h$ calculated from phase three with sample size $n_{h}^{*}$. The proportion of first-phase sample points per stratum is used for weighting the strata means.

$$
\widehat{\bar{Y}}_{2 s t, 2 l r}=\sum_{h=1}^{L} \frac{n_{h}^{\prime}}{n^{\prime}} \widehat{\bar{Y}}_{h, 2 l r}=\sum_{h=1}^{L} w_{h}\left(\bar{y}_{h}^{*}+b_{h}\left(\bar{x}_{h}-\bar{x}_{h}^{*}\right)\right)
$$




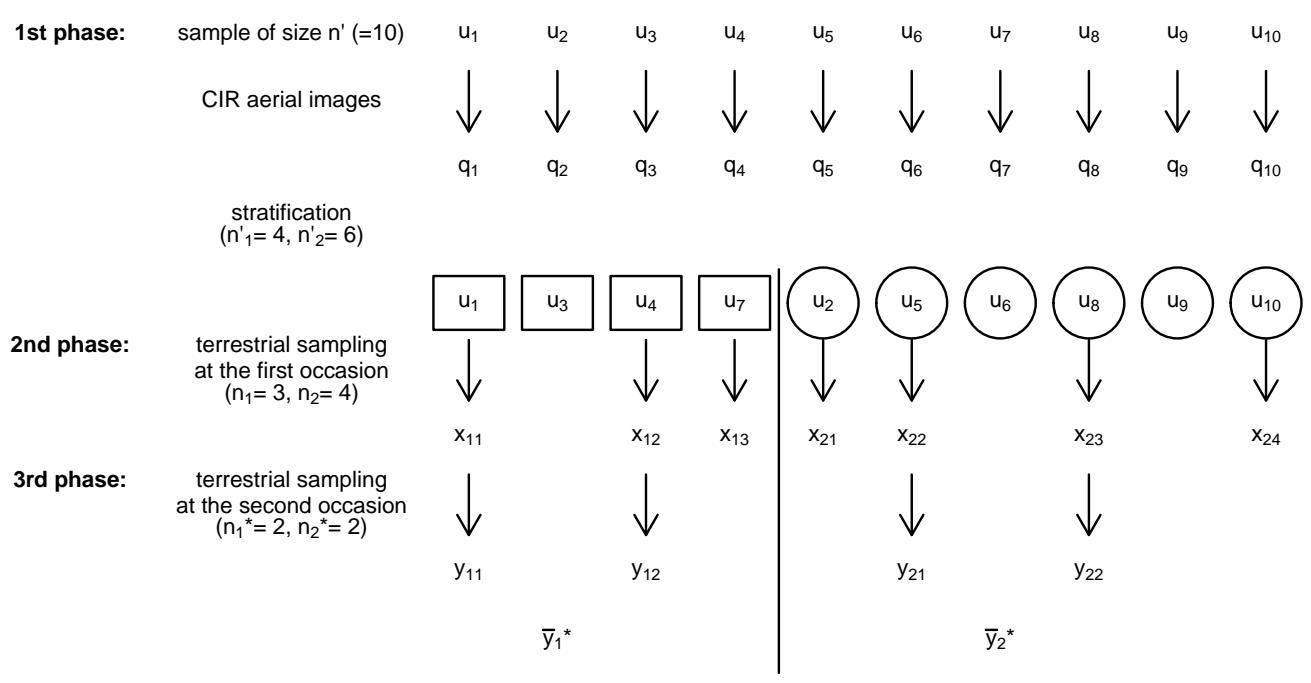

Figure 3.2: Sampling procedure of the three-phase design.

The estimated regression coefficient $b_{h}$ is calculated per stratum as follows.

$$
b_{h}=\frac{\sum_{j=1}^{n_{h}^{*}}\left(y_{h j}-\bar{y}_{h}^{*}\right)\left(x_{h j}-\bar{x}_{h}^{*}\right)}{\sum_{j=1}^{n_{h}^{*}}\left(x_{h j}-\bar{x}_{h}^{*}\right)^{2}}
$$

$x_{h j}$ and $y_{h j}$ are the auxiliary and the target variable at unit $j$ of stratum $h$.

Estimator 3.7 is identical with the so-called updated first-occasion mean of Scott \& Köhl (1994), which is one of two components of their stratified SPR estimator, but their variance estimator is based on the finite population approach of Cochran (1977).

The approximate variance under the infinite population approach for the first phase, as a measure of precision of estimation, is given by Equation 3.9, an estimator by Equation 3.10 (for the proofs see Appendix). $s_{h}^{* 2}$ and $r_{h}^{* 2}$ are the empirical variance and the squared empirical correlation between $\mathrm{x}$ and $\mathrm{y}$ of the third-phase sample in stratum $h, s_{h}^{\prime 2}$ and $r_{h}^{\prime 2}$ the respective statistics of the first-phase samples. The structure of the variance and its estimator, simply a sum of the respective statistic for pure 2stsampling and an additional term accounting for the third phase variability, is a direct consequence of the well-known variance decomposition given in Appendix (3.12).

$$
\begin{aligned}
& V\left(\widehat{\bar{Y}}_{2 s t, 2 l r}\right) \\
& \approx \frac{1}{n^{\prime}} S^{2}+E \frac{1}{n^{\prime}} \sum_{h=1}^{L} w_{h}\left(\frac{s_{h}^{\prime 2}\left(1-r_{h}^{\prime 2}\right)}{\nu_{h}^{*} \nu_{h}}+\frac{s_{h}^{\prime 2} r_{h}^{\prime 2}}{\nu_{h}}-s_{h}^{\prime 2}\right) \\
& =V\left(\widehat{\bar{Y}}_{2 s t}\right)+E \frac{1}{n^{\prime}} \sum_{h=1}^{L} w_{h}\left(\frac{1}{\nu_{h}^{*}}-1\right) \frac{s_{h}^{\prime 2}\left(1-r_{h}^{\prime 2}\right)}{\nu_{h}}
\end{aligned}
$$


3. A three-phase sampling procedure for continuous forest inventory with partial re-measurement and updating of terrestrial sample plots

$$
\begin{aligned}
& \widehat{V}\left(\widehat{\bar{Y}}_{2 s t, 2 l r}\right) \\
& =\widehat{V}\left(\widehat{\bar{Y}}_{2 s t}\right)+\frac{1}{n^{\prime}} \sum_{h=1}^{L} w_{h}\left(\frac{1}{\nu_{h}^{*}}-1\right) \frac{s_{h}^{* 2}\left(1-r_{h}^{* 2}\right)}{\nu_{h}} \frac{n_{h}^{*}-1}{n_{h}^{*}-2}
\end{aligned}
$$

The expectation in Equation 3.9 is calculated over all first-phase samples of size $n^{\prime}$. With increasing correlations ${r_{h}^{\prime}}^{2}$ the variance of the three-phase estimator converges from above to the variance of the 2st estimator. Foresters are usually also interested in the relative Sampling Error (rel. SE) as given in Equation 3.11.

$$
\text { rel.SE }=\frac{\sqrt{\operatorname{Var} \widehat{\bar{Y}}_{2 s t, 2 l r}}}{\widehat{\bar{Y}}_{2 s t, 2 l r}}
$$

\subsection{Case Study}

\subsubsection{Sampling Scheme and Inventory Data}

Since 1999 the Forest District Inventory of Lower Saxony (Germany) has been carried out in a cycle of approximately ten years according to a 2st design (Böckmann et al., 1998; Saborowski et al., 2010). In the first phase of this sampling procedure sample points are located in a $100 \mathrm{~m} \times 100 \mathrm{~m}$ grid, and CIR aerial images are used to assess stand age and type at these points. As a result of this assessment, every point is assigned to one of eight strata depending on dominating species group (DEC: Deciduous; CON: Coniferous) and age class (1: $\leq 40$ years; $2:>40-80$ years; $3:>80-120$ years; 4 : $>120$ years). As Saborowski et al. (2010) point out, this stratification assumes (1) a close relationship between age and species group and volume, (2) that the distinction of four age classes and two species groups can easily be done using aerial images, and (3) that the optimum allocation is expected to hold, at least approximately, for a repeated inventory. A certain proportion $\left(\nu_{h}\right)$ of first-phase points differing among the strata is systematically chosen in the second phase from a list of all $n_{h}^{\prime}$ points of stratum $h$. These proportions differ because the estimation precision required by the forest administration was higher for trees above a specified dbh-threshold ( $5 \%$ rel. SE) and lower for smaller trees (down to $30 \%$ rel. SE). At the second-phase points, two concentric plots with a radius of $6 \mathrm{~m}$ (for trees with $7 \mathrm{~cm} \leq \mathrm{dbh}<30 \mathrm{~cm}$ ) and $13 \mathrm{~m}$ (trees with $\mathrm{dbh} \geq 30 \mathrm{~cm}$ ), respectively, are established and inventoried. In four forest districts of Lower Saxony, Liebenburg, Reinhausen, Grünenplan and Saupark, the inventory has meanwhile been carried out twice. Differing from the regular ten year time span between two inventories it ranged here from seven to ten years. A new stratification with the help of aerial images did not take place at the second occasion, and so the stratification of the first inventory was used. Due to problems with the identification of the exact plot position, not all plots surveyed from the first occasion could be resampled. In total, data from 27,332 first- and 6,343 second phase-plots were used for this case study (Table 3.1). For these 
Table 3.1: First- and second-phase sample sizes in the eight strata of the four forest districts.

\begin{tabular}{ccrrrrrrrrr}
\hline Forest District & Phase & DEC1 & DEC2 & DEC3 & DEC4 & CON1 & CON2 & CON3 & CON4 & $\sum$ \\
\hline \multirow{2}{*}{ Liebenburg } & I & 550 & 1064 & 636 & 624 & 169 & 589 & 84 & 18 & 3734 \\
& II & 123 & 166 & 136 & 180 & 65 & 343 & 41 & 9 & 1063 \\
\hline \multirow{2}{*}{ Reinhausen } & I & 912 & 1538 & 1473 & 1503 & 409 & 548 & 218 & 104 & 6705 \\
& II & 191 & 230 & 287 & 430 & 153 & 318 & 112 & 55 & 1776 \\
\hline \multirow{2}{*}{ Grünenplan } & I & 1710 & 1800 & 1517 & 1577 & 917 & 1168 & 788 & 162 & 9639 \\
& II & 231 & 197 & 191 & 316 & 199 & 375 & 217 & 42 & 1769 \\
\hline \multirow{2}{*}{ Saupark } & I & 997 & 1240 & 1021 & 1790 & 524 & 1401 & 248 & 33 & 7254 \\
& II & 170 & 141 & 148 & 376 & 160 & 627 & 100 & 13 & 1735 \\
\hline
\end{tabular}

plots, data from two occasions were available. In our case study we assume random sampling in the first and second phase, as well as for the subsampling in the third phase, which was not carried out in practice. The third phase was only virtually implemented in our study.

\subsubsection{Tree Growth Simulation}

The simulations were carried out with the program WaldPlaner 2.0, which uses the statistical individual-tree growth model BWINPro (Nagel \& Schmidt, 2006). This program was developed by the Northwest German Forest Research Station and is used in the planning process of the Forest Service in Lower Saxony (Nagel \& Schmidt, 2006). Therefore the default settings follow the Federal State silvicultural program $(L O ̈ W E)$, which aims to rise the proportion of mixed and broadleafed stands. Due to the fact that it was parameterised with data from Northern Germany, particularly from Lower Saxony, the results of this simulator are expected to be more reliable for our case study than the results of other growth simulators such as SILVA or SIBYLA, which have been parameterised with data from Southern Germany and Slovakia, respectively (Fabrika \& Ďurský, 2006; Pretzsch et al., 2006). Different studies (e.g. Vospernik et al., 2010) show that the growth projections of this program provide reasonable results.

WaldPlaner 2.0 generates a model stand of predetermined extent driven by the inputdata for better representation of neighbourhood and for the minimisation of edge-effects. This model stand is built with clones of the sample-trees. Depending on their dbh and differing selection probabilities (concentric circles) the measured trees are cloned several times, smaller trees $(\mathrm{dbh}<30 \mathrm{~cm})$ more often than bigger ones $(\mathrm{dbh} \geq 30 \mathrm{~cm})$. The coordinates of these clone-trees are initialised randomly. Afterwards an algorithm moves the coordinates until a constellation with little competition is achieved. For height and diameter increment a normally distributed error is computed on the tree level.

The data from the second phase of the first inventory were used for simulation runs using the program WaldPlaner 2.0. The sizes of the model stands were 0.2 ha and we derived key figures, such as volume per ha, from these stands and assigned them to the sample units. We tested different realistic parameterisations, but due to the fact that in most target populations the influence of the parameterisations on the sampling error of 
3. A three-phase sampling procedure for continuous forest inventory with partial re-measurement and updating of terrestrial sample plots

Table 3.2: The nine target populations in the case study.

\begin{tabular}{llll}
\hline & \multicolumn{3}{c}{ DBH-Interval $(\mathrm{cm})$} \\
\hline Beech & $<25$ & $25-50$ & $>50$ \\
Oak & $<25$ & $25-50$ & $>50$ \\
Spruce & $<25$ & $25-35$ & $>35$ \\
\hline
\end{tabular}

the inventory was extremely low, we used the results of the simulation runs with default settings for further calculations. We also tested the effect of different initialisations and predictions in the Forest District Liebenburg with ten different simulations on the correlations between simulated and measured values. The values were calculated stratum-wise for every target population, as needed for Equation 3.10. Due to the fact that the effect was very small (the range of the squared correlations can be described by $q_{0.25}=0.0004$ and $\left.q_{0.75}=0.025\right)$, we used the results of just one simulation run in each district and did not compute mean values. In Lower Saxony clear-cuts are not allowed as a regular silvicultural treatment and therefore it is not assumed to happen between the two occasions of the inventory.

\subsubsection{Evaluation procedure}

With this case study we tried to figure out (1) the performance of the new estimator and (2) the effect of using growth model based updates instead of original data from the first inventory occasion. For the latter all steps explained in the following were done with these two types of data as auxiliary variable in the regression part of the new estimator. The measured volumes per ha of the second occasion served as values of the dependent variable.

Correlations between these two variables were calculated as required for Equation 3.10. Differing from the most general case in that Equation, we used the same thirdphase proportion in all strata $\left(\nu_{h}^{*}=\nu^{*}\right)$ instead of proportions differing among strata. Values for $\nu^{*}$ ranged from $1 / n$ to 1 . Wherever an estimation of the volume was required we used the value that was calculated with the 2 st-estimator and all terrestrial sampling points. All calculations were carried out for nine different target populations, defined by dbh and tree species (Table 3.2). Whereas the volume per tree was calculated within the growth model, all other calculations were done with the statistical software package R (R Core Team, 2012).

Correlations between (updated) first occasion and second occasion volumes were calculated within each stratum and across all strata for every target population. Furthermore we fitted linear regressions for every target population, separately for each stratum and over all strata.

The rel. SEs of the new estimator were compared with the corresponding values calculated from the data of the second occasion according to the classical 2st approach. Because the variances and thus the rel. SEs of the two estimators are identical if the 

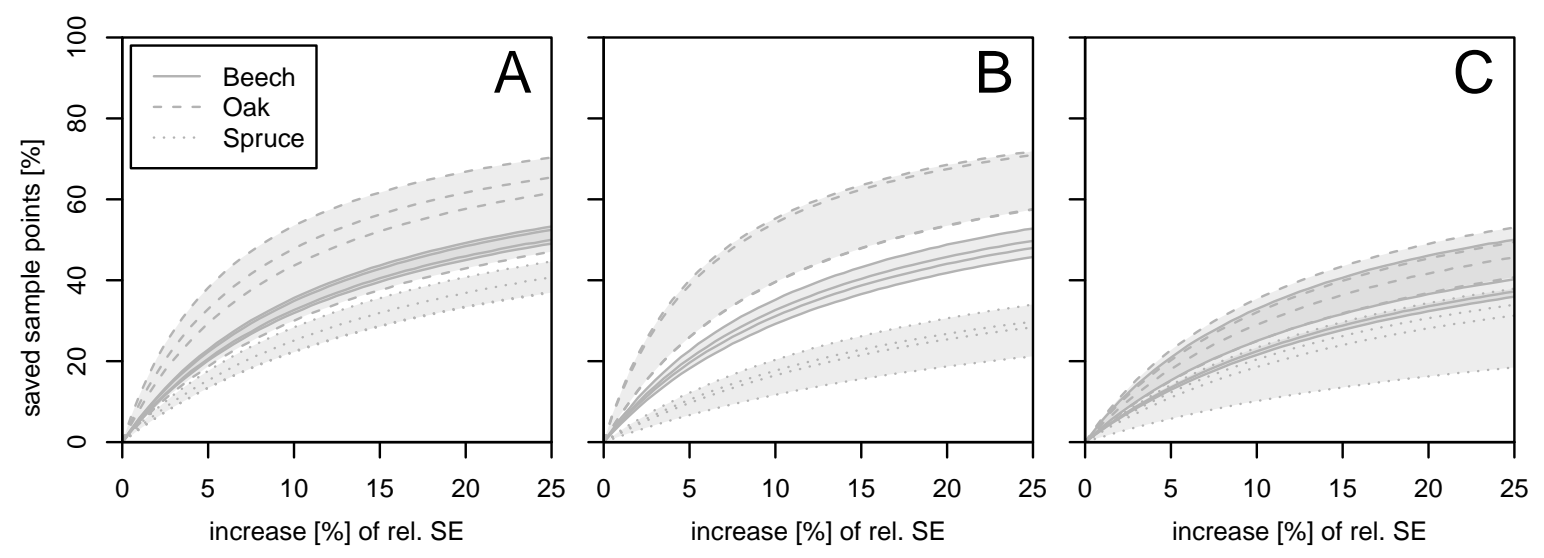

Figure 3.3: The proportion of saved sample points (\%) as a function of increasing relative sampling error (\%) in the small (A), medium (B) and big (C) diameter classes in the four forest districts. The shaded areas indicate the spread of values across the forest districts. In the regression estimator the correlations between growth model-based updates and measured values at the second occasion were used.

values of all second phase plots $(n)$ are included in the calculations (Equation 3.10, $\nu^{*}=1$ ), we looked at the proportion of saved sample plots in dependance on the relative increase of the rel. SE.

To compare the two different types of auxiliary data in the regression estimator we calculated the differences between the proportions of saved sample points of these estimations at the same increases of rel. SE.

\subsubsection{Results}

The results of the inventory on the second occasion show that the actual 2st scheme is appropriate to generate good and reliable results (Table 3.3 in the Appendix). In 29 of 36 target populations the achieved rel. SE is below or equal to the requested precision. The estimated rel. SEs vary between 3.04\% (Beech 25-50 in Reinhausen) and 18.33 $\%$ (Oak $<25$ in Liebenburg). The precision differs among forest districts, species and diameter classes. Whereas the precision is very good for the Beech and Spruce target populations, it is lower for the Oaks. Only in the Forest District Liebenburg was the target precision achieved for less than $75 \%$ of the target populations. As for the precisions in the different diameter classes, the 2 st scheme provides the requested rel. $\mathrm{SE}$ in all small and medium, but only in 5 of the 12 big diameter classes, although in $2 / 3$ of the latter the rel. SE is below $7 \%$.

\section{Growth model based updates}

The relationship between simulated and measured volumes, indicated by Pearson's correlation coefficient (see Table 3.4 in the Appendix), is very strong. Values, calculated 
3. A three-phase sampling procedure for continuous forest inventory with partial re-measurement and updating of terrestrial sample plots

over all strata, vary between 0.73 and 0.93 among target populations. Calculation of the correlation coefficients within each stratum shows that the values vary considerably more among the eight strata. While for some target populations only weaker correlations $(-0.01 \leq \mathrm{r}<0.5)$ could be found in one or more strata, a very strong correlation $(r \geq 0.75)$ appears for other target populations in all strata. This leads to a broad range of correlations including extremes such as -0.01 and 1.00 , the quantile $q_{0.25}$ is 0.71 and $q_{0.75}$ is 0.9 . Comparing the correlations of the different species groups, it becomes obvious that the correlations of the Beech group are very good in most cases $(r>0.75$ in $86 \%)$. In contrast, the values for the Spruce groups indicate weaker relationships $(0.5<r \leq 0.75$ in $40 \%)$ in a lot of strata.

Calculation of linear regressions showed that the relationships between measured and simulated volumes vary remarkably among strata. For some target populations the slope is the same in all strata, hence no interaction between stratum and slope exists. Other target populations show a high variety of slope-values, indicating strong interactions between stratum and slope. Overall the slope parameters range from -0.01 to 3.14 and the intercepts from -2.19 to 279.89 . The $r^{2}$-values of the linear regressions vary from 0 to 1 , the quantiles $\left(q_{0.25}=0.56, q_{0.75}=0.82\right)$ indicate that these regressions are able to explain the variability well in most cases.

The results for the new estimator (Figure 3.3) show, that it could reduce the number of sample plots remarkably compared to pure 2 st, accepting a certain decrease in precision. In the three diameter classes the proportions of saved sample points are highest for the Oaks and lowest for the Spruces. The range of the proportions of saved sample points between forest districts is very narrow for the Beech populations and wider for the two other species groups.

For example for the big Beeches (Figure 3.3 C) a $10 \%$ higher rel. SE, compared to the 2st procedure with full second-phase sample size $n$, could be achieved with the 2st,2lr-procedure using $22 \%$ to $33 \%$ (depending on the district) less sample plots on the second occasion than with the reduced 2st-procedure. For the Spruces that span is from $10 \%$ to $23 \%$, for the Oaks from $25 \%$ to $35 \%$. For the smaller diameter classes (Figures $3.3 \mathrm{~A}, \mathrm{~B}$ ) these savings are even higher.

\section{Data from the first inventory occasion}

Over all strata the values of Pearson's correlation coefficient vary between 0.6 and 0.97 among target populations (Table 3.4 in the Appendix). Like for the case described above, the correlation coefficients vary considerably when calculated stratum-wise. The values range from -0.03 to $1, q_{0.25}$ is 0.66 and $q_{0.75}$ 0.89. In general the correlations are highest for the Beech target populations and lowest for the Spruce target populations.

Within the target populations the relationships between the data of the first and the second occasion also vary among strata, the slope parameters between -0.04 and 3.50. The values for the intercepts range from -8.72 to 265.56. For some target populations strong interactions between stratum and slope exist, for other target populations no interaction is detectable. The $r^{2}$ of the linear regressions vary between 0 and 1 , the 

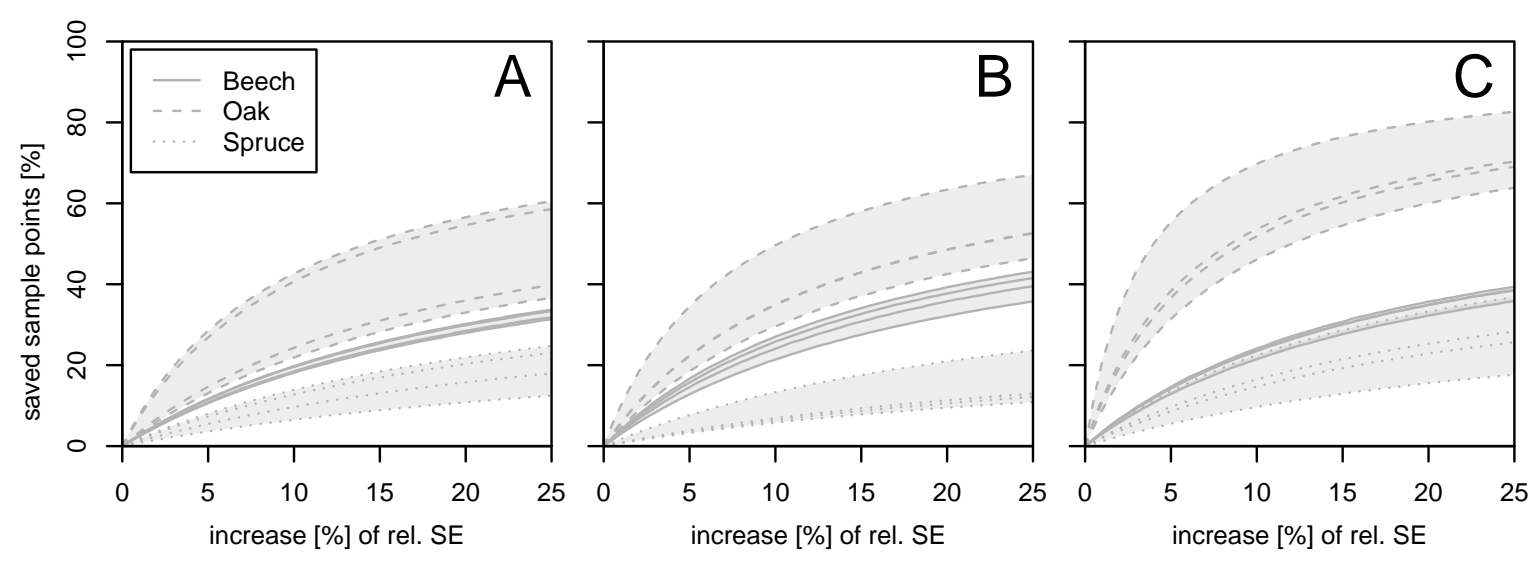

Figure 3.4: The proportion of saved sample points (\%) as a function of increasing relative sampling error (\%) in the small (A), medium (B) and big (C) diameter classes in the four forest districts. The shaded areas indicate the spread of values across the forest districts. In the regression estimator the correlations between measured values at the first and second occasion were used.

corresponding quantiles are $0.57\left(q_{0.25}\right)$ and $0.84\left(q_{0.75}\right)$. Hence, it seems as if the regressions are mostly able to explain the variability well.

In all diameter-classes the highest proportions of saved sample points could be achieved for the Oaks and the lowest for the Spruces (Figure 3.4). Again the range of the results is narrow for the Beeches and wider for the two other species.

\section{Comparison of input data}

In most of the cases the use of growth model based updates clearly improves the performance of the 2st,2lr-estimator (Figure 3.5) compared to the approach based on the measurements of occasion 1. Only for the Oaks with big diameters the use of the data from the first occasion leads to considerable better results.

\subsubsection{Discussion}

Coming back to the initial question of the general performance of the 2st,2lr-estimator, we state that it is possible to save sample plots and thereby inventory-costs, if a certain decrease in precision is accepted. The extent of savings depends on the correlation between the auxiliary and the original data. The main result is that in almost all target populations of our case study the correlation between updated data from the first and measured data from the second occasion is higher than the one between measured data from the first and second occasion, yielding a higher cost saving potential for the growth-model based updates of the previous inventory data.

Our results are mostly, apart from the large Oaks, consistent with different other studies (e.g. Vospernik et al., 2010), which show that WaldPlaner 2.0 is able to produce 
3. A three-phase sampling procedure for continuous forest inventory with partial re-measurement and updating of terrestrial sample plots
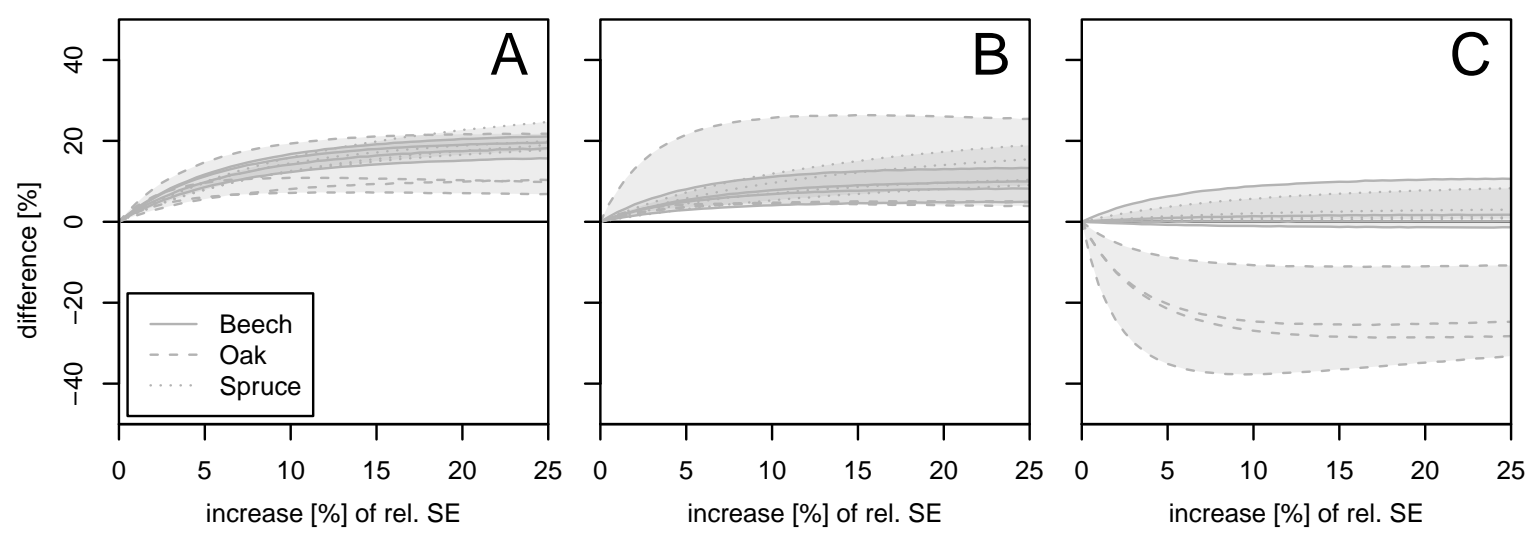

Figure 3.5: The differences of the proportions of saved sample points (\%) between the results of the 2 st,2lr with simulated values and with values of the first inventory. Results are shown as a function of increasing relative sampling error (\%) for the small (A), medium (B) and big (C) diameter classes in the four forest districts. The shaded areas indicate the spread of values across the forest districts.

realistic results. The use of the results of the simulation runs with default settings can be justified by the extremely low influence of these settings on the sampling errors of the inventory and the fact that the default settings follow the silvicultural program of Lower Saxony. Moreover, changes of these settings can in principle be made in the model, but they require further detailed knowledge of the thinning strategies applied in the forest districts, which are difficult to quantify in practice. A reason for the similarity between the simulation runs can be seen in the short simulation period of approximately ten years. In longer simulation periods the differences between these runs are expected to be bigger. Also the effect of different initialisations and simulation runs is expected to be bigger in longer simulation periods. With larger variability among different runs several simulations should be carried out and the mean value be used, because the auxiliary variable is assumed to be non-random. In our case study the variability was negligible.

The many high values of Pearson's correlation coefficient show that the growth projections produce reasonable results. Hence WaldPlaner 2.0 seems to be a suitable tool for this study. However, it has to be considered that points, where volume of trees in a certain target population has been neither measured nor simulated, are included in the calculation and raise the correlation. It is interesting to note, that the correlation for some target populations is very high in strata, where one would not expect a high occurrence of this population, for example, the Oaks in the coniferous strata of Liebenburg. A possible explanation for these high correlations might be seen in the high number of plots with a stand volume of $0 \mathrm{~m}^{3} / \mathrm{ha}$ in the considered target population.

Even though the correlations are high in most cases, a further increase of these values is desirable but can hardly be achieved with the current growth models for several reasons: (1) Extreme differences between measured and simulated volumes can partly 
be explained by calamities. At some points the standing volume has been reduced through insect outbreaks, windstorms or fire. These calamities could not be simulated by the growth model and therefore the differences between the volumes are big at these points. (2) Another reason for discrepancies between the two volumes can be seen in the strict thinning routine in the model, where all trees are harvested when they reach the species-specific target-diameter. In reality not every tree, which reaches the corresponding target-diameter is harvested. Rather the neighbourhood-situation is evaluated by the forester and tree-harvesting follows his assessment. The targetdiameter is handled with much more flexibility in practical forestry than in the growth model. In our case study this may especially be the case for the Oaks with big diameters. (3) The combination of using clone-trees in the model and of analysing the results per target population might explain some of the observed differences between the two values. In reality a target-population might disappear, when only one tree is harvested and no other trees of this target-population exist. Due to the use of clone-trees it is unlikely that a target-population disappears in the model.

A recent approach for the improvement of growth models is the inclusion of calamities, such as infestation by bark beetles (Overbeck \& Schmidt, 2012) or windstorms (Schmidt et al., 2010). Moreover, new approaches for modelling height growth exist. Further enhancement of growth models can be expected from parameterisation of additional tree species, climate-sensitive and local calibration or an improved modelling of silvicultural treatments.

The advantage of the new approach is that it uses the correlations between simulations and measurements which are high, even though the deviations of the simulations from the measurements can be quite large. With the achieved precisions, this procedure is attractive for periodic forest inventories under temporarily restrictive financial constraints. This is because the growth projections for the regression part of the estimator require a data base of recent inventory data, where more terrestrial plots are measured than is planned for the current, reduced inventory.

The results for the linear regressions support the findings about the correlation coefficients, and the broad range of possible relationships within the different strata becomes obvious. Slope parameters of 0 or smaller indicate a bad performance of the growth model or a volume reduction between the two occasions. These cases are assumed to occur in target populations with a low number of plots having a stand volume $>0$ $m^{3} / h a$. From the slope parameters it can be seen that the growth model overestimates the stand volume in some strata and underestimates it in others.

Of course, the new estimator could not reach the target precision in cases where the 2st scheme was already above. Looking at the savings which could be achieved with the new sampling procedure, it has to be noted that additional costs for the simulations and calculations incur. However, these costs will be negligible compared to those of terrestrial sampling. 
3. A three-phase sampling procedure for continuous forest inventory with partial re-measurement and updating of terrestrial sample plots

\subsection{Conclusions}

Comparing classical 2st with the approach proposed here, it is clear that the new approach coincides with simple 2st if the same second- and third-phase sample size is realised. The new approach becomes advantageous when the sample size of the current inventory is reduced and hence a lower accuracy of estimation is accepted. In these cases the savings of sample plots and resultant inventory costs are remarkable. The 2st,2lr-estimator can be used with data from the last occasion or with growth model based updates. Using the latter allows for potentially higher savings, due to higher correlations.

The superiority of this three-phase estimator over the composite estimator analyzed earlier (von Lüpke et al., 2011) can be explained by the often large bias of the WaldPlaner 2.0 predictions as one component of the composite estimator. Despite this large bias, the correlations with plot measurements are usually high and can successfully be exploited in the regression estimator, which is part of the new three-phase approach. Of course this sampling scheme cannot be applied continuously in forest inventories, because a continuous reduction of sample sizes would occur. Thus, we recommend its use as a low-cost inventory alternating with the regular full double sampling inventory or as a temporary intermediate inventory between two regular sampling occasions of a continuous forest inventory.

Assuming additional enhancement of forest growth models through e.g. model calibration implying higher estimation accuracies, the results of this estimator are likely to be further improved.

\section{Acknowledgements}

We would like to thank the German Science Foundation (DFG) for financial support of this study (Sachbeihilfe SA 415/5-1) and Dr. Böckmann of the Lower Saxony Forest Planning Office for his kind provision of the inventory data. Moreover, we would like to thank two anonymous reviewers for their helpful comments.

\subsection{Appendix}

\subsubsection{Proofs}

To derive the variance and a variance estimator for $\widehat{\bar{Y}}_{2 s t, 2 l r}$, we decompose the variance as usual into

$$
V\left(\widehat{\bar{Y}}_{2 s t, 2 l r}\right)=V\left(E\left(\widehat{\bar{Y}}_{2 s t, 2 l r} \mid \text { phase } 1\right)\right)+E V\left(\widehat{\bar{Y}}_{2 s t, 2 l r} \mid \text { phase } 1\right)
$$


The conditional expectation of $\widehat{\bar{Y}}_{2 s t, 2 l r}$, given phase 1 (finite populations of size $n_{h}^{\prime}$ ), is

$$
E\left(\widehat{\bar{Y}}_{2 s t, 2 l r} \mid \text { phase } 1\right) \approx \sum_{h=1}^{L} \frac{n_{h}^{\prime}}{n^{\prime}} \frac{1}{n_{h}^{\prime}} \sum_{i=1}^{n_{h}^{\prime}} y_{h i}=\frac{1}{n^{\prime}} \sum_{j=1}^{n^{\prime}} y_{i}
$$

and its variance can be calculated as (infinite population, Mandallaz, 2008, with $\left.S^{2}=V_{S}\right)$

$$
V\left(E\left(\widehat{\bar{Y}}_{2 s t, 2 l r} \mid \text { phase } 1\right)\right)=V\left(\frac{1}{n^{\prime}} \sum_{j=1}^{n^{\prime}} y_{i}\right)=\frac{1}{n^{\prime}} S^{2}
$$

For the second term of the decomposition, we need the conditional variance of $\widehat{\bar{Y}}_{2 s t, 2 l r}$

$$
\begin{aligned}
V\left(\widehat{\bar{Y}}_{2 s t, 2 l r} \mid \text { phase } 1\right)=\sum_{h=1}^{L} w_{h}^{2} V\left(\widehat{\bar{Y}}_{h, 2 l r} \mid \text { phase } 1\right) & \\
& \approx \sum_{h=1}^{L} w_{h}^{2}\left(\frac{s_{h}^{\prime 2}\left(1-r_{h}^{\prime 2}\right)}{n_{h}^{*}}+\frac{{s_{h}^{\prime}}^{2} r_{h}^{\prime 2}}{n_{h}}-\frac{s_{h}^{\prime 2}}{n_{h}^{\prime}}\right)
\end{aligned}
$$

Substituting 3.14 and 3.15 in 3.12 finally yields

$$
V\left(\widehat{\bar{Y}}_{2 s t, 2 l r}\right) \approx \frac{1}{n^{\prime}} S^{2}
$$

$$
+E \frac{1}{n^{\prime}} \sum_{h=1}^{L} w_{h}\left(\frac{s_{h}^{\prime 2}\left(1-r_{h}^{2}\right)}{\nu_{h}^{*} \nu_{h}}+\frac{s_{h}^{\prime 2} r_{h}^{\prime 2}}{\nu_{h}}-s_{h}^{\prime 2}\right)
$$

Since

$$
V\left(\widehat{\bar{Y}}_{2 s t}\right) \approx \frac{1}{n^{\prime}} S^{2}+E \sum_{h=1}^{L} \frac{w_{h} s_{h}^{2}}{n^{\prime}}\left(\frac{1}{\nu_{h}}-1\right)
$$

(A.1 in Saborowski et al. (2010)) we have

$$
V\left(\widehat{\bar{Y}}_{2 s t, 2 l r}\right) \approx V\left(\widehat{\bar{Y}}_{2 s t}\right)+E \frac{1}{n^{\prime}} \sum_{h=1}^{L} w_{h}\left(\frac{1}{\nu_{h}^{*}}-1\right) \frac{s_{h}^{\prime 2}\left(1-r_{h}^{\prime 2}\right)}{\nu_{h}}
$$

which can be estimated by 
3. A three-phase sampling procedure for continuous forest inventory with partial re-measurement and updating of terrestrial sample plots

$\widehat{V}\left(\widehat{\bar{Y}}_{2 s t, 2 l r}\right) \approx \widehat{V}\left(\widehat{\bar{Y}}_{2 s t}\right)$

$$
+\frac{1}{n^{\prime}} \sum_{h=1}^{L} w_{h}\left(\frac{1}{\nu_{h}^{*}}-1\right) \frac{s_{h}^{* 2}\left(1-r_{h}^{* 2}\right)}{\nu_{h}} \frac{n_{h}^{*}-1}{n_{h}^{*}-2}
$$

because

$$
\begin{aligned}
s_{h}^{* 2}\left(1-r_{h}^{* 2}\right) \frac{n_{h}^{*}-1}{n_{h}^{*}-2}=\frac{1}{n_{h}^{*}-2} & {\left[\sum_{i=1}^{n_{h}^{*}}\left(y_{h i}-\bar{y}_{h}\right)^{2}-b^{2} \sum_{i=1}^{n_{h}^{*}}\left(x_{h i}-\bar{x}_{h}\right)^{2}\right] }
\end{aligned}
$$

is an unbiased estimator of ${s_{h}^{\prime}}^{2}\left(1-{r_{h}^{\prime}}^{2}\right)$ (Cochran, 1977, 12.66).

\subsubsection{Tables}

Table 3.3: Estimated volume $\left(m^{3} h a^{-1}\right)$ and standard deviations $\left(m^{3} h a^{-1}\right)$ of the 9 tar-

\begin{tabular}{|c|c|c|c|c|c|c|c|c|}
\hline \multirow[b]{2}{*}{ Target Population } & \multicolumn{2}{|c|}{ Liebenburg } & \multicolumn{2}{|c|}{ Reinhausen } & \multicolumn{2}{|c|}{ Grünenplan } & \multicolumn{2}{|c|}{ Saupark } \\
\hline & $\widehat{\bar{Y}}$ & $\widehat{S D}(\widehat{\bar{Y}})$ & $\widehat{\bar{Y}}$ & $\widehat{S D}(\widehat{\bar{Y}})$ & $\widehat{\bar{Y}}$ & $\widehat{S D}(\widehat{\bar{Y}})$ & $\widehat{\bar{Y}}$ & $\widehat{S D}(\widehat{\bar{Y}})$ \\
\hline Beech $<25$ & 19.44 & 1.08 & 26.47 & 1.09 & 22.19 & 1.07 & 18.2 & 1.02 \\
\hline Oak $<25$ & 2.41 & 0.44 & 3.09 & 0.48 & 3.2 & 0.47 & 2.4 & 0.43 \\
\hline Spruce $<25$ & 3.7 & 0.47 & 4.04 & 0.4 & 7.79 & 0.61 & 5.33 & 0.45 \\
\hline Beech $25-50$ & 61.95 & 2.9 & 95.38 & 2.9 & 74.08 & 2.58 & 63.4 & 2.46 \\
\hline Oak $25-50$ & 19 & 1.58 & 11.23 & 1.05 & 8.55 & 1.1 & 7.71 & 1.03 \\
\hline Spruce $25-35$ & 16.83 & 1.23 & 11.64 & 0.73 & 19.86 & 0.96 & 22.41 & 1.01 \\
\hline Beech $>50$ & 41.92 & 2.78 & 88.58 & 3.26 & 57.65 & 2.68 & 81.89 & 3.33 \\
\hline Oak $>50$ & 25.11 & 2.47 & 19.69 & 1.72 & 15.25 & 1.63 & 18.99 & 2.24 \\
\hline Spruce $>35$ & 34.71 & 2.18 & 27.99 & 1.45 & 49.86 & 2.07 & 47.83 & 1.78 \\
\hline
\end{tabular}
get populations in the four forest districts. The values were calculated with the 2st-estimators from all terrestrial sampling points at the second occasion. 


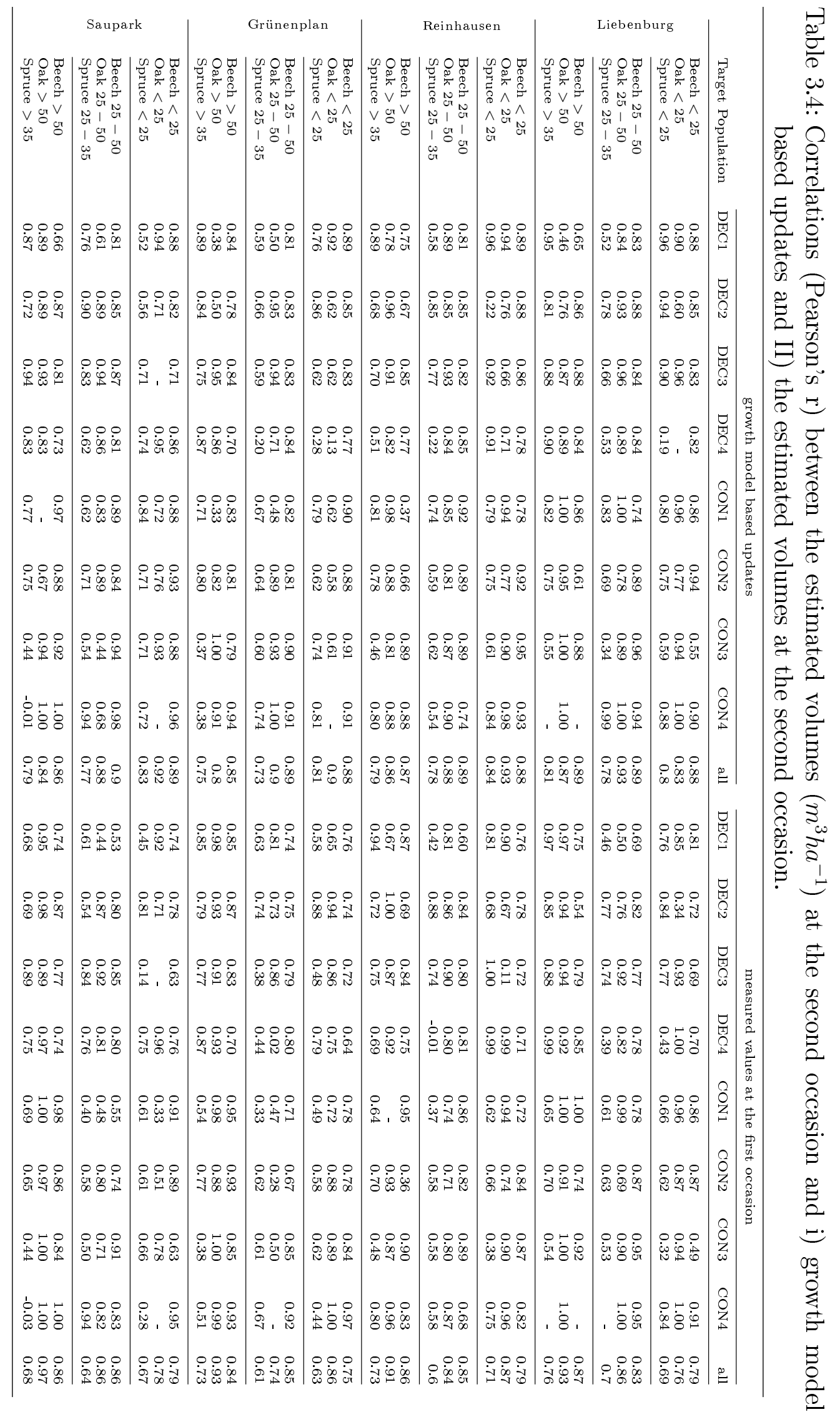




\section{Chapter 4}

\section{Combining double sampling for stratification and cluster sampling to a three-phase sampling design for continuous forest inventories}

Nikolas von Lüpke ${ }^{1}$ - Joachim Saborowski1 ${ }^{1,2}$

\footnotetext{
${ }^{1}$ Department of Ecoinformatics, Biometrics and Forest Growth,

University of Göttingen, Büsgenweg 4, 37077 Göttingen, Germany

${ }^{2}$ Department of Ecosystem Modelling,

University of Göttingen, Büsgenweg 4, 37077 Göttingen, Germany
} 
- Joachim Saborowski developed the estimators for cluster subsampling of double sampling for stratification. Moreover, he supported the analysis of the results and the writing of the manuscript. 
4. Combining double sampling for stratification and cluster sampling to a three-phase sampling design for continuous forest inventories

\section{Abstract}

We extend the well-known double sampling for stratification sampling scheme by cluster sub-sampling to a three-phase design and present corresponding estimators based on the infinite population approach in the first phase. After stratification of the sample points (phase I), a second-phase sample is drawn independently among the first-phase points within each stratum. For phase III, clusters are formed of those phase II points, and a sample of clusters is finally drawn without replacement. We used the forest planning units compartment and sub-district as clusters and moreover formed clusters with a heuristic for the vehicle routing problem. The precision of the new estimator was compared to that achieved with classical double sampling for stratification in a case study. The results indicate that the expected increase of sampling errors caused by clustering cannot be compensated by the reduced inventory costs under the conditions given in the case study.

\section{keywords}

continuous forest inventory - double sampling for stratification - cluster sampling infinite population approach

\subsection{Introduction}

Generating statistically sound information is the main challenge of forest inventories, even though they additionally have to fulfil other demands (Lund, 1998). The information gained from an inventory is valuable not only in the planning process of the forest-authorities or -owners. Moreover, the reporting for international conventions (e.g. biodiversity or climate change) needs statistically sound information.

An important constraint in the development of an adequate inventory design is (cost-) efficiency. It is desirable to either achieve the highest precision with predefined inventory costs or to minimise the inventory costs for achieving a predefined precision.

One method that has prooved its efficiency and practicability often in the last decades is double sampling for stratification (2st) (Cochran, 1977; de Vries, 1986; Schreuder et al., 1993; Köhl, 1994; Särndal et al., 2003; Gregoire \& Valentine, 2008; Mandallaz, 2008). Saborowski et al. (2010) recently studied this method for periodic inventories under the infinite population approach, and Scott \& Köhl (1994) extended it by sampling with partial replacement (SPR). Two phases can be distinguished in this procedure: In the first phase qualitative information is obtained from a large number of sampling units. Based on these qualitative data, a stratification of the first-phase units is carried out and a sub-sample of every stratum is inventoried. The second-phase points are usually assumed to be chosen by simple random sampling (SRS) without replacement. Whereas it is common to obtain the qualitative data using aerial images, the quantitative data are usually gained through terrestrial sampling. The aim of the stratification is 
to create strata with a low within-strata variability and a high between-strata variability. In comparison with other methods the costs of this design are usually low (Brassel \& Köhl, 2001; Saborowski et al., 2010). Nevertheless, a further reduction of costs is desirable.

Another common and potentially efficient method is cluster sampling (cl), where spatial clusters of sampling units are formed and a sub-sample of these clusters is inventoried (Cochran, 1977; Gregoire \& Valentine, 2008). Usually the clusters are designed in a way that makes it possible to execute the field work per cluster within one day (Kleinn, 1996). Several shapes of clusters such as triangle, square or cross exist, their efficiency has been studied e.g. by Kleinn $(1994,1996)$. The aim of clustering is to achieve a high variability within and a low variability between clusters. In comparison to SRS this method may be advantageous because of reduced travelling costs. Although the clustering always leads to a loss in precision compared to SRS (Cochran, 1977), it might be more efficient if the precision of SRS can be achieved by a larger number of population elements sampled at lower costs. Cluster sampling is usually applied in tropical forests, where sample plots are difficult to access, but also for example in the national forest inventories of Finland and Germany (Tomppo et al., 2010a).

It was conjectured by foresters that spatial clustering of second-phase units of the Lower Saxony State Forest District Inventories might also be more efficient, because clusters of an appropriate size could already cover a sufficiently large amount of variability and consequently the current relation between travelling- and inventory-time was detrimental. Therefore, we aimed at clustering the sample points of the second phase spatially, even though a loss in precision must be taken into account. In this article we present a new three-phase estimator with cluster subsampling of second-phase units and its application in a case study carried out with data of the State Forest District Inventory in Lower Saxony, Germany.

\subsection{An estimator for cluster subsampling of double sampling for stratification}

\subsubsection{Double sampling for stratification}

In this two-phase sampling scheme, measurements only take place in a sub-sample $(n)$ of all first-phase plots $\left(n^{\prime}\right)$. Using low-cost qualitative variables, the first-phase sample points are stratified into $L$ strata. Strata means of the target variable $\left(\bar{y}_{h}\right)$ are then weighted with the proportion of first-phase sample points per stratum $\left(n_{h}^{\prime} / n^{\prime}=w_{h}\right)$ and summarised to estimate the overall mean $\bar{Y}$ (Equation 4.1) (Cochran, 1977).

$$
\hat{\bar{Y}}_{2 s t}=\sum_{h=1}^{L} w_{h} \frac{1}{n_{h}} \sum_{i=1}^{n_{h}} y_{h i}=\sum_{h=1}^{L} w_{h} \bar{y}_{h}
$$


4. Combining double sampling for stratification and cluster sampling to a three-phase sampling design for continuous forest inventories

An unbiased estimator for the variance of this estimator under the infinite population approach (see e.g. Mandallaz, 2008) is given by

$$
\begin{gathered}
\hat{V}\left(\hat{\bar{Y}}_{2 s t}\right)=\frac{1}{n^{\prime}-1}\left(\sum_{h=1}^{L} \frac{n_{h}^{\prime}-1}{n^{\prime}} \frac{s_{h}^{2}}{\nu_{h}}+\sum_{h=1}^{L} w_{h}\left(\bar{y}_{h}-\hat{\bar{Y}}_{2 s t}\right)^{2}\right) \\
s_{h}^{2}=\frac{1}{n_{h}-1} \sum_{i=1}^{n_{h}}\left(y_{h i}-\bar{y}_{h}\right)^{2}
\end{gathered}
$$

(Saborowski et al., 2010). Here, $s_{h}^{2}$ is the estimated within-stratum variance of the target variable (Equation 4.3), and $\nu_{h}=n_{h} / n_{h}^{\prime}$ is the proportion of terrestrial sample points per stratum.

\subsubsection{Cluster sampling}

In cluster sampling, where a population is split into $K$ clusters, $k$ of which are randomly sampled, two estimation approaches exist, (1) the unbiased estimator (unb) and (2) the Ratio-to-Size estimator (RtS) (Cochran, 1977, with $n=k$ and $N=K$ ).

\section{Unbiased estimator}

An unbiased estimator of the population total $Y$ in a finite population of size $M_{0}=$ $\sum_{i=1}^{K} M_{i}$ is

$$
\hat{Y}_{u n b}=\frac{K}{k} \sum_{i=1}^{k} y_{i},
$$

where $y_{i}$ is the total of the target variable in cluster $i$. The corresponding variance is given by Equation 4.5, where $\bar{Y}_{(K)}=Y / K$ is the population mean per cluster unit (Cochran, 1977).

$$
V\left(\hat{Y}_{\text {unb }}\right)=\frac{K^{2}}{k}\left(1-\frac{k}{K}\right) \frac{\sum_{i=1}^{K}\left(y_{i}-\bar{Y}_{(K)}\right)^{2}}{K-1}
$$

The population mean per element $(\overline{\bar{Y}})$ can then be estimated by dividing the estimator of the population total by the total number of elements in the population $\left(M_{0}\right)$ (Equation 4.6).

$$
\hat{\overline{\bar{Y}}}_{u n b}=\frac{\hat{Y}_{u n b}}{M_{0}}=\frac{K}{k M_{0}} \sum_{i=1}^{k} y_{i}
$$




\section{Ratio-to-Size estimator}

In this approach the population mean is estimated by the ratio of the sum of the target variables $\left(y_{i}\right)$ in the sample to the total number of elements in the sample.

$$
\hat{\bar{Y}}_{R t S}=\frac{\hat{Y}_{R t S}}{M_{0}}=\frac{\sum_{i=1}^{k} y_{i}}{\sum_{i=1}^{k} M_{i}}
$$

what is known to be an approximately unbiased estimator. Multiplying by the total number of elements in the population yields

$$
\hat{Y}_{R t S}=M_{0} \frac{\sum_{i=1}^{k} y_{i}}{\sum_{i=1}^{k} M_{i}},
$$

an estimator for the population total. The formula of the corresponding approximate variance is similar to Equation 4.5, the variance of the unbiased estimator. It differs only in that it replaces the mean per cluster $\bar{Y}_{(K)}$ by $M_{i} \overline{\bar{Y}}$.

$$
V\left(\hat{Y}_{R t S}\right) \doteq \frac{K^{2}}{k}\left(1-\frac{k}{K}\right) \frac{\sum_{i=1}^{K}\left(y_{i}-M_{i} \overline{\bar{Y}}\right)^{2}}{K-1}
$$

\subsubsection{Cluster subsampling of double sampling for stratification}

The envisaged procedure comprises three phases (Figure 4.1). Phases I and II follow the well-known 2st design (see "Double sampling for stratification"). In the third phase, the second-phase units are clustered into $K$ clusters and $k \leq K$ clusters are randomly sampled without replacement. These $k$ sample clusters are finally measured in the field. Due to the fact that the Ratio-to-Size estimator mostly performed better than the unbiased estimator in our case study, we restrict the following presentation to the estimators and the results based on (4.7) and (4.9). The estimator of the overall mean

$$
\hat{\bar{Y}}_{2 s t, c l}=\sum_{h=1}^{L} w_{h} \hat{\bar{y}}_{h}=\sum_{h=1}^{L} w_{h} \frac{\sum_{i=1}^{k} \breve{y}_{i h}}{\sum_{i=1}^{k} M_{i h}}
$$

differs from the 2st-estimator (Equation 4.1) merely in the estimator of the mean per stratum $\left(\bar{y}_{h}\right)$, which is now replaced by

$$
\hat{\bar{y}}_{h}=\frac{\sum_{i=1}^{k} \breve{y}_{i h}}{\sum_{i=1}^{k} M_{i h}} .
$$

$\breve{y}_{i h}=\sum_{l=1}^{M_{i h}} \breve{y}_{i h l}$ is the sum of the target variable over all second-phase units in cluster $i$ which belong to stratum $h$ (clusters may overlap different strata), and $M_{i h}$ is the number of those second-phase units. The estimator $\hat{\bar{y}}_{h}$ is nothing else than the Ratioto-Size estimator for the mean per element (Equation 4.7) in stratum $h$, if we consider 
4. Combining double sampling for stratification and cluster sampling to a three-phase sampling design for continuous forest inventories

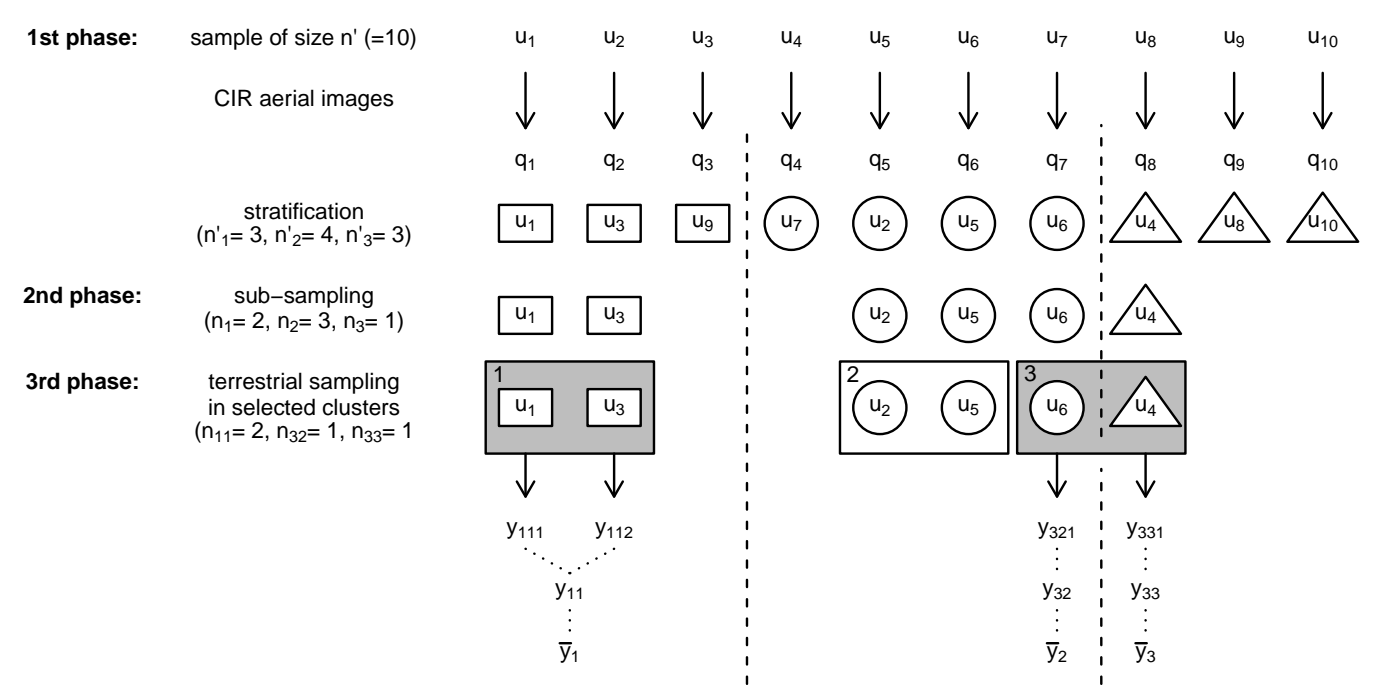

Figure 4.1: Sampling procedure of the three-phase sampling design.

the second-phase units as a finite population of size $M_{0}=n_{h}$. Thus (4.10) is also approximately unbiased.

An estimator for the variance (Equation 4.12) is given in Equation 4.13 (for the proof see the Appendix).

$$
\begin{aligned}
V\left(\hat{\bar{Y}}_{2 s t, c l}\right) & =\frac{1}{n^{\prime}}\left(\sum_{h=1}^{L} \frac{W_{h} S_{h}^{2}}{\nu_{h}}+\sum_{h=1}^{L} W_{h}\left(\bar{Y}_{h}-\bar{Y}\right)^{2}\right) \\
& +E \sum_{h=1}^{L}\left(\frac{n_{h}^{\prime}}{n^{\prime}}\right)^{2} \frac{1}{n_{h}^{2}} \frac{K^{2}}{k}\left(1-\frac{k}{K}\right) \breve{S}_{h}^{2} \\
& +E \sum_{h \neq h^{\prime}}^{L} \frac{n_{h}^{\prime} n_{h^{\prime}}^{\prime}}{n^{\prime 2}} \frac{1}{n_{h} n_{h^{\prime}}} \frac{K^{2}}{k}\left(1-\frac{k}{K}\right) \breve{S}_{h h^{\prime}} . \\
\hat{V}\left(\hat{\bar{Y}}_{2 s t, c l}\right)= & \frac{1}{n^{\prime}-1}\left(\sum_{h=1}^{L} \frac{n_{h}^{\prime}-1}{n^{\prime}} \frac{s_{h, c l}^{2}}{\nu_{h}}+\sum_{h=1}^{L} \frac{n_{h}^{\prime}}{n^{\prime}}\left(\hat{\bar{y}}_{h}-\hat{\bar{Y}}_{2 s t, c l}\right)^{2}\right) \\
+ & \sum_{h=1}^{L}\left(\frac{n_{h}^{\prime}}{n^{\prime}}\right)^{2} \frac{1}{n_{h}^{2}} \frac{K^{2}}{k}\left(1-\frac{k}{K}\right) \breve{s}_{h}^{2} \\
+ & \frac{2 K^{2}}{k n^{\prime 2}}\left(1-\frac{k}{K}\right) \sum_{h<h^{\prime}}^{L} \frac{n_{h}^{\prime} n_{h^{\prime}}^{\prime}}{n_{h} n_{h^{\prime}}} \breve{s}_{h h^{\prime}} .
\end{aligned}
$$

The first of the three main terms of (4.12) is the variance under 2st; terms for the variances within strata and the covariances between strata are added. 
Equation 4.14 is the within-stratum variance between clusters, the corresponding estimator is given in Equation 4.15.

$$
\begin{aligned}
& \breve{S}_{h}^{2}=\frac{1}{K-1} \sum_{i=1}^{K}\left(\breve{y}_{i h}-M_{i h} \bar{y}_{h}\right)^{2} \\
& \breve{s}_{h}^{2}=\frac{1}{k-1} \sum_{i=1}^{k}\left(\breve{y}_{i h}-M_{i h} \hat{\bar{y}}_{h}\right)^{2}
\end{aligned}
$$

$s_{h, c l}^{2}$, a conditionally unbiased estimator for $s_{h}^{2}$, given the first two phases, is given in Equation 4.16, where $\overline{\breve{y}}_{i h}$ is the mean over all $M_{i h}$ sampling units in cluster $i$ and stratum $h$.

$$
s_{h, c l}^{2}=\frac{1}{n_{h}-1} \frac{K}{k}\left[\sum_{i=1}^{k} M_{i h}\left(\overline{\breve{y}}_{i h}-\hat{\bar{y}}_{h}\right)^{2}+\sum_{i=1}^{k} \sum_{l=1}^{M_{i h}}\left(\breve{y}_{i h l}-\overline{\breve{y}}_{i h}\right)^{2}\right]
$$

Thus $s_{h, c l}^{2}$ is also unbiased for $S_{h}^{2}$. The covariance between the sampling units of different strata within a cluster can be calculated using Equation 4.17, an estimator is given in Equation 4.18.

$$
\begin{aligned}
& \breve{S}_{h h^{\prime}}=\frac{1}{K-1} \sum_{i=1}^{K}\left(\breve{y}_{i h}-M_{i h} \bar{y}_{h}\right)\left(\breve{y}_{i h^{\prime}}-M_{i h^{\prime}} \bar{y}_{h^{\prime}}\right) \\
& \breve{s}_{h h^{\prime}}=\frac{1}{k-1} \sum_{i=1}^{K}\left(\breve{y}_{i h}-M_{i h} \hat{\bar{y}}_{h}\right)\left(\breve{y}_{i h^{\prime}}-M_{i h^{\prime}} \hat{\bar{y}}_{h^{\prime}}\right)
\end{aligned}
$$

The relative sampling error (rel. SE), as given in Equation 4.19, will also be interesting for evaluating the performance of the estimator.

$$
\text { rel.SE }=\frac{\sqrt{\operatorname{Var} \hat{\bar{Y}}_{2 s t, c l}}}{\hat{\bar{Y}}_{2 s t, c l}}
$$

\subsection{Case Study}

\subsubsection{Data Base}

Since 1999 the State Forest District Inventory of Lower Saxony is carried out according to a 2st-design (Böckmann et al., 1998). In the first phase CIR aerial images are taken at every grid point of a $100 \mathrm{~m} \times 100 \mathrm{~m}$ grid. Every sample point is assigned to one of eight strata, defined by age class $(1: \leq 40$ years, $2:>40-80$ years, 3 : $>80-120$ years, 4: > 120 years) and dominating species group (CON: Coniferous, DEC: Deciduous). Afterwards terrestrial sampling is carried out in a sub-sample of each stratum. The proportion of terrestrial sample points $\left(\nu_{h}\right)$ differs between the strata. 
In every stratum the $n_{h}$ second-phase sample points are chosen systematically from a list of all sample points in the stratum; in the following study, we deal with the according sample plots as randomly selected plots in both phases. Measurements then are executed in two concentric circular plots. In a plot of radius $6 \mathrm{~m}$ all trees with a $\mathrm{dbh} \geq 7 \mathrm{~cm}$ and $<30 \mathrm{~cm}$ are measured. Trees with larger dbh are measured in a plot of $13 \mathrm{~m}$ radius. Tree heights were only partly measured during the inventory. In cases without height measurements we used species-specific height curves for estimation of tree heights (Sloboda et al., 1993). Finally, the solid tree volumes were calculated with species-specific form factors (Bergel, 1973, 1974). The first run of the inventory has been carried out between 1999 and 2008 subsequently in all forest districts. Here, we used the data of seven state forest districts in the regions Harz (Clausthal, Lauterberg, Riefensbeek, Seesen) and Solling (Dassel, Neuhaus, Winnefeld) (Table 4.1). Meanwhile forest districts were merged to larger units (see www.landesforsten.de).

\subsubsection{Evaluation procedure}

The aim of the case study is to assess (1) the general performance of the 2st,cl-estimator compared to simple 2st and (2) the effect of different cluster types on the variance of the estimator. As clusters we used (a) forest sub-districts (Revier), (b) compartments (Abteilung) and (c) daily workloads (Table 4.2), the latter calculated with a heuristic for the vehicle routing problem (VRP) (Dantzig \& Ramser, 1959), the Record-to-Record algorithm from Li et al. (2005).

Very famous in Operations Research, the VRP describes the problem of supplying several customers from one depot with a truck of given capacity. It is desired to fulfil all customer demands, which can be different, and to find the shortest route. Adapting the algorithm to our problem, we assumed a daily working time of eight hours as capacity. Assuming as demand per sample plot a mean working time of $1.5 \mathrm{~h}$ for a two-people inventory-team (Zinggeler \& Herold, 1997; Zinggeler, 2001), it is possible to measure five plots during a day on average. Due to the high number of sample plots per forest district and the lack of realistic depots, we used the forest sub-districts as unit for the calculations in case of this cluster type and assumed the starting point to lie in the center of all terrestrial sample plots of a sub-district. The clusters have been postoptimised with a 2-opt-algorithm (R library "TSP") (Hahsler \& Hornik, 2007). The workload-clusters were calculated with the VRPH-library (Gröer et al., 2010), all other calculations were carried out with the statistical software package $R$ ( $R$ Core Team, 2012).

Due to the fact, that data from all terrestrial sample points (phase II) and thus all clusters $K$ are available in the data sets, we used $\breve{S}_{h}^{2}$ (Equation 4.14) instead of $\breve{s}_{h}^{2}$ (Equation 4.15) and $s_{h}^{2}$ (Equation 4.3) instead of $s_{h, c l}^{2}$ (Equation 4.16) in the variance estimator (Equation 4.13) to increase precision of the estimation and to avoid the otherwise necessary simulations of cluster sampling. For the same reasons, we replaced 
Table 4.1: First- and second-phase sample sizes in the eight strata of the seven forest districts.

\begin{tabular}{|c|c|c|c|c|c|c|c|c|c|c|c|}
\hline Forest District & year & Phase & $\mathrm{DEC} 1$ & $\mathrm{DEC} 2$ & DEC3 & $\mathrm{DEC} 4$ & CON1 & $\mathrm{CON} 2$ & $\mathrm{CON} 3$ & CON4 & $\Sigma$ \\
\hline Clausthal & 1999,2002 & $\begin{array}{c}\text { I } \\
\text { II }\end{array}$ & $\begin{array}{r}287 \\
31 \\
\end{array}$ & $\begin{array}{r}490 \\
52 \\
\end{array}$ & $\begin{array}{r}362 \\
50 \\
\end{array}$ & $\begin{array}{r}428 \\
61 \\
\end{array}$ & $\begin{array}{r}1445 \\
171 \\
\end{array}$ & $\begin{array}{r}5084 \\
855 \\
\end{array}$ & $\begin{array}{r}2250 \\
346\end{array}$ & $\begin{array}{r}1244 \\
198 \\
\end{array}$ & $\begin{array}{r}11590 \\
1764 \\
\end{array}$ \\
\hline Dassel & 2000,2001 & $\begin{array}{c}\text { I } \\
\text { II }\end{array}$ & $\begin{array}{r}1049 \\
145 \\
\end{array}$ & $\begin{array}{r}1205 \\
132 \\
\end{array}$ & $\begin{array}{r}1327 \\
159 \\
\end{array}$ & $\begin{array}{r}1613 \\
280 \\
\end{array}$ & $\begin{array}{r}1334 \\
281 \\
\end{array}$ & $\begin{array}{r}1928 \\
578 \\
\end{array}$ & $\begin{array}{l}895 \\
241 \\
\end{array}$ & $\begin{array}{r}188 \\
52 \\
\end{array}$ & $\begin{array}{l}9539 \\
1868 \\
\end{array}$ \\
\hline Lauterberg & 2002 & $\begin{array}{c}\text { I } \\
\text { II }\end{array}$ & $\begin{array}{r}945 \\
89\end{array}$ & $\begin{array}{r}1269 \\
87\end{array}$ & $\begin{array}{r}1139 \\
95\end{array}$ & $\begin{array}{r}2091 \\
267\end{array}$ & $\begin{array}{r}1833 \\
321\end{array}$ & $\begin{array}{r}3783 \\
970\end{array}$ & $\begin{array}{r}2320 \\
528\end{array}$ & $\begin{array}{l}897 \\
200\end{array}$ & $\begin{array}{r}14277 \\
2557\end{array}$ \\
\hline Neuhaus & 1999,2000 & $\begin{array}{c}\text { I } \\
\text { II } \\
\end{array}$ & $\begin{array}{r}1687 \\
172 \\
\end{array}$ & $\begin{array}{r}1521 \\
102 \\
\end{array}$ & $\begin{array}{r}1113 \\
103 \\
\end{array}$ & $\begin{array}{r}1663 \\
218 \\
\end{array}$ & $\begin{array}{r}1919 \\
343 \\
\end{array}$ & $\begin{array}{r}2326 \\
614 \\
\end{array}$ & $\begin{array}{r}1627 \\
384 \\
\end{array}$ & $\begin{array}{r}241 \\
60 \\
\end{array}$ & $\begin{array}{r}12097 \\
1996 \\
\end{array}$ \\
\hline Seesen & $1999,2001,2002$ & $\begin{array}{c}\text { I } \\
\text { II }\end{array}$ & $\begin{array}{r}1227 \\
238 \\
\end{array}$ & $\begin{array}{r}1328 \\
230 \\
\end{array}$ & $\begin{array}{l}707 \\
184 \\
\end{array}$ & $\begin{array}{r}1428 \\
374 \\
\end{array}$ & $\begin{array}{r}1229 \\
271 \\
\end{array}$ & $\begin{array}{r}3329 \\
855 \\
\end{array}$ & $\begin{array}{r}1306 \\
320 \\
\end{array}$ & $\begin{array}{r}375 \\
78 \\
\end{array}$ & $\begin{array}{r}10929 \\
2550 \\
\end{array}$ \\
\hline Winnefeld & 2000 & $\begin{array}{c}\text { I } \\
\text { II }\end{array}$ & $\begin{array}{r}1664 \\
207\end{array}$ & $\begin{array}{r}2312 \\
196\end{array}$ & $\begin{array}{r}1573 \\
172 \\
\end{array}$ & $\begin{array}{r}2889 \\
463 \\
\end{array}$ & $\begin{array}{r}1501 \\
337\end{array}$ & $\begin{array}{r}1656 \\
544 \\
\end{array}$ & $\begin{array}{l}707 \\
209\end{array}$ & $\begin{array}{r}165 \\
50\end{array}$ & $\begin{array}{r}12467 \\
2178\end{array}$ \\
\hline
\end{tabular}

$\hat{\bar{y}}_{h}$ by $\bar{y}_{h}$ and $\hat{\bar{Y}}_{2 s t, c l}$ by $\hat{\bar{Y}}_{2 s t}$ and achieved

$$
\begin{aligned}
\hat{V}\left(\hat{\bar{Y}}_{2 s t, c l}\right) & =\frac{1}{n^{\prime}-1}\left(\sum_{h=1}^{L} \frac{n_{h}^{\prime}-1}{n^{\prime}} \frac{s_{h}^{2}}{\nu_{h}}+\sum_{h=1}^{L} \frac{n_{h}^{\prime}}{n^{\prime}}\left(\bar{y}_{h}-\hat{\bar{Y}}_{2 s t}\right)^{2}\right) \\
& +\sum_{h=1}^{L}\left(\frac{n_{h}^{\prime}}{n^{\prime}}\right)^{2} \frac{1}{n_{h}^{2}} \frac{K^{2}}{k}\left(1-\frac{k}{K}\right) \breve{S}_{h}^{2} \\
& +\frac{2 K^{2}}{k n^{\prime 2}}\left(1-\frac{k}{K}\right) \sum_{h<h^{\prime}}^{L} \frac{n_{h}^{\prime} n_{h^{\prime}}^{\prime}}{n_{h} n_{h^{\prime}}} \breve{S}_{h h^{\prime}}
\end{aligned}
$$

as an estimator for (4.12). The first term equals the 2st variance estimator (4.2). Please note that this estimator is not applicable in forest inventory practice because of the aforementioned substitutions. Finally, variances according to (4.20) were calculated for three different target populations defined by species group and dbh: Beech $>50 \mathrm{~cm}$, Oak $>50 \mathrm{~cm}$, Spruce $>35 \mathrm{~cm}$.

For estimation of the travelling distances of 2 st and 2 st,cl we carried out simulations. In 100 simulation runs, a random sample of a given percentage of sample points or clusters was drawn without replacement from all terrestrial sample plots of a forest district. During clustering we already calculated the travelling-distances within each cluster and so the distances of the selected clusters had to be summarised for estimation of the overall 2st,cl-travelling-distance within clusters. To estimate the travellingdistance of 2 st, we built clusters of sample plots per sub-district with the same procedure as described above for the VRP-clusters. Afterwards the total distance within clusters per forest district was calculated.

\subsubsection{Results}

The volumes per ha and rel. SEs, calculated with the full second phase sample size i.e. using (4.1) and (4.2), are shown in Table 4.3. It becomes obvious that relative 
4. Combining double sampling for stratification and cluster sampling to a three-phase sampling design for continuous forest inventories

Table 4.2: Number and mean size of clusters per forest district defined by different rules. The values in brackets indicate the standard deviations.

\begin{tabular}{|c|c|c|c|c|c|c|}
\hline \multirow[t]{2}{*}{ Forest District } & \multicolumn{2}{|c|}{ compartment } & \multicolumn{2}{|c|}{ VRP-cluster } & \multicolumn{2}{|c|}{ sub-district } \\
\hline & number & size & number & size & number & size \\
\hline Clausthal & 667 & $\begin{array}{r}2.6 \\
( \pm 1.35)\end{array}$ & 357 & $\begin{array}{r}4.94 \\
( \pm 0.33)\end{array}$ & 9 & $\begin{array}{r}196 \\
( \pm 17.01)\end{array}$ \\
\hline Dassel & 524 & $\begin{array}{r}3.56 \\
( \pm 2.07)\end{array}$ & 378 & $\begin{array}{r}4.94 \\
( \pm 0.41)\end{array}$ & 8 & $\begin{array}{r}233.5 \\
( \pm 48.35)\end{array}$ \\
\hline Lauterberg & 726 & $\begin{array}{r}3.52 \\
( \pm 1.86)\end{array}$ & 516 & $\begin{array}{r}4.96 \\
( \pm 0.34)\end{array}$ & 11 & $\begin{array}{r}232.45 \\
( \pm 69.07)\end{array}$ \\
\hline Neuhaus & 517 & $\begin{array}{r}3.86 \\
( \pm 1.96)\end{array}$ & 402 & $\begin{array}{r}4.97 \\
( \pm 0.25)\end{array}$ & 10 & $\begin{array}{r}199.6 \\
( \pm 34.40)\end{array}$ \\
\hline Riefensbeek & 720 & $\begin{array}{r}3.24 \\
( \pm 1.61)\end{array}$ & 472 & $\begin{array}{r}4.94 \\
( \pm 0.39)\end{array}$ & 11 & $\begin{array}{r}212.09 \\
( \pm 48.15)\end{array}$ \\
\hline Seesen & 586 & $\begin{array}{r}4.35 \\
( \pm 3.13)\end{array}$ & 514 & $\begin{array}{r}4.96 \\
( \pm 0.28)\end{array}$ & 10 & $\begin{array}{r}255 \\
( \pm 118.19)\end{array}$ \\
\hline Winnefeld & 701 & $\begin{array}{r}3.11 \\
( \pm 1.66)\end{array}$ & 438 & $\begin{array}{r}4.97 \\
( \pm 0.22)\end{array}$ & 11 & $\begin{array}{r}198 \\
( \pm 29.07)\end{array}$ \\
\hline
\end{tabular}

precisions of about $5 \%$ and below could be achieved for the Spruces and Beeches in almost all forest districts. Only for the Oaks, which are generally rarer, and the small Beech population in Clausthal we observe lower rel. precisions, mostly above $10 \%$ and up to $33 \%$.

Using the planning units compartment and sub-district as clusters leads to cluster sizes, which are either too big or too small to be sampled within one day (Table 4.2). In addition, their size is highly variable as the standard deviations show. In contrast, the $V R P$-clusters contain on average five points and therefore fit better to a one day workload. Besides, the variation in cluster size is low.

Using 2st,cl the rel. SE increases with decreasing percentage of sampled clusters (Figure 4.2). The rel. SEs are lowest for the Spruces and highest for the Oaks. Sampling $50 \%$ of the VRP-clusters the rel. SE varies between $7.53 \%$ and $21.44 \%$ for the Beeches, between $14.28 \%$ and $61.25 \%$ for the Oaks and between $3.37 \%$ and $5.5 \%$ for the Spruces. A comparison of the different cluster-forms shows that the differences between the compartments and the VRP-clusters are very small, whereas using the sub-districts as clusters leads to higher rel. SE than using the two other cluster-forms.

Comparing the 2st,cl-results with those of 2 st assuming equal numbers of terrestrial sample plots, shows that the rel. SEs of 2st,cl are always higher than those of 2st (Figure 4.3). When sampling $50 \%$ of the VRP-clusters, the rel. SE of the Beeches is at least $25.78 \%$ and at most $33.53 \%$ higher than the corresponding value of 2 st which can be achieved with the same number of terrestrial sample plots. Sampling the same percentage of VRP-clusters leads to increases of the rel. SE between $25.22 \%$ and 40.96 
Table 4.3: Estimated volumes $\left(\mathrm{m}^{3} h \mathrm{a}^{-1}\right)$ and rel. SE (\%) for the 3 target populations in the different Forest Districts using double sampling for stratification. Bold numbers indicate target precisions below $5 \%$.

\begin{tabular}{lrrrrrrrr}
\hline & \multicolumn{2}{c}{ Beech $>50$} & & \multicolumn{2}{c}{ Oak $>50$} & & \multicolumn{2}{c}{ Spruce $>35$} \\
\cline { 2 - 3 } Forest District & $\hat{\bar{Y}}$ & rel. SE & & $\hat{\bar{Y}}$ & rel. SE & & $\hat{\bar{Y}}$ & rel. SE \\
\hline Clausthal & 8.61 & 12.10 & & 3.33 & 16.00 & & 132.96 & $\mathbf{2 . 1 9}$ \\
Dassel & 45.81 & $\mathbf{4 . 7 9}$ & & 6.61 & 14.21 & & 78.87 & $\mathbf{2 . 9 2}$ \\
Lauterberg & 26.05 & 5.61 & & 3.89 & 18.07 & & 111.88 & $\mathbf{1 . 9 7}$ \\
Neuhaus & 38.20 & 5.23 & & 13.26 & 12.93 & & 100.36 & $\mathbf{2 . 4 0}$ \\
Riefensbeek & 15.25 & 7.87 & & 1.93 & 33.37 & & 145.64 & $\mathbf{1 . 9 0}$ \\
Seesen & 38.15 & $\mathbf{4 . 4 4}$ & & 4.57 & 13.98 & & 82.97 & $\mathbf{2 . 4 4}$ \\
Winnefeld & 58.98 & $\mathbf{4 . 0 6}$ & 25.26 & 7.52 & & 55.63 & $\mathbf{3 . 2 8}$ \\
\hline
\end{tabular}

$\%$ for the Oaks and between 25.31\% and 34.82\% for the Spruces. With decreasing number of sampled clusters the rel. increase of the rel. SE increases nearly linearly. The cluster-forms compartment and VRP-cluster lead to similar results for all tree species. Using the sub-districts as clusters, on the contrary leads to worse results and pronounced differences between the tree species. The highest differences were calculated for the Spruces and the lowest for the Beeches.

The additional sampling effort of 2st,cl compared to 2st is shown in Figure 4.4 as a relative difference. Obviously, the same rel. SE can be achieved with less terrestrial sample points in 2 st than in 2 st,cl. The rel. increase of the number of sample points lies between $37.51 \%$ and $44.85 \%$ for the Beeches, between $36.26 \%$ and $49.9 \%$ for the Oaks and between $40.68 \%$ and $46.7 \%$ for the Spruces, when using $50 \%$ of the VRP-clusters. These rel. increases correspond to absolute increases between 306 and 577 sample plots for the Beeches, between 344 and 680 sample plots for the Oaks and between 389 and 640 sample plots for the Spruces. With decreasing percentage of sampled clusters the rel. increase of sample points increases with a concave shape. Again, the differences between the results of the two cluster-forms compartment and VRP-cluster are small for all species. The use of the sub-districts as clusters leads to considerably worse results, a much higher percentage of points has to be sampled additionally. Moreover, the differences between the different target populations become more pronounced with the sub-districts as clusters. The lowest efficiency in the case of sub-districts is achieved for the Spruces, the highest for the Beeches.

On the other hand, drawing samples from single terrestrial sample plots leads to longer total within-cluster travelling-distances per forest district than drawing samples from clusters of sample plots (Figure 4.5). When sampling $50 \%$ of the sample plots or clusters, the difference between the resulting mean overall travelling-distances per forest district lies between $94.95 \mathrm{~km}$ (Dassel) and $146.79 \mathrm{~km}$ (Seesen). 
4. Combining double sampling for stratification and cluster sampling to a three-phase sampling design for continuous forest inventories
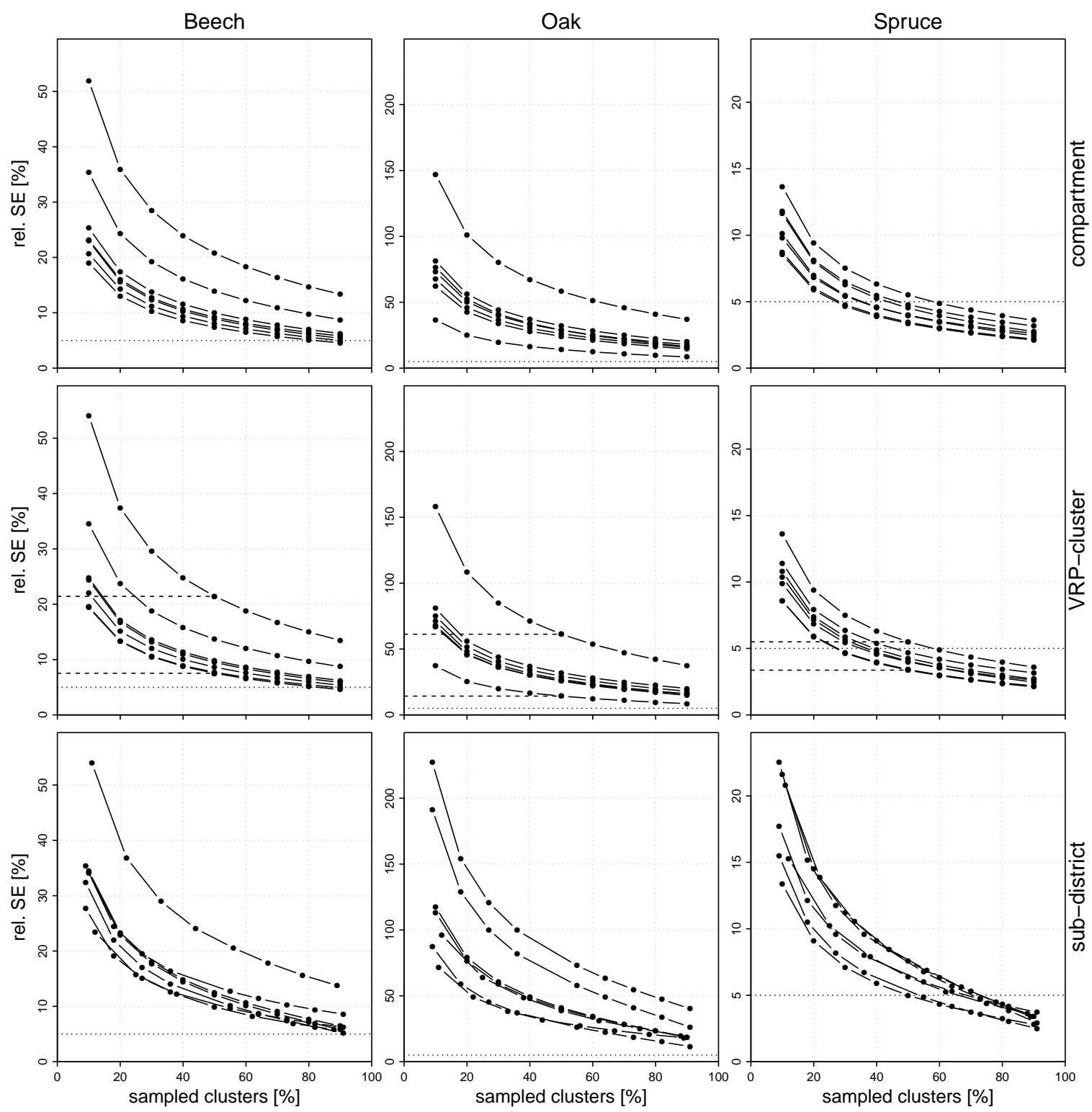

Figure 4.2: Rel. SE (\%), calculated with 2st,cl and the Ratio-to-Size approach, as a function of the percentage of sampled clusters. The results are shown for three different target populations (columns) and cluster-forms (rows) in seven forest districts (curves). The dotted horizontal line depicts the $5 \%$ level usually strived for in inventories of bigger diameter classes. The broken lines depict Minimum and Maximum of the rel. SEs, when sampling $50 \%$ of the VRP-clusters. 

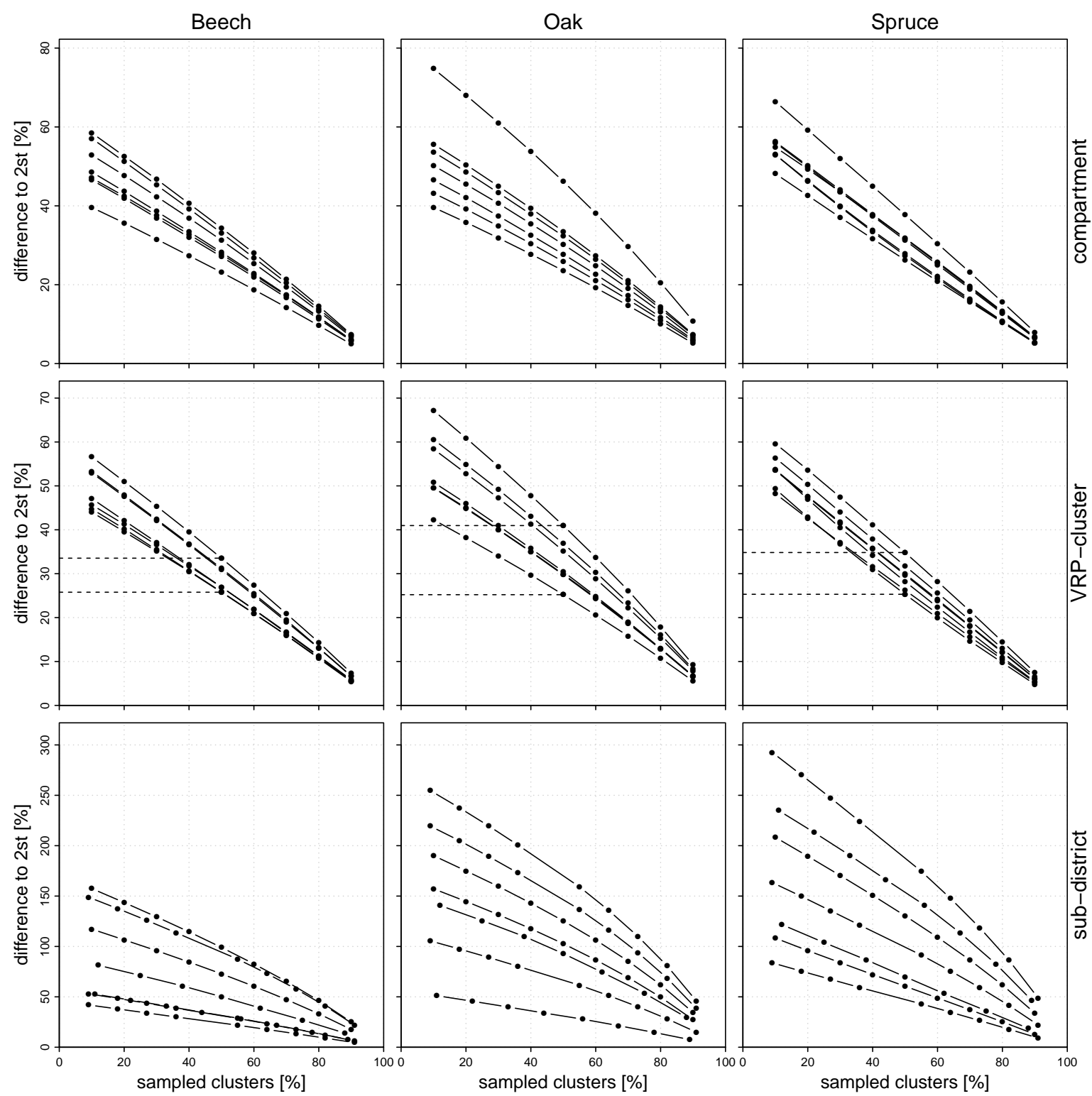

Figure 4.3: The differences between the rel. SEs of 2st,cl and 2st as percentage of the rel. SE of 2st. The results are shown for three different target populations (columns) and cluster-forms (rows) in seven forest districts (curves). Identical numbers of terrestrial sample plots are assumed for both designs. The broken lines depict Minimum and Maximum of the difference, when sampling $50 \%$ of the VRP-clusters. 
4. Combining double sampling for stratification and cluster sampling to a three-phase sampling design for continuous forest inventories
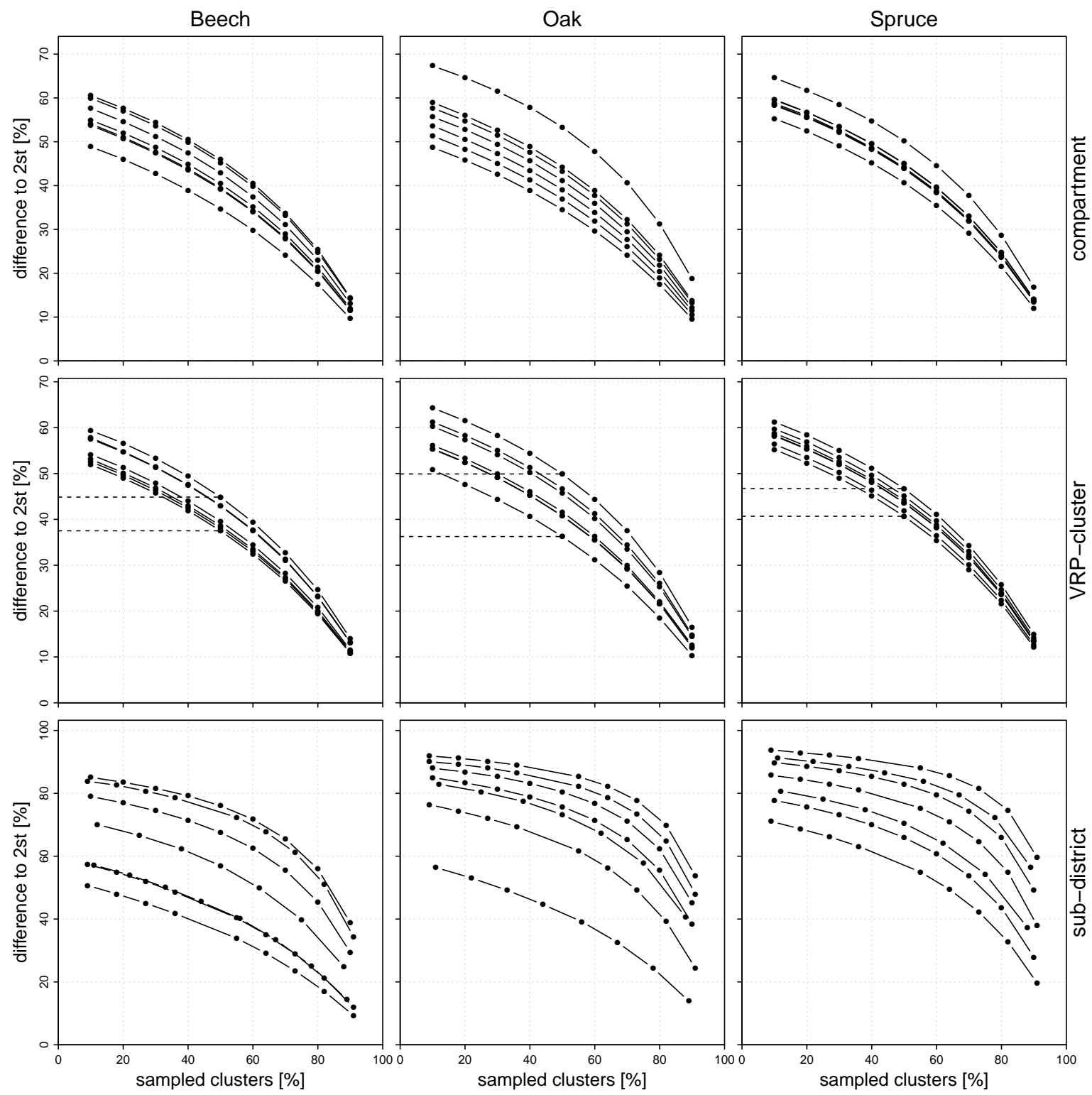

Figure 4.4: The relative increase of the number of sample plots (phase II) measured in 2 st,cl compared to the number of sample plots which is necessary to achieve the same precision using 2st. The results are shown for three different target populations (columns) and cluster-forms (rows) in seven forest districts (curves). The broken lines depict Minimum and Maximum of the relative increase, when sampling $50 \%$ of the VRP-clusters. 

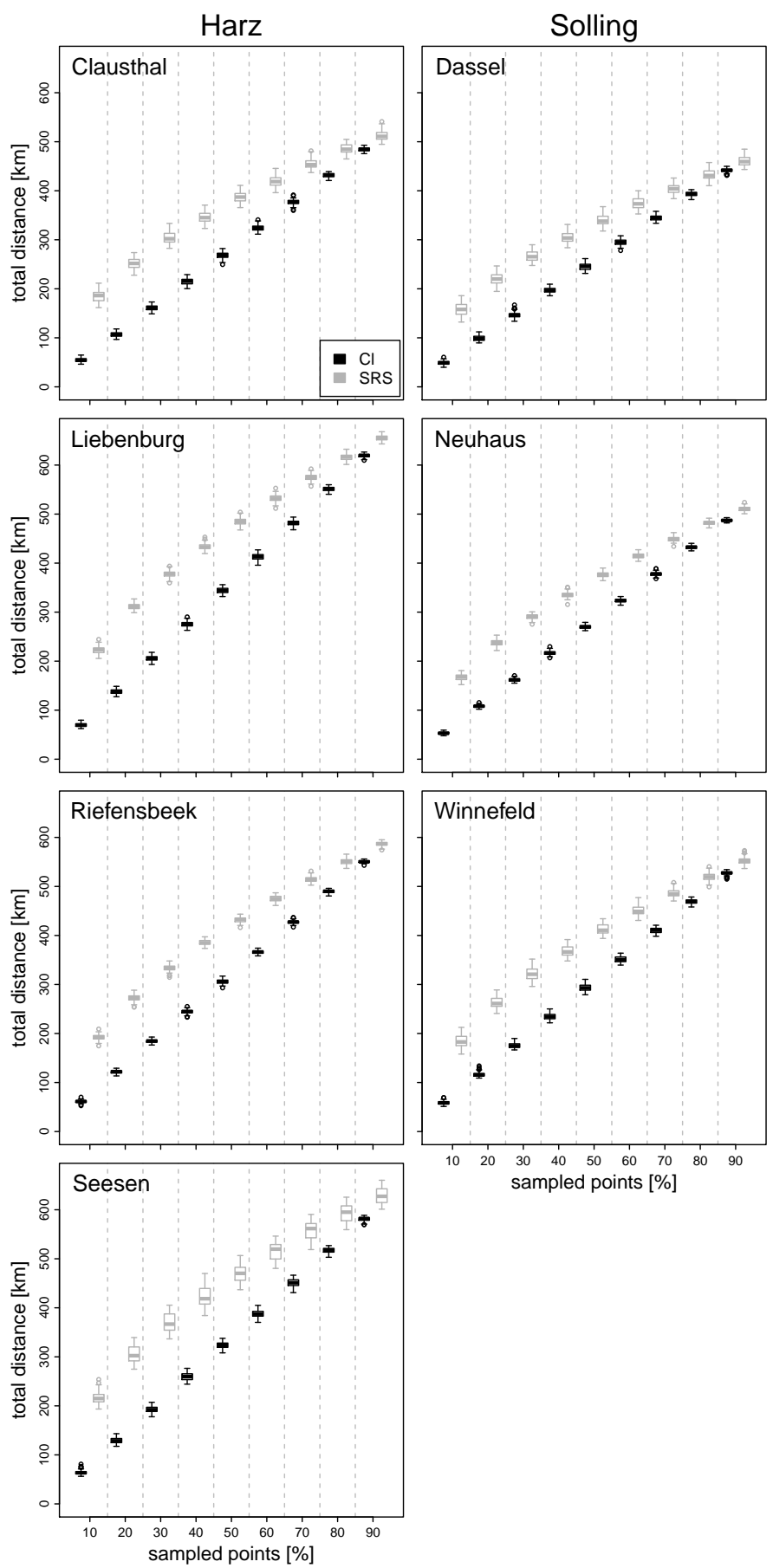

Figure 4.5: The estimated total travelling-distances per forest district. In 100 simulation runs a sample was randomly drawn without replacement from either single terrestrial sample plots (SRS) or clusters of sample plots $(\mathrm{Cl})$. Clustering of the sample plots with a VRP-algorithm and calculation of the travelling-distance within a cluster were executed afterwards for the first case. For the second case these calculations were executed based on all terrestrial sample plots. 


\subsubsection{Discussion and Conclusions}

Coming back to the initial question of the general performance of the 2st,cl-estimator, we quantified additional sampling efforts and vice versa losses in precision, compared to pure 2st, for three target populations in seven forest districts. The additional sampling efforts can be justified in cases where SRS leads to a higher time consumption between sampling points than 2st,cl. However, the results of our case study indicate that the additional travelling-costs for SRS must be extremely large for justifying the additional sampling effort through 2st,cl. Assuming a time consumption of $1.5 \mathrm{~h}$ per plot for a twopeople inventory-team, like in the Second Swiss National Forest Inventory (Zinggeler \& Herold, 1997; Zinggeler, 2001), an additional sampling-effort of 306 to 577 sample plots corresponds to an additional time-consumption of $459 \mathrm{~h}$ to $856.5 \mathrm{~h}$ for sampling, disregarding the additional time-consumption for travelling (Beech, $50 \%$ of the VRPclusters). In contrast, the distance-reduction through clustering of the sample plots lies between $94.95 \mathrm{~km}$ and $146.79 \mathrm{~km}$ for the same sampled perecentage and cluster-type. These distances correspond to time-consumptions of $28.51 \mathrm{~h}$ and $44.08 \mathrm{~h}$, assuming a walking-speed of $3.33 \mathrm{~km} / \mathrm{h}$, as given by Scott (1993) for medium terrain. For longer distances this speed is a conservative estimation, it is likely that longer distances between sample plots will be covered by car and hence faster. Longer distances can especially be expected for 2 st with reduced sample sizes. It has to be kept in mind that the considered distances only account for the distances within clusters; distances between starting point and sample points are disregarded. So, the resulting distances are only an approximation. In our opinion it is reasonable to focus on the within-cluster distances, because they are assumed to depend on the cluster-sizes, whereas the distances between starting point and clusters are independent from the cluster-sizes. Due to the fact that the same method has been applied for estimating the travel distances of the two methods, we assume the values to be comparable. Moreover, it is realistic to assume walking between sample plots.

Thus, for relatively small planning units with a good infrastructure, like the forest districts in our case study, 2st,cl cannot achieve a higher efficiency than 2st. However, in large areas with bad infrastructure and access to the points, travelling between sample points might be so time-consuming that 2 st,cl can be advantageous.

The second aim of our study was to assess the effect of different cluster forms on the performance of the 2st,cl-estimator. Due to their highly variable and inadequate size, the use of the compartments and sub-districts as clusters is detrimental and VRPclusters thus preferable. Nevertheless, the resulting 2st,cl-variances of the compartmentand VRP-clusters are similar and high, compared to the values of pure 2 st. This may be explained by their similar and small sizes, which most likely lead to low within-cluster variablility. The stand type at neighbouring sample points will often be similar, contradicting the aim of creating heterogenous clusters. Creating clusters being spatially compact and, at the same time, of high within-cluster variability can hardly be achieved under the conditions in this case study. 


\section{Acknowledgements}

We thank the German Science Foundation (DFG) for financial support of this study (Sachbeihilfe SA 415/5-1) and Dr. Böckmann of the Lower Saxony Forest Planning Office for his kind provision of the inventory data.

\subsection{Appendix}

\subsubsection{Proofs}

To derive the variance of the new estimator, we decompose $\hat{\bar{y}}_{h}$ as follows

$$
\hat{\bar{y}}_{h}=\bar{y}_{h}+\left(\hat{\bar{y}}_{h}-\bar{y}_{h}\right) .
$$

The variance of $\hat{\bar{y}}_{h}$ is then given as the sum of the variances of the two components, because both components are not correlated (see (12.6) in Cochran, 1977).

$$
\operatorname{Var} \hat{\bar{Y}}_{c l}=\operatorname{Var} \sum_{h=1}^{L} \frac{n_{h}^{\prime}}{n^{\prime}} \bar{y}_{h}+\operatorname{Var} \sum_{h=1}^{L} \frac{n_{h}^{\prime}}{n^{\prime}}\left(\hat{\bar{y}}_{h}-\bar{y}_{h}\right)
$$

In this equation the first variance is the variance from 2st (Equation 4.2). Due to the fact that $E_{3}\left(\hat{\bar{y}}_{h}-\bar{y}_{h}\right)=0$,

$$
\operatorname{Var} \sum_{h=1}^{L} \frac{n_{h}^{\prime}}{n^{\prime}}\left(\hat{\bar{y}}_{h}-\bar{y}_{h}\right)=\operatorname{EVar}_{3} \sum_{h=1}^{L} \frac{n_{h}^{\prime}}{n^{\prime}}\left(\hat{\bar{y}}_{h}-\bar{y}_{h}\right)
$$

holds for the second variance. Assuming simple random sampling with drawing without replacement for the clusters, the variance and the covariance can be calculated as

$$
\operatorname{Var}_{3}\left(\hat{\bar{y}}_{h}-\bar{y}_{h}\right)=\operatorname{Var}_{3} \hat{\bar{y}}_{h}=\frac{1}{n_{h}^{2}} \frac{K^{2}}{k}\left(1-\frac{k}{K}\right) \breve{S}_{h}^{2}
$$

and

$$
\operatorname{Cov}_{3}\left(\hat{\bar{y}}_{h}-\bar{y}_{h}, \hat{\bar{y}}_{h^{\prime}}-\bar{y}_{h^{\prime}}\right)=\operatorname{Cov}_{3}\left(\hat{\bar{y}}_{h}, \hat{\bar{y}}_{h^{\prime}}\right)=\frac{1}{n_{h} n_{h^{\prime}}} \frac{K^{2}}{k}\left(1-\frac{k}{K}\right) \breve{S}_{h h^{\prime}}
$$

respectively. Substituting (4.4) and (4.5) in (4.3) yields:

$$
\begin{aligned}
\operatorname{Var} \sum_{h=1}^{L} \frac{n_{h}^{\prime}}{n^{\prime}}\left(\hat{\bar{y}}_{h}-\bar{y}_{h}\right)= & E \sum_{h=1}^{L}\left(\frac{n_{h}^{\prime}}{n^{\prime}}\right)^{2} \frac{1}{n_{h}^{2}} \frac{K^{2}}{k}\left(1-\frac{k}{K}\right) \breve{S}_{h}^{2} \\
& +E \sum_{h \neq h^{\prime}}^{L} \frac{n_{h}^{\prime} n_{h^{\prime}}^{\prime}}{n^{\prime 2}} \frac{1}{n_{h} n_{h^{\prime}}} \frac{K^{2}}{k}\left(1-\frac{k}{K}\right) \breve{S}_{h h^{\prime}}
\end{aligned}
$$




\section{Chapter 5}

\section{Clustering existing sample points in resource inventories}

Nikolas von Lüpke ${ }^{1}$ - Marco Bender ${ }^{2}$ - Jonas Ide ${ }^{2}$ - Joachim Saborowski ${ }^{1,3}$

${ }^{1}$ Department of Ecoinformatics, Biometrics and Forest Growth,

University of Göttingen, Büsgenweg 4, 37077 Göttingen, Germany

${ }^{2}$ Institute for Numerical and Applied Mathematics,

University of Göttingen, Lotzestraße 16-18, 37083 Göttingen, Germany

${ }^{3}$ Department of Ecosystem Modelling,

University of Göttingen, Büsgenweg 4, 37077 Göttingen, Germany 
- Marco Bender and Jonas Ide developed the optimisation algorithm for the calculation of benchmark solutions and suppoerted the writing of the manuscript.

- Joachim Saborowski supported the analysis of the results and the writing of the manuscript. 


\section{Abstract}

Cluster sampling is a well-known and widely used sampling scheme in resource inventories. Shape and size of the clusters have usually to be determined when setting up a new inventory. In cases where an existing sampling scheme of a previous inventory shall be reduced by subsampling, e.g. for cost reduction or for a fast intermediate inventory, it might be desirable to cluster neighbouring sample points in a way that minimises the within-cluster distances and use clustered subsampling. This is important for achieving high efficiency of terrestrial sampling. Furthermore, it is mostly desirable to generate equally sized clusters that can be sampled within a one-day workload.

The Vehicle Routing Problem (VRP), well-known in Operations Research, can be seen as a similar problem. Its basic idea is that several customers should be supplied from one depot. Therefore, the shortest route covering all customers and fulfilling all customer-demands has to be found. Several heuristics exist for solving that problem.

In a case study in Lower Saxony, Germany, we applied three of these heuristics for building clusters of sample points of the periodic forest district inventory, the (1) Savings-Algorithm, a classical heuristic, and two metaheuristics, (2) a Record-to-Record travel and (3) a Simulated Annealing algorithm. Beyond these VRP-heuristics, we applied (4) a k-means, (5) an equal area partitioning and (6) a hierarchical clustering algorithm, and (7) used the planning unit compartment (Abteilung) as clusters. The results indicate that the VRP-heuristics are well-suited for defining clusters of approximately the same size, whereas the other algorithms produce clusters of highly variable size. Comparing the results with computer intensive benchmark solutions, it could be shown that the total distances are close to the optimal ones.

\section{keywords}

vehicle routing problem - k-means - hierarchical clustering - equal area partitioning forest inventory - cluster sampling

\subsection{Introduction}

High efficiency and thus high precision at low inventory-costs are expected from forest inventories. It can be achieved by an adequate sampling-scheme fulfilling the aims of the inventory under the given conditions. Therefore, a multitude of efficient inventoryschemes has been developed over the last decades and still new methods are proposed. Particularly, selection of clustered sampling units can often be a measure to increase efficiency.

When setting up a clustered sampling scheme, mainly two cases are imaginable:

1. An inventory is planned with a clustered sampling procedure from the beginning. 
2. The sampling scheme of an existing periodic inventory is to be converted into a clustered sampling scheme with reduced sample size, temporarily or regularly, and with the aim of cost-reduction in mind.

Several studies of the efficiency of different cluster shapes like triangle, cross or square exist (e.g. Kleinn, 1994, 1996) and it is possible to follow the advices, given in these studies, when setting up a new forest inventory (case 1). In national forest inventories a multitude of different cluster shapes is used (Tomppo et al., 2010a), and usually the clusters are designed in a way that makes it possible to execute the field work per cluster within one day (Kleinn, 1996). The latter commonly implies homogenous cluster sizes.

Building such equally sized clusters of existing sample plots (case 2) is especially difficult, when the sample plots are selected by simple random sampling (SRS) and hence the distances between neighbouring sample plots are variable. Studies of the national forest inventories in Switzerland (Zinggeler \& Herold, 1997; Zinggeler, 2001) and Germany (Kroiher, 2006) showed that the measurements on the plots accounted for 25-40\% (Switzerland) and $51 \%$ (Germany) of the total working time. It has to be kept in mind that these numbers are highly influenced by road infrastructure, density of sample plots, plot design, elevation, and slope of the study area. Nevertheless, it becomes obvious that the time-consumption for travelling and indirect inventory-work accounts for a high percentage of the total inventory-time. Therefore, it is desirable to reduce this percentage wherever possible. One approach is to cluster sample plots to daily workloads in a way which minimises the within-cluster distances and thereby the time-consumption for travelling.

An intuitive clustering is to divide the study area into partitions of approximately the same size. This can either be done with special algorithms or by using existing management units such as forest districts (Forstamt), forest sub-districts (Revier) or compartments (Abteilung) as partitions. Another possibility is to use cluster-algorithms, from which a plethora exists (Anderberg, 1973; Hartigan, 1975). Well-known and established clustering-methods are k-means and hierarchical algorithms. Whereas in k-means the points are allocated to a given number of clusters with the aim of minimising a targetfunction, in hierarchical methods points or point-clusters are combined to new clusters in every iteration-step until all points belong to the same cluster. This is done with the aim of combining the most similar clusters in every iteration-step (Anderberg, 1973; Hartigan, 1975). These algorithms were not originally developed for spatial clustering, but they can be used for that purpose using the coordinates of the sample points as attributes.

The combination of sample plots to a cluster of spatially contiguous sample points can also be seen as a Vehicle Routing Problem (VRP), which has been introduced by Dantzig \& Ramser (1959) and is well-known in Operations Research. The basic idea of this problem is that several customers should be supplied from one depot and therefore it is desirable to find the shortest route(s) covering all customers and thereby fulfilling all customer-demands. Up to now heuristic methods are often used in practice for solving VRPs, although exact algorithms exist. This is due to the facts that even the best exact algorithms are able to solve only VRPs with approximately 100 vertices 
and that quick solutions are expected from the users (Laporte, 2009). The number of possible routes through $n$ vertices can be calculated by $(n-1) ! / 2$ for the symmetric case, assuming the same distance between two points in both directions. For a problem with 100 points $4.66 \cdot 10^{155}$ possible solutions exist. Obviously, the calculation of an exact solution would be extremely time-consuming.

Even though the VRP is one of the most famous problems in Distribution Science and one of the most widely studied problems in Combinatorial Optimisation (Cordeau et al., 2002), applications in Forest Science are still rare. Thiele (2008) presented results for wood delivery to a fictitious pulp mill, calculated with two classical heuristics for solving this VRP. Flisberg et al. (2009) combined linear programming and VRP-techniques for routing of logging trucks. Their approach is used in the decision support system for routing of logging trucks RuttOpt (Andersson et al., 2008).

In the following article we present results that have been obtained with several methods of spatial clustering in a case study with data of the Forest District Inventory of Lower Saxony, Germany. The resulting clusters were evaluated regarding their withincluster distances and their homogeneity of size; the efficiency of clustered sampling schemes is not part of this study. Obviously, the within-cluster distances should be small for raising the efficiency of an inventory design.

\subsection{Methods}

\subsubsection{Algorithms of the Vehicle Routing Problem}

Formally the VRP is defined as follows: $G=(V, A)$ is a graph with a vertex set $V=$ $\left\{\nu_{0}, \nu_{1}, \ldots, \nu_{n}\right\}$ and an arc set $A=\left\{\left(\nu_{i}, \nu_{j}\right): \nu_{i}, \nu_{j} \in V, i \neq j\right\}$. The depot is represented by vertex $\nu_{0}$, the customers by the remaining vertex set $V_{c}=\left\{\nu_{1}, \nu_{2}, \ldots, \nu_{n}\right\}$. A cost and a travel time matrix are associated with $A$, and often these matrices are assumed to be symmetrical. In such cases the VRP is defined on an undirected graph. A nonnegative demand $q_{i}$ and a service time $t_{i}$ are associated to every customer $i$. The total number of vehicles $m$ of capacity $Q$ might be known in advance or treated as a decision variable. The whole problem is a generalisation of the Traveling Salesman Problem (TSP), which aims at determining the cheapest round-tour, covering all customers. It arises when $m=1$ and $Q \geq \sum_{i \in V_{c}} q_{i}$ (Baldacci et al., 2010).

In general, it can be distinguished between (1) exact algorithms, (2) classical heuristics and (3) metaheuristics. Within these categories a high variety of algorithms has been developed, the explanation of which would go beyond the scope of this article. A good introduction to the different approaches can be found in Laporte (2009). Cordeau et al. (2002) compared different heuristics under several aspects and gave advices for the use of these methods. 


\section{Savings-Algorithm (CW)}

This algorithm has been developed by Clarke \& Wright (1964), it is well-known and widely used in practice, although its shortcomings are known (Cordeau et al., 2002). Based on an initial solution of tours which consist of only one vertex, two routes $\left(\nu_{0}, \ldots, \nu_{i}, \nu_{0}\right)$ and $\left(\nu_{0}, \ldots, \nu_{j}, \nu_{0}\right)$ are combined into one $\left(\nu_{0}, \ldots, \nu_{i}, \nu_{j}, \ldots, \nu_{0}\right)$ at every iteration step, as long as the restrictions are maintained. Therefore the savings $s_{i j}=$ $c_{i 0}+c_{0 j}-c_{i j}$ of these point-combinations have to be calculated based on the distancematrix, where $c_{i 0}$ is the cost for the way from $\nu_{i}$ to $\nu_{0}, c_{0 j}$ the cost for the way between $\nu_{0}$ and $\nu_{j}$, and $c_{i j}$ the cost for the way from $\nu_{i}$ to $\nu_{j}$. The combination of routes which yields the highest saving without violating the restrictions is chosen at every step. Afterwards a post-optimisation is carried out. Cordeau et al. (2002) attested this method in their comparison a low accuracy and flexibility, but a very high speed and simplicity.

\section{Record-to-Record travel Algorithm (RTR)}

Dueck (1993) introduced the Record-to-Record travel Algorithm and presented applications to the TSP. During the iteration-process the results do not necessarily need to improve the value of the target function, whose currently best value is called Record. The iteration proceeds even if a new configuration leads to a value worse than the current Record as long as it does not exceed a certain deviation from the latter. Li et al. (2005) extended this method by a variable-length neighbour list and applied it to very large scale VRPs. Their proposal is provided in the VRPH-library (Gröer et al., 2010), and we will describe the technique only briefly in the following. An initial solution is generated with a modified Savings-Algorithm. Its value of the target function is used as Record and the Deviation is defined as $1 / 10$ of this Record. Within a loop the current solution is improved, Record and Deviation are updated afterwards. Post-Optimisation of this solution is carried out, and if an improvement is possible, Record and Deviation are updated again. After repetitions and perturbations the best solution generated so far is kept.

\section{Simulated annealing (SA)}

The first mentioning of Simulated Annealing in the context of Combinatorial Optimisation dates back to 1983, when Kirkpatrick et al. proposed its use, based on the algorithm of Metropolis et al. (1953). Starting from an initial solution, a new solution is randomly chosen from the neighbourhood of the actual one. Both solutions are compared and the current solution is accepted if it leads to a better value of the target function, or if not, with a probability that decreases with increasing simulation time and growing differences between the values of the target function (Laporte, 2009).

\subsubsection{K-means algorithm (KM)}

The k-means algorithms belong to the partitioning-algorithms, and in contrast to the VRP-algorithms the number of clusters $(h)$ is known in advance and an important 
input variable for these algorithms. $h$ centroids are initially placed and the sum of the within-cluster sum of squares $J=\sum_{k=1}^{h} \sum_{j=1}^{m_{k}} \sum_{i=1}^{n}\left(x_{i j k}-x_{i k}\right)^{2}$ is calculated, where $m_{k}$ denotes the number of points in cluster $k$ and $n$ the dimension of the space of variables (Anderberg 1973, Hartigan 1975). Here, $n=2$ and $x$ stands for the coordinates of the sample points. Through shifts of the $m$ points from one cluster to another and recalculation of the centroids in an iteration-process it is desired to minimise $J$. It is this iteration-process that makes the different k-means algorithms distinct from each other. Well-known are those of Lloyd (1982), Forgy (1965), MacQueen (1967) and Hartigan \& Wong (1979), from which we applied the latter.

\subsubsection{K-means algorithm for equal area partitioning (EAP)}

This method has been presented and thoroughly described by Walvoort et al. (2010) for grid cell data. The spatial data are converted to grid cells and these cells are initially partitioned into clusters. In an iteration process swops of two cells from different clusters are carried out if the sum of the distances between the cells and the centroids of the clusters is shortened through this swop.

\subsubsection{Hierarchical clustering (HC)}

Whereas the number of clusters is an important input variable in the k-means algorithms, it is not predefined in hierarchical clustering. Here points or point-clusters are combined to a new cluster in every iteration step until all points $n$ belong to the same cluster; thus the number of iteration steps is $n-1$. Different algorithms use different criterions for combining sample points to a cluster (Anderberg, 1973).

Well-known is the method of Ward (1963). As in the k-means algorithms, the sum of the within-cluster sum of squares $J$ is used as target-variable. The combination of point-clusters that leads to the smallest increase in $J$ is selected in every iteration-step (Ward, 1963; Anderberg, 1973).

\subsubsection{Planning Unit (PU)}

In Germany several different administrative planning units exist, one of the smallest ones is the compartment (Abteilung), on an average being of 18.84 ha in size in the seven forest districts. We used the terrestrial sample plots within each compartment as a cluster.

\subsubsection{Benchmark Solution}

As mentioned above heuristics do not guarantee optimality of a solution. To be able to evaluate their quality, we make use of a lexicographic integer programming approach that yields optimal solutions for the considered instances. During this process we only 
considered feasible tours, i.e. tours that can be finished within one day and thus do not exceed a predefined time-limit per tour.

First, we generate all feasible tours $\mathcal{T}$. For these tours we first solve the integer programme

$$
\begin{aligned}
& \min \sum_{t \in \mathcal{T}} x_{t} \\
& \text { s.t. } \sum_{t \in \mathcal{T}} \text { contains }[v, t] x_{t}=1 \quad \text { for all } v \in V \\
& x_{t} \in\{0,1\} \quad \text { for all } t \in \mathcal{T} \text {, }
\end{aligned}
$$

which minimises the number of tours necessary to cover all vertices.

Here, we have a binary decision variable $x_{t}$ associated with each tour $t \in \mathcal{T}$ that is 1 if tour $t$ is chosen, and 0 else. The parameter contains $[v, t]$ is 1 if tour $t \in \mathcal{T}$ contains vertex $v \in V$, and 0 else, and therefore the constraints ensure that every vertex is visited exactly once.

We denote by $z^{*}$ the optimal objective value of the programme above. Among all of those cluster partitions we then want to choose a combination of $z^{*}$ tours that minimise the total distances that need to be travelled. If we denote by length $[t]$ the length of tour $t \in \mathcal{T}$, this can be done by solving the integer programme

$$
\begin{aligned}
& \min \sum_{t \in \mathcal{T}} \text { length }[t] x_{t} \\
& \text { s.t. } \sum_{t \in \mathcal{T}} \text { contains }[v, t] x_{t}=1 \quad \text { for all } v \in V \\
& \sum_{t \in \mathcal{T}} x_{t}=z^{*} \\
& x_{t} \in\{0,1\} \quad \text { for all } t \in \mathcal{T} .
\end{aligned}
$$

\subsection{Case study}

\subsubsection{Data base}

For the case study we used data from the Forest District Inventory (Betriebsinventur) of Lower Saxony, Germany. This inventory is carried out according to a double sampling for stratification scheme since 1999 in a cycle of about ten years (Böckmann et al., 1998). Sample points are located in a $100 \mathrm{~m} \times 100 \mathrm{~m}$ grid within the first phase of this procedure. Depending on dominating species group (DEC: Deciduous; CON: Coniferous) and age class (1: $\leq 40$ years; 2 : 41-80 years; $3: 81-120$ years; $4:>120$ years) every point is assigned to one of eight strata. In the second phase a certain proportion 


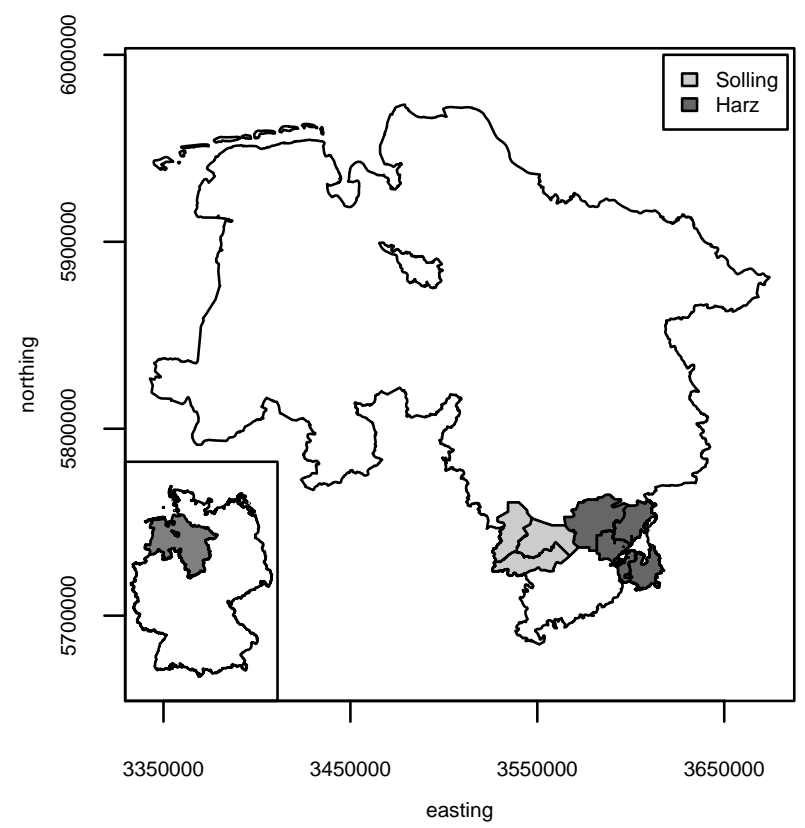

Figure 5.1: The seven Forest Districts analysed in the case study.

of sample points, differing among the strata, is chosen in each stratum. The selection is done systematically from a list of first-phase units per stratum, which however leads to an irregular (random-like) spatial distribution of second-phase units on the first-phase grid.

Two concentric plots $(6 \mathrm{~m}$ radius for trees with $7 \mathrm{~cm} \leq \mathrm{dbh}<30 \mathrm{~cm}$ and $13 \mathrm{~m}$ radius for trees with $\mathrm{dbh} \geq 30 \mathrm{~cm})$ are established and inventoried at these points. The first run of this inventory has been carried out between 1999 and 2008, and we used the sample points of seven forest districts (Forstämter) in the regions Harz and Solling (Figure 5.1). Meanwhile merges of forest districts have been executed (see www.landesforsten.de), so that not all of those forest districts still exist in the shape underlying our study. As calculation units for the clustering we used the 70 forest sub-districts (Reviere), each of which contains between 120 and 514 sample points.

\subsubsection{Data processing}

\section{Software}

For solving the VRP we used the VRPH-library of Gröer et al. (2010). In this open access library several algorithms are implemented, from which we applied the three algorithms mentioned earlier. Both, pre-processing of the data and evaluation of the VRPH-results, were done with the statistical software package R (R Core Team, 2012). The R-package "spcosa" (Walvoort et al., 2010, 2012) was used for the modified kmeans algorithms for equal area partitioning. For calculation of the benchmark solution, 
the generation of the tours has been implemented in $\mathrm{C}++$. The integer programme modelling was performed in IBM ILOG OPL 6.3 and as solver we used IBM ILOG CPLEX 12.4.

\section{Pre-processing of the data}

Originating from their original purpose in logistics, all VRP-heuristics need a load, which the truck should deliver or pick up at each vertex, and a capacity of the trucks. In our application we set the load at every sample point to 1 and the capacity to 5 . This assumption is based on the observations of Zinggeler \& Herold (1997) and Zinggeler (2001), who gave a per plot working time for the terrestrial inventory of 179 minutes for one person during the Second Swiss National Forest Inventory. Due to the fact that the sampling scheme of this inventory is similar to the one used in the Forest District Inventory of Lower Saxony (Böckmann et al., 1998; Stierlin \& Zinggeler, 2001), we assumed a two-people inventory team to sample on average five sample plots per day. We calculated results for ten randomly distributed starting points for a sub-district, because these algorithms need a starting point, which is not naturally and uniquely defined in our study. These starting points were distributed in a rectangle, defined by the ranges of a sub-district in east-west and south-north direction. The side-lengths of the rectangle were 1.25 times the respective range.

For KM, EAP and HC the number of clusters has to be defined in advance of the iterations. For the three techniques we calculated the number of clusters by $n / 5$ and rounding up to the next integer (function "ceil") if necessary.

Whereas it was possible to use the Euclidean Distances between the sample points in all but one algorithm, it was necessary to convert the point data to pixel data for the application of EAP (Walvoort et al., 2010). Thus, the shape-files were converted into grid cell data with a cell size of $50 \mathrm{~m}$.

During the calculation of the benchmark solution only feasible tours should be considered. Therefore, it was necessary to assess the time consumption for the inventory on the plot and for walking between the plots. As for the VRP-algorithms, we assumed a working time of $1.5 \mathrm{~h}$ per plot, like in the Second Swiss National Forest Inventory (Zinggeler \& Herold, 1997; Zinggeler, 2001). For walking between the plots we presumed a walking speed of $3.33 \mathrm{~km} / \mathrm{h}$, as given by Scott (1993) for medium terrain.

\section{Post-processing of the tours}

First of all we built a circle tour, in which the last point $\nu_{n}$ is connected to the first point of the tour $\nu_{1}$. Afterwards we further optimised this tour with a 2-opt Algorithm (Figure 5.2) (R library "TSP", Hahsler \& Hornik, 2007, 2011). 

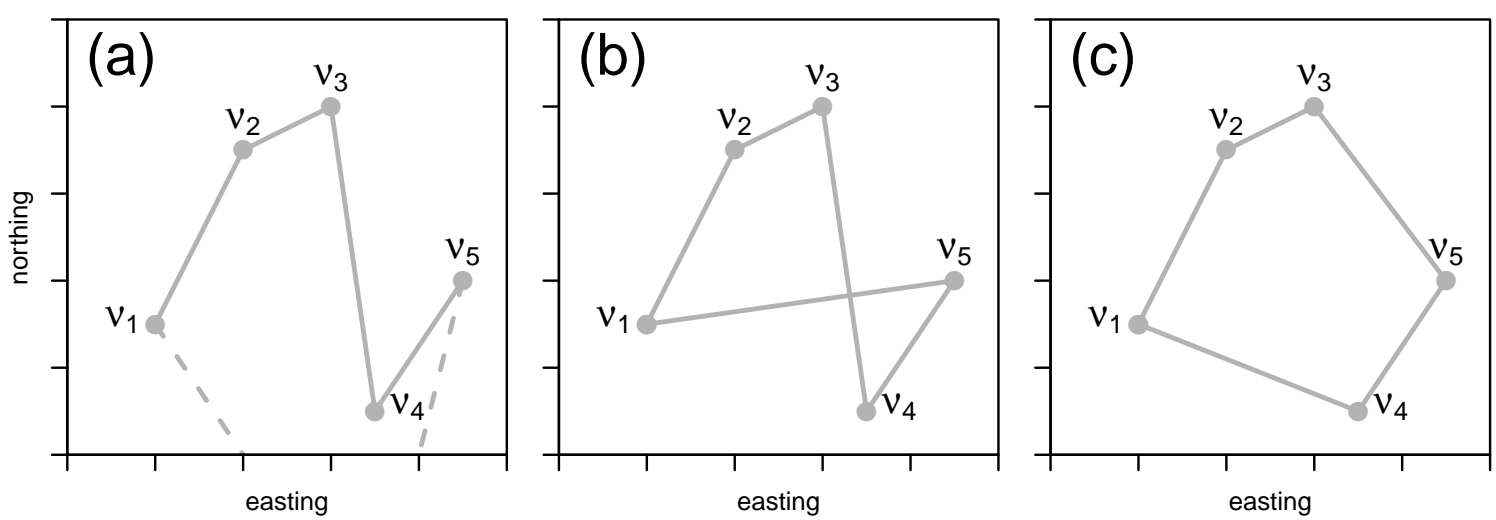

Figure 5.2: Post-Optimisation of the generated tours with help of a 2-opt algorithm. The start- and endpoint of the initial solution (a) are connected (b). Finally, two edges of the tour are systematically exchanged (c) until the tour could not further be improved.

\section{Evaluation of the data}

With this case study we tried to figure out the performance of the seven different clustering methods and therefore calculated the total within-cluster distance and the number of sample plots per cluster. For the comparison of the methods we used the best as well as the worst result of VRP-algorithms in each forest district, in terms of total distances, achieved using the different starting points. Multiple comparisons were done with pairwise, paired Wilcoxon comparisons with adjustment of p-values after Bonferroni and a significance level of $5 \%$.

\subsubsection{Results}

Already a rapid visible inspection of Figure 5.3 shows that the different algorithms lead to different results in terms of different tour-lengths and -sizes. Obviously, the three VRP-algorithms generate clusters of approximately the same size, whereas the resulting cluster-sizes of the three other algorithms and the PUs are highly variable. It can be seen from Figure 5.4a that the VRP-algorithms and the EAP lead to nearly the same mean tour length of approx. $1.5 \mathrm{~km}$ in the 70 forest sub-districts. The three other methods lead to shorter mean tour lengths. Significant differences could not be detected only between $\mathrm{CW}_{\mathrm{Min}}$ and $\mathrm{SA}_{\mathrm{Min}}$ and between $\mathrm{CW}_{\mathrm{Max}}$ and $\mathrm{SA}_{\mathrm{Max}}$. The differences between the shortest and the longest total tour length per sub-district of the VRP-algorithms, caused by different starting points, are mostly small (Figure 5.5). The longest sub-district tour is mostly less than $10 \mathrm{~km}$ longer than the shortest sub-district tour. These absolute values correspond to relative differences of about $10 \%$, related to the minimal total tour length per sub-district. The mean range of RTR is significantly different from that of $\mathrm{CW}$ and SA. One aim of clustering was to achieve clusters of 

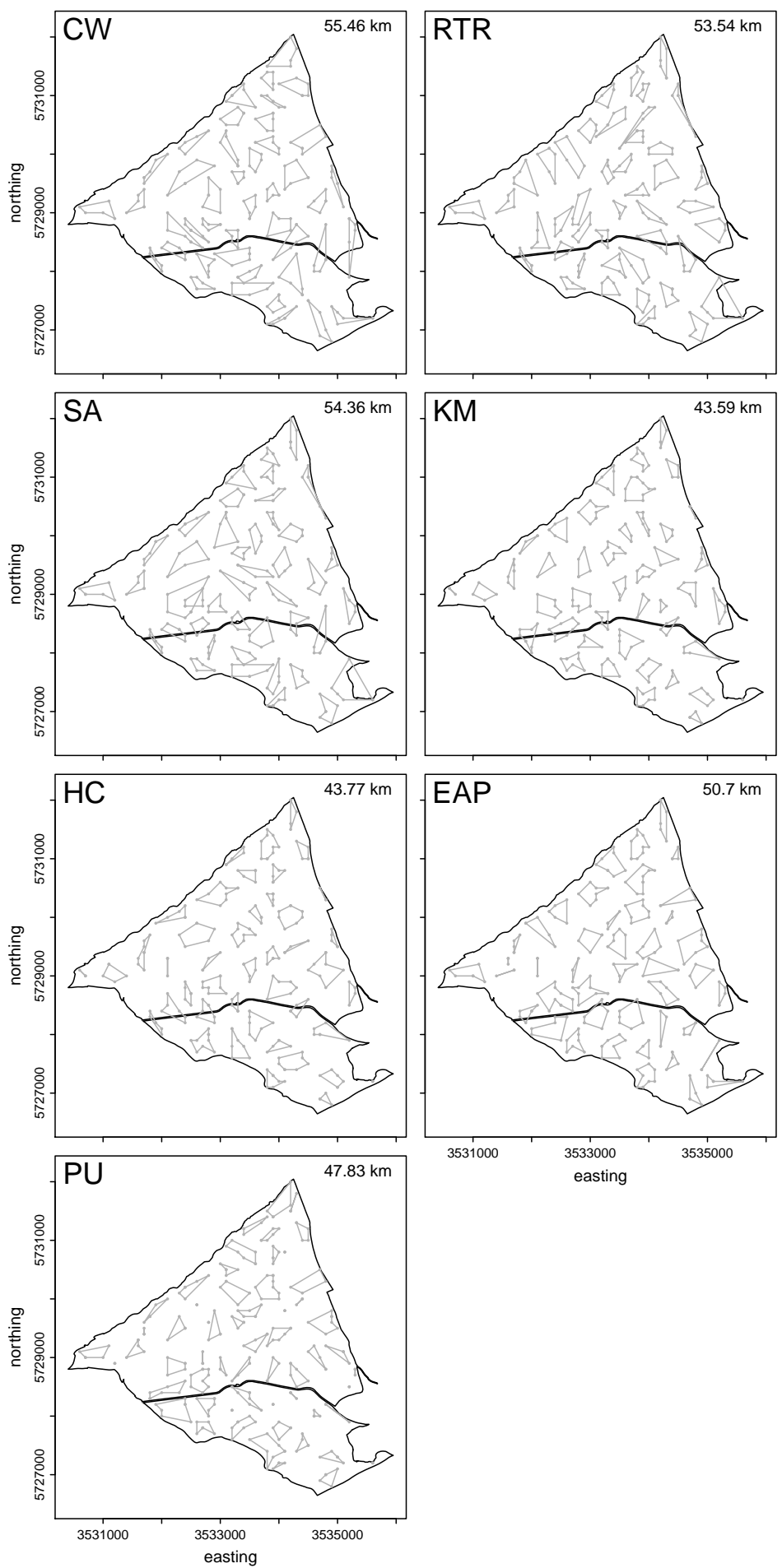

Figure 5.3: Clusters of sub-district 11 in the Forest District Winnefeld. The results were generated with three VRP-heuristics (CW: Savings, RTR: Record-to-Record Travel, SA: Simulated Annealing), two classical clustering algorithms (KM: K-means, HC: Hierarchical Clustering), an equal area partitioning algorithm (EAP), and by using the planning unit compartment (PU). 

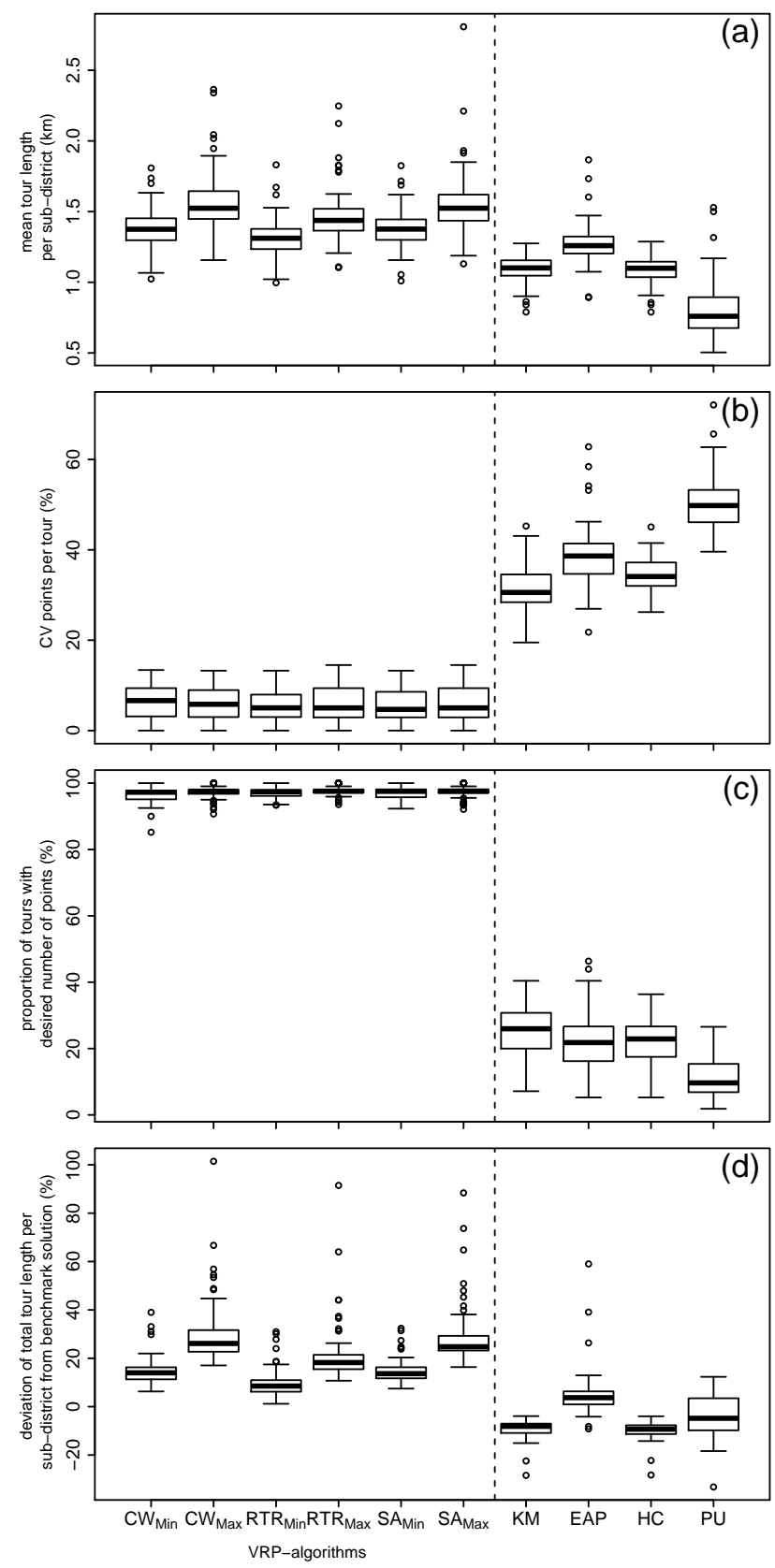

Figure 5.4: Key figures of the tours of the 70 forest sub-districts. The tours were calculated with seven different algorithms. From the three VRP-heuristics CW (Savings), RTR (Record-to-Record) and SA (Simulated Annealing) the best (Min) as well as the worst (Max) solution of the 10 starting points was used. Moreover, hierarchical clustering (HC), k-means (KM), equal area partitioning (EAP) and using compartments as clusters (PU) were applied. a) mean tour length $(\mathrm{km}), \mathrm{b})$ Coefficient of Variation (\%) of the number of plots per tour, c) proportion (\%) of tours with 5 sample plots, d) relative deviation (\%) of the overall length from the overall length of the benchmark solution. 


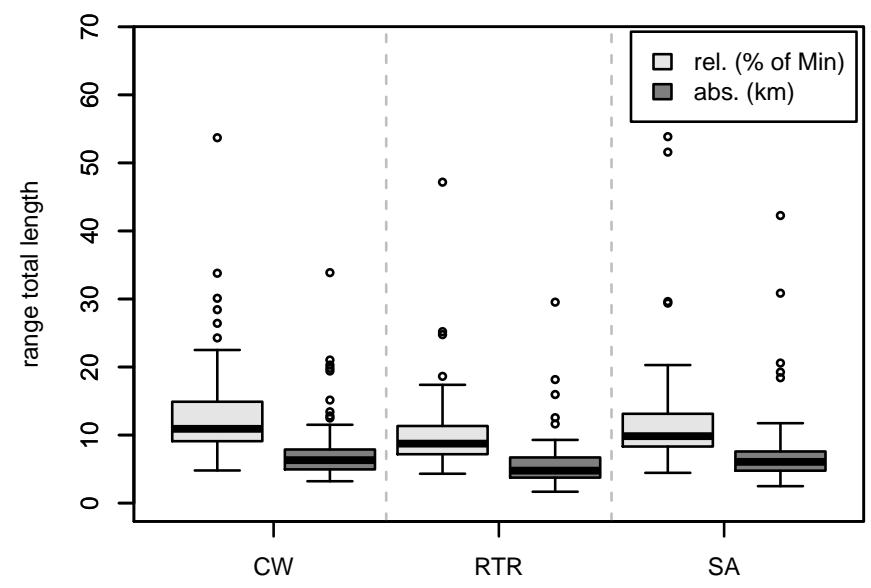

Figure 5.5: Range between the total tour distances per sub-district of the worst and the best solution. The absolute values $(\mathrm{km})$ as well as the relative values (\%), relating to the best solution, are shown for the three VRP-heuristics CW (Savings), RTR (Record-to-Record) and SA (Simulated Annealing). 10 starting points were used for every algorithm and forest district.

approximately the same size. Therefore, we looked at the Coefficient of Variation (CV) of the number of sample points per tour in every forest district and the percentage of clusters that contain the desired number of sample points ( 5 in our case study) (Figure $5.4 \mathrm{~b}, \mathrm{c})$. It is evident that the VRP-algorithms are well suited for generating clusters of the same size. The CV is low and the percentage of plots with the desired size is high, even for the worst solutions in terms of overall tour length per sub-district. In contrast HC, KM, EAP and PU naturally generate clusters of variable size. This can be seen from the low percentage of tours with 5 sampling points and the high CV.

Compared to the (optimal) benchmark solution (Figure 5.4d), the VRP-algorithms and EAP generate longer overall distances per sub-district, whereas the three other algorithms lead to even shorter sub-district distances. The latter is possible, because the benchmark solution obeys the maximal cluster size constraint. Significant differences could not be detected between $\mathrm{CW}_{\mathrm{Max}}$ and $\mathrm{SA}_{\mathrm{Max}}$ and between $\mathrm{CW}_{\mathrm{Min}}$ and $\mathrm{SA}_{\mathrm{Min}}$.

\subsubsection{Discussion and Conclusions}

Obviously, only the VRP-algorithms are suitable tools for generating clusters of approximately the same size with short overall distances, even though the resulting tour-lengths are longer than those generated with the other clustering-techniques. Homogenous clusters are generated independently from the starting point with the VRP-heuristics.

The hierarchical clustering is not appropriate for this purpose, because clusters of different sizes result. This is due to the fact that the algorithm tries to minimise the overall sum of the within-cluster sum of squares. Within this process the cluster-size is irrelevant. The same holds for the k-means algorithm, where the number of clusters is 
pre-defined instead of the cluster-size. By minimising the sum of the within-cluster sum of squares the cluster-size is again disregarded. This leads to smaller overall distances but, seen as a drawback in our context, to highly variable cluster-sizes.

The equal area partitioning aims at dividing the study area into partitions of approximately the same size. Thus, all the resulting clusters represent nearly the same area, but not the same number of sample points, because the sampling density varies within a sub-district. Also the use of the compartments as clusters leads to highly variable cluster-sizes. Using the planning units as clusters yields also only small mean deviations from the (optimal) benchmark solution, but shows the absolutely highest CV of cluster sizes.

With mean deviations of less than $15 \%$ from the benchmark solution, the best VRPsolutions are close to the optimal solution. Unfortunately, some few starting points lead to inacceptable solutions with deviations of more than $50 \%$. Regarding the benchmark solutions, it has to be kept in mind that a time- and thus distance limit for every tour exist. Such a limit does not exist within the VRP-heuristics; rather tours of five sample plots are built. In contrast to the benchmark solution, tours with less than five plots are exceptional. Hence, the resulting within-cluster and overall distances are longer. This form of clustering becomes especially disadvantageous in cases where spatial clusters of sample points exist. In such cases sample points of different spatial clusters will be combined to a tour resulting in larger tour lengths.

The comparison of the three different VRP-heuristics shows that the RTR-algorithm seems to be the preferable heuristic. It yields the smallest deviation from the benchmark solution and the smallest range between the worst and best solution, generated with different starting points. This dependence of the results from the starting point is one of the main problems of using the VRP-heuristics for clustering, even though the differences between the two extreme values are mostly small. For practical applications the position of the administration or the central office could be used as a starting point or several runs could be executed and the best result used. Due to the short computationtimes, the latter is easily possible. In cases where more than one starting point exists, it should be possible to solve the routing-problem with one of the algorithms for the Multi Depot Vehicle Routing Problem (MDVRP). Another possibility would be to split the area of interest into several sub-units and apply the VRP-algorithms therein afterwards.

An advantage of the VRP-heuristics is that they can be applied even for a high number of sample points, where an optimal solution cannot be calculated at all or at least in an acceptable time. With help of the VRPH-library (Gröer et al., 2010) they are easy to implement and can be calculated fast.

Even though we consider three of the presented heuristics as suitable tools, their use is not free of problems and the results have to be questioned. Thus it is questionable, if we have chosen a realistic calculation unit when deciding for forest sub-districts. A subdistrict is a human-made planning unit, the shape of which is not completely dependent on spatial reasons. Thus, closely neighbouring sample points might belong to different sub-districts. Nevertheless, the sub-districts are a meaningful calculation unit. The number of sample points within them is manageable for the presented heuristics and it 
makes sense to plan the execution of the inventory in accordance with existing planning units.

Clustering is usually aimed at achieving a high variation within the clusters and a low variation between them. Due to the fact that neighbouring sample plots often fall into the same or similar stand type, the fulfilment of this request cannot be ensured with the algorithms. To increase variability within clusters, the clusters would have to be enlarged to an extent that exceeds the daily workload of an inventory team, or spatial contiguity would have to be disregarded, in contradiction to the requirement of short sample point distances within clusters. Unfortunately, we could not use exact distances between the terrestrial sample plots in our calculations. This is due to the fact, that only values of easting and northing and not of the elevation were available. We used Euclidean Distances as proxies and are aware of the facts that this leads to biased results and that the real distances are longer. In our application the distances between sample points are short in most cases - with a mean tour length of $1.5 \mathrm{~km}$ and a tour of 5 sample points approximately $300 \mathrm{~m}$ (Figure 5.4) - and so the differences between the real and the Euclidean Distances will likely be negligible. Moreover, the use of these algorithms might help to estimate the resources needed for executing the inventory, which is interesting for the responsible authorities. The generated clusters can be used as suggestions for the execution of the inventory or as clusters in further clustered sub-sampling. Due to the large number of sample points in the Forest subdistricts, the use of heuristics seems to be a good choice for calculating solutions in an acceptable time.

\section{Acknowledgements}

We thank the German Science Foundation (DFG) for financial support of this study (Sachbeihilfe SA 415/5-1) and Dr. T. Böckmann of the Lower Saxony Forest Planning Office for his kind provision of the inventory data. 


\section{Chapter 6}

\section{General Discussion}

The present thesis aims at further increasing the efficiency of double sampling for stratification (2st) in repeated forest inventories. Three approaches for achieving this aim are presented in chapters 2-4. All these approaches are applied in individual case studies and the results are thoroughly discussed in the respective chapters. A further case study deals with the problem of clustering existing sample points and compares different approaches (chapter 5). In the following, the results of these four case studies are only briefly and generally discussed.

The first case study (chapter 2) presents a Composite Estimator (Schaible, 1978) that combines data from a current inventory occasion with growth model based updates of data from a previous inventory occasion. In this study, the effect of reducing the number of terrestrial sample plots at the second occasion was analysed. It was assumed that incorporating the simulation results from all first occasion plots can decrease the loss in precision, and thereby raise the efficiency at the second occasion. This assumption could be verified in so far as the precision of the Composite Estimator was always higher than that of pure 2st. However, considering the efforts for updating the previous inventory data, an increase of efficiency could not clearly be shown in the case study. As discussed in chapter 2.3.3, this can be explained by the fact that the bias of the predictions was considerably high. It has to be considered that the evaluation in the case study was done for target populations and not for the complete stand. Errors in the simulations of these small populations cannot be outbalanced, as it is the case for bigger populations. Applications of the Composite Estimator, as presented in this case study, cannot be recommended for the Forest District Inventory of Lower Saxony, due to the inefficiency of this method. However, advances in forest growth-modelling may lead to smaller biases of the simulations and thereby a higher efficiency of the Composite Estimator. The alternative estimators presented by Green \& Strawderman (1990, 1991), were shown to be superior to the composite estimator in the multivariate case if one of the two composed estimators is biased. Our application can easily be seen as such a multivariate case with one biased and one unbiased estimator, because the estimated volumes per ha of the different target populations can be arranged as components of a vector. However, those alternative estimators assume independence between the two composed estimators and, moreover, equal variances of the estimators the vector comprises. Both assumptions are violated in our application.

Even though the bias of the growth simulations used in the preceding approach is relatively high, the correlations between the results of these simulations and the data 
from the current inventory occasion are considerably large. These large correlations can successfully be exploited in the three-phase design presented in chapter 3 (2st,2lr), that combines 2 st with double sampling for regression (2lr). As the case study shows, both data from a previous inventory occasion and growth model-based updates of these data can be used together with current inventory data in this approach. Mostly, the correlations between the simulations and the current inventory data are higher than those between first and second occasion inventory data. This positive effect of using the growth model emphasises the reliability of its simulations, as already shown in different studies (e.g. Vospernik et al., 2010). Only for the big Oaks the use of simulations does not improve the estimates; reasons are thoroughly discussed in chapter 3.3.5. In general, the presented approach is a suitable tool for the reduction of inventory costs. If a certain decrease of precision is accepted, the proposed design can raise the efficiency and thereby lead to remarkable savings. Obviously, a repeated application of this sampling procedure would lead to a gradual reduction of sample size. Therefore, and because it coincides with a loss in precision, this three-phase design can especially be recommended for low-cost inventories between two full 2 st inventories. The expected enhancements of forest growth models will further increase the savings gained by including their results into repeated forest inventories.

Using data of previous inventory occasions, as done in the first two case studies is a common means for raising the efficiency of sampling schemes. In Forest Science applications are e.g. known from Sampling with partial replacement-schemes (SPR) (Scott \& Köhl, 1994) or in the context of Rotating Panels (van Deusen, 1996). Differing from these two approaches, the two procedures presented in this thesis aim at a temporal reduction of the number of terrestrial sample plots for reducing the inventory costs. In contrast, the omitted sample points are replaced by others in SPR-schemes, leading to the same sample size and thereby the same costs for terrestrial sampling. Also in Rotating Panels no temporary reduction of sample size takes place. Rather, specific representative sub-samples are measured at every inventory occasion and the data of all other sub-samples measured before are updated, leading to a constant sampling effort per time interval.

In another case study the extension of 2 st by clustered sub-sampling to a three-phase design was applied (chapter 4). New estimators for the mean and the variance were presented for the Ratio-to-Size approach. Clustering generally leads to a loss in precision (Cochran, 1977), and therefore the new design can only be advantageous if its inventory costs are remarkably lower than those of pure 2 st. In the test application, no remarkable differences of the inventory costs could be detected between the two sampling schemes. Possible explanations can be seen in the relatively small spatial extent of the forest districts and in the high density and easy accessibility of terrestrial sampling points in Lower Saxony. Thus, the presented system cannot be recommended for applications in small and intensively sampled regions with well-developed infrastructure. Nevertheless, reasonable applications may be possible in remote and large areas. Usually, clusters are supposed to cover a high variability. Obviously, this aim is contradictory to the aim of spatially connected, compact clusters. Even though the new approach could not be proved to be advantageous in the current case study, its development provides the 
necessary estimators for applications under more appropriate conditions.

Following the case study in chapter 5 , it is possible to convert existing sampling schemes into clustered designs through a subsequent clustering of sample points. If such a conversion is desired, the use of each of the three VRP-heuristics 'Record-to-Record Travel', 'Savings' or 'Simulated Annealing' seems to be an appropriate technique for rapidly building clusters of homogenous sizes. Results of good quality can be calculated easily and fast using these techniques, as the comparison with benchmark-solutions shows. A problem of using these heuristics in the context of clustering may be seen in the dependence of the results on the selected starting point, which is required for the calculations. Yet, the results of the case study indicate that the influence of the starting point position is relatively small. However, this problem cannot be neglected and should be handled with care in applications. Using existing planning units as clusters does not require further calculations, but the resulting clusters are of variable size and can therefore not be recommended for efficient forest inventories. The same holds for the results of the three other clustering-algorithms: 'k-means', 'equal area partitioning' and 'hierarchical clustering'. As pointed out above, such conversion into clustered sampling schemes can only be recommended for large and remote areas. For other cases the expected decrease in precision will be considerably high, associated with only relatively small savings through the reduction of travel costs. Moreover, these clusters of sample points can be used in fully sampled inventories as proposals for daily workloads of inventory teams.

Trying to evaluate the results of the case studies, it has to be kept in mind that they mostly focus on efficiency and the overall sampling error. Other errors like assessment, prediction or non-statistical errors (Köhl et al., 2000) are not considered, even though they are known to have an influence on the precision of estimation. However, it is not possible to influence them through methodological developments like the ones presented in this thesis.

Another aspect that has to be considered in the discussion of the results is the fact, that not only the efficiency is important in the evaluation of forest inventory techniques. As Kleinn \& Ståhl (2006) and Kleinn et al. (2010) point out there are a lot of other aspects that are worth to be taken into consideration when setting up new forest inventories. Nevertheless, further improvements of sampling techniques are valuable. 


\section{Chapter 7}

\section{Summary}

Double sampling for stratification is an efficient sampling scheme that could prove its practicability in different forest inventories. Nevertheless, further increases of efficiency are desired. Several approaches for achieving this aim are presented and discussed separately in this thesis. The approaches are tested in case studies with data from the Forest District Inventory of Lower Saxony.

The first approach (chapter 2) deals with double sampling for stratification in repeated inventories. A Composite Estimator is constructed with data from the current inventory occasion and simulation results of the preceding occasion. Therein the sample size of the current inventory can be reduced, whereas the full number of sample plots of the previous occasion is used for simulations. Even though such an estimator can be constructed, the case study indicates that no, or at least no sufficient, increase of efficiency can be achieved. This can be explained by the big differences between the results of the reduced, current terrestrial inventory and the predicted volumes of the simulations. An increase of the efficiency of this approach can only become possible through further developments of forest growth models.

With a three-phase sampling design, that combines double sampling for stratification and double sampling for regression, a higher efficiency can, however, be achieved for applications in repeated inventories (chapter 3). Estimators for the mean and the variance are presented that are based on the so-called infinite population approach in the first phase. The correlations between current inventory data and growth-simulations on the basis of the previous inventory are used in this approach. Instead of the simulations, the data of the previous inventory can simply be used directly for calculating the correlations. However, using the simulations as regressors mostly leads to better results. The efficiency of the presented three-phase design is higher than the one of the classical two-phase design if the sample size of the second inventory occasion is reduced and a decrease in precision is accepted. Thus, the use of the data from a previous inventory occasion in terms of a strata-wise regression estimator could be shown to be successful and superior to the Composite Estimator.

Another presented method is the expansion of the double sampling for stratification design by clustered sub-sampling to a three-phase design (chapter 4). For the Ratioto-Size approach as well as for the unbiased approach estimators for the mean and the variance are given. Compared to pure double sampling for stratification, using this three-phase design cannot increase the efficiency in the corresponding case study. Reasons for this might be seen in the small spatial extent of the forest districts and the 
high sampling density in there. Meaningful applications of this procedure are possibly thinkable in large areas with bad infrastructure.

In a further case study, it is aimed to cluster existing sample points into clusters of homogenous size (chapter 5). This clustering shall help to optimise the travel time for the inventory of sampling points. Therefore, seven different methods are tested and their results are compared. Moreover, the quality of the solutions is evaluated through a comparison with optimised benchmark-solutions. It becomes obvious that three algorithms of the Vehicle Routing Problem are well suited for generating such clusters of homogenous size. Three clustering-algorithms as well as using planning units as clusters do not produce clusters of very homogenous size, and can thus not be recommended. 


\section{Chapter 8}

\section{Zusammenfassung}

Die zweiphasige Stichprobe zur Stratifizierung ist ein effizientes Inventurverfahren, das seine Praxistauglichkeit in verschiedenen Waldinventuren unter Beweis stellen konnte. Dennoch sind weitere Effizienzsteigerungen wünschenswert. In der vorliegenden Arbeit werden verschiedene Ansätze die Effektivität dieses Verfahrens zu steigern separat vorgestellt, in Fallstudien mit Daten der Niedersächsischen Betriebsinventur getestet und diskutiert.

Der erste Ansatz (Kapitel 2) beschäftigt sich mit der Anwendung der zweiphasigen Stichprobe zur Stratifizierung in Wiederholungsinventuren. In einem Zusammengesetzten Schätzer werden Daten eines aktuellen mit Simulationsergebnissen des vorhergehenden Inventurdurchgangs kombiniert. Dabei kann der Stichprobenumfang der aktuellen Inventur verringert werden, während die Daten aller Inventurpunkte des vorherigen Durchgangs für Simulationen genutzt werden. Zwar kann ein solcher Schätzer konstruiert werden, jedoch lässt die Fallstudie darauf schließen, dass keine, oder zumindest keine ausreichende, Effizienzsteigerung erzielt werden kann. Erklärt werden kann dies durch die großen Unterschiede zwischen den aktuellen Inventurergebnissen aus den reduzierten Inventuren und den prognostizierten Volumina aus den Simulationen. Eine Erhöhung der Effizienz dieses Verfahrens könnte nur durch Weiterentwicklungen der Waldwachstumsmodelle möglich werden.

In Wiederholungsinventuren kann jedoch eine höhere Effizienzsteigerung mit einem dreiphasigen Verfahren erreicht werden, das die zweiphasige Stichprobe mit der zweiphasigen Regressionsstichprobe kombiniert (Kapitel 3). Mittelwert- und Varianzschätzer, die auf dem sogenannten infinite population approach in der ersten Phase beruhen, werden präsentiert. Genutzt werden dabei die Korrelationen zwischen den aktuellen Inventurergebnissen und den Wachstumssimulationen auf der Basis des vorherigen Inventurdurchgangs. Statt der Simulationsergebnisse können auch einfach die Ergebnisse des vorherigen Inventurdurchgangs zur Berechnung der Korrelationen genutzt werden. Allerdings führt die Nutzung der Simulationsergebnisse als Regressor in den meisten Fällen zu besseren Ergebnissen. Bei verringertem Stichprobenumfang der Folgeinventur und damit einhergehendem Präzisionsverlust, ist die Effizienz des dreiphasigen Verfahrens höher als die des klassischen zweiphasigen Verfahrens. Die Nutzung der Vorinventur in Form eines stratenweisen Regressionsschätzers hat sich damit als erfolgreich und gegenüber dem zusammengesetzten Schätzer als deutlich überlegen gezeigt.

Als weiterer Ansatz wird die Erweiterung der zweisphasigen Stichprobe zur Stratifizierung um eine geclusterte Unterstichprobe zu einem dreiphasigen Design vorgestellt 
(Kapitel 4). Sowohl für den Ratio-to-Size- als auch für den unverzerrten Ansatz werden entsprechende Mittelwert- und Varianzschätzer präsentiert. Verglichen mit dem zweiphasigen Verfahren, führt dieses dreiphasige Design in der Fallstudie zu keiner Effizienzsteigerung. Gründe hierfür können in der vergleichsweise kleinen Größe der Forstämter und der hohen Stichprobendichte der Niedersächsischen Betriebsinventur gesehen werden. Sinnvolle Anwendungen dieses Verfahrens sind aber möglicherweise unter anderen Erschließungsbedingungen in Großgebieten denkbar.

In einer weiteren Fallstudie wird versucht existierende Probepunkte in Clustern von homogener Größe zusammenzufassen (Kapitel 5). Eine solche Zusammenfassung soll der Optimierung der Wegzeiten bei der Aufnahme von Inventurpunkten dienen. Dazu werden sieben verschiedene Methoden getestet und deren Ergebnisse miteinander verglichen. Durch einen Vergleich mit optimierten Richtwert-Lösungen wird zudem die Qualität dieser Lösungen evaluiert. Es zeigt sich, dass drei Algorithmen des Vehicle Routing Problems gut dazu geeignet sind, Cluster von homogener Größe zu erstellen. Nicht empfohlen werden kann dagegen die Verwendung von drei anderen ClusterAlgorithmen, sowie die Nutzung von Bewirtschaftungseinheiten als Cluster, da diese Methoden zu Clustern von sehr heterogener Größe führen. 


\section{Bibliography}

Albert, M. \& Hansen, J. (2007). Ein Entscheidungsunterstützungssystem für die multifunktionale Forstplanung auf Landschaftsebene. Forst und Holz, 62, 14-18.

Albrecht, A., Hein, S., Kohnle, U., \& Biber, P. (2009). Evaluierung des Waldwachstumssimulators Silva 2.2 anhand langfristiger ertragskundlicher Versuchsflächen in Baden-Württemberg. Allgemeine Forst- und Jagdzeitung, 180, 55-64.

Albrecht, A., Kohnle, U., \& Nagel, J. (2011). Übertragbarkeit empirischer statistischer Waldwachstumsmodelle: Prüf- und Anpassungsverfahren anhand des Beispiels von BWinPro für Baden-Württemberg. Allgemeine Forst- und Jagdzeitung, 182(1/2), $11-23$.

Anderberg, M. R. (1973). Cluster Analysis for Applications. Academic Press.

Andersson, G., Flisberg, P., Lidén, B., \& Rönnqvist, M. (2008). RuttOpt - a decision support system for routing of logging trucks. Canadian Journal of Forest Research, $38,1784-1796$.

Baldacci, R., Toth, P., \& Vigo, D. (2010). Exact algorithms for routing problems under vehicle capacity constraints. Annals of Operations Research, 175(1), 213-245.

Böckmann, T. (2004). Möglichkeiten und Grenzen von Waldwachstumsmodellen aus Sicht der forstlichen Praxis. In M. Hanewinkel \& K. von Teuffel (Eds.), Waldwachstumsmodelle für Prognosen in der Forsteinrichtung - Stand der Wissenschaft in Mitteleuropa, volume 50 of Berichte Freiburger Forstliche Forschung (pp. 95-102).: Forstliche Versuchs- und Forschungsanstalt Baden-Württemberg.

Böckmann, T., Saborowski, J., Dahm, S., Nagel, J., \& Spellmann, H. (1998). Die Weiterentwicklung der Betriebsinventur in Niedersachsen. Forst und Holz, 53(8), 219-226.

Bergel, D. (1973). Formzahluntersuchungen an Buche, Fichte, europäischer Lärche und japanischer Lärche zur Aufstellung neuer Massentafeln. Allgemeine Forst- und Jagdzeitung, 144, 117-124.

Bergel, D. (1974). Massentafeln für Nordwestdeutschland II: Eiche, Roteiche, Kiefer. Niedersächsische Forstliche Versuchsanstalt Göttingen.

Bickford, C. A., Mayer, C. E., \& Ware, K. D. (1963). An Efficient sampling Design for Forest Inventory: The Northeastern Forest Resurvey. Journal of Forestry, 61, $826-833$. 
Bierer, D. (2008). Composite Estimation of Stand Tables. PhD thesis, Fakultät für Forstwissenschaften und Waldökologie der Georg-August-Universität Göttingen.

Brassel, P. \& Köhl, M. (2001). Visions. In P. Brassel \& H. Lischke (Eds.), Swiss National Forest Inventory: Methods and Models on the Second Assessment (pp. 321-326).

Chojnacky, D. C. (1998). Double Sampling for Stratification: a Forest Inventory Application in the Interior West. USDA Forest Service Rocky Mountain Forest and Range Experiment Station Research Paper, RP-7, 1-20.

Clarke, G. \& Wright, J. (1964). Scheduling of vehicles from a central depot to a number of delivery points. Operations Research, 12, 568-581.

Cochran, W. G. (1977). Sampling Techniques. John Wiley \& Sons New York Chichester Brisbane Toronto Singapore, 3 edition.

Cordeau, J.-F., Gendreau, M., Laporte, G., Potvin, J.-Y., \& Semet, F. (2002). A Guide to Vehicle Routing Heuristics. Journal of the Operational Research Society, 53(5), $512-522$.

Dahm, S. \& Saborowski, J. (1998). Neukonzeption der niedersächsischen kontrollstichprobe. In Deutscher Verband Forstlicher Forschungsanstalten, Sektion Forstliche Biometrie und Informatik - 10. Tagung, Universität Freiburg (pp. 24-31).

Dantzig, G. \& Ramser, J. (1959). The Truck Dispatching Problem. Management Science, 6, 80-91.

de Vries, P. G. (1986). Sampling Theory for Forest Inventory. Springer-Verlag Berlin Heidelberg New York London Paris Tokyo.

Dueck, G. (1993). New optimization Heuristics. Journal of Computational Physics, 104, 86-92.

Fabrika, M. \& Ďurský, J. (2006). Sustainable Forest Management, Growth Models for Europe., chapter Implementing Tree Growth Models in Slovakia, (pp. 315-341). Springer-Verlag Berlin Heidelberg.

Fattorini, L., Marcheselli, M., \& Pisani, C. (2006). A Three-Phase Sampling Strategy for Large-Scale Multiresource Inventories. Journal of Agricultural, Biological and Enviromental Statistics, 11(3), 296-316.

Flisberg, P., Lidén, B., \& Rönnqvist, M. (2009). A hybrid method based on linear programming and tabu search for routing of logging trucks. Computers 86 Operations Research, 36, 1122-1144.

Forgy, E. W. (1965). Cluster Analysis of Multivariate Data: Efficiency vs. Interpretability of Classifications. Biometrics, 21, 768-769.

Frayer, W. (1979). Multi-Level Sampling Designs for Ressource Inventories. Rocky Mountain Forest and Range Experiment Station USDA Forest Service. 
Gabler, K. \& Schadauer, K. (2007). Some Approaches and Designs of Sample-based National Forest Inventories. Austrian Journal of Forest Science, 124, 105-133.

Gasparini, P., Tosi, V., \& DiCosmo, L. (2010). National Forest Inventories. Pathways for Common Reporting, chapter Italy, (pp. 311-331). Springer Heidelberg Dordrecht London New York.

Gillis, M. D., Boudewyn, P., Power, K., \& Russo, G. (2010). National Forest Inventories. Pathways for Common Reporting, chapter Canada, (pp. 97-111). Springer Heidelberg Dordrecht London New York.

Green, E. J. \& Strawderman, W. E. (1986). Reducing sample size through the use of a composite estimator: an application to timber volume estimation. Canadian Journal of Forest Research, 16, 1116-1118.

Green, E. J. \& Strawderman, W. E. (1990). Combining Inventory Estimates with Possibly Biased Auxiliary Information. Forest Science, 36(3), 693-704.

Green, E. J. \& Strawderman, W. E. (1991). A James-Stein Type Estimator for Combining Unbiased and Possibly Biased Estimators. Journal of the American Statistical Association, 86(416), 1001-1006.

Gregoire, T. (2005). Sampling with partial replacement bibliography, 1942 - present.

Gregoire, T. G. \& Valentine, H. (2008). Sampling Strategies for Natural Ressources and the Environment. Chapman \& Hall/CRC. Boca Raton, London, New York.

Gröer, C., Golden, B., \& Wasil, E. (2010). A library of local search heuristics for the vehicle routing problem. Mathematical Programming Computation, 2, 79-101.

Gschwantner, T., Gabler, K., Schadauer, K., \& Weiss, P. (2010). National Forest Inventories. Pathways for Common Reporting, chapter Austria, (pp. 57-71). Springer Heidelberg Dordrecht London New York.

Hahsler, M. \& Hornik, K. (2007). TSP-Infrastructure for the Traveling Salesperson Problem. Journal of Statistical Software, 23(2), 1-21.

Hahsler, M. \& Hornik, K. (2011). Traveling Salesman Problem (TSP). R-package version 1.0-6.

Hansen, J. (2006). Der WaldPlaner - Ein System zur Entscheidungsunterstützung in einer nachhaltigen Forstwirtschaft. In A. Degenhardt \& U. Wunn (Eds.), Beiträge von der 18. Jahrestagung der Sektion Biometrie und Informatik des DVFFA in Trippstadt., Die Grüne Reihe (pp. 112-119).

Hartigan, J. A. (1975). Clustering Algorithms. John Wiley \& Sons New York London Sydney Toronto.

Hartigan, J. A. \& Wong, M. (1979). A K-Means Clustering Algorithm. Applied Statistics, 28(1), 100-108. 
Härkönen, S., Mäkinen, A., Tokola, T., Rasinmäki, J., \& Kalliovirta, J. (2010). Evaluation of forest growth simulators with NFI permanent sample plot data from Finland. Forest Ecology and Management, 259(3), 573-582.

Kangas, A. \& Maltamo, M., Eds. (2006). Forest Inventory. Methodology and Applications, volume 10 of Managing Forest Ecosystems. Springer Heidelberg Dordrecht London New York.

Köhl, M. (1994). Statistisches Design für das zweite Schweizerische Landesforstinventar: Ein Folgeinventurkonzept unter Verwendung von Luftbildern und terrestrischen Aufnahmen. Mitteilungen der Eidgenössischen Forschungsanstalt für Wald, Schnee und Landschaft, 69, 3-141.

Köhl, M., Traub, B., \& Paivinen, R. (2000). Harmonisation and standardisation in multi-national environmental statistics - Mission impossible? Environmental Monitoring and Assessment, 63(2), 361-380.

Kirkpatrick, J., Gelatt, C., \& Vecchi, M. (1983). Optimization by Simulated Annealing. Science, 220, 671-680.

Kleinn, C. (1994). Comparison of the performance of line sampling to other forms of cluster sampling. Forest Ecology and Management, 68, 365-373.

Kleinn, C. (1996). Ein Vergleich der Effizienz von verschiedenen Clusterformen in forstlichen Großrauminventuren. Forstwissenschaftliches Centralblatt, 115, 378-390.

Kleinn, C. \& Ståhl, G. (2006). Forest Inventories Generate Statistically Sound Information on the Forest Resource, But Do Our Data and Information Really matter? In R. E. McRoberts, G. A. Reams, P. C. van Deusen, \& W. H. McWilliams (Eds.), Proceedings of the Eighth Annual Forest Inventory and Analysis Symposium (pp. 71-77).

Kleinn, C., Ståhl, G., Fehrmann, L., \& Kangas, A. (2010). Issues in forest inventories as an input to planning and decision processes. Allgemeine Forst- und Jagdzeitung, $181(11 / 12), 205-210$.

Kroiher, F. (2006). Zeit- und Kostenerfassungen. In H. Polley (Ed.), Bundeswaldinventur: Weiterentwicklung des Inventurverfahrens durch Integration von Erdbeobachtungsdaten.

Lanz, A., Brändli, U.-B., Brassel, P., Ginzler, C., Kaufmann, E., \& Thürig, E. (2010). National Forest Inventories. Pathways for Common Reporting, chapter Switzerland, (pp. 555-565). Springer Heidelberg Dordrecht London New York.

Laporte, G. (2009). Fifty Years of Vehicle Routing. Transportation Science, 43(4), 408-416.

Lawrence, M., McRoberts, R. E., Tomppo, E. O., Gschwantner, T., \& Gabler, K. (2010). National Forest Inventories. Pathways for Common Reporting, chapter Comparisons of National Forest Inventories, (pp. 19-32). Springer Heidelberg Dordrecht London New York. 
Bibliography

Li, F., Golden, B., \& Wasil, E. (2005). Very large-scale vehicle routing: new test problems, algorithms, and results. Computers $\&$ Operations Research, 32, 1165-1179.

Lloyd, S. P. (1982). Least squares quantization in PCM. IEEE Transactions on Information Theory, 28(2), 128-137.

Loetsch, F. \& Haller, K. (1973). Forest Inventory. Volume 1. BLV Verlagsgesellschaft, München Bern Wien.

Lund, H. (1998). IUFRO Guidelines for Designing Multipurpose Ressource Inventories: A Project of IUFRO Research Group 4.02.02, volume 8 of IUFRO World Series. IUFRO Secretariat Vienna.

MacQueen, J. (1967). Some methods for classification and analysis of multivariate observations. In L. M. LeCam \& J. Neyman (Eds.), Proceedings of the Fifth Berkeley Symposium on Mathematical Statistics and Probability, volume 1 (pp. 281-297).: Berkeley, CA: University of California Press.

Mandallaz, D. (2008). Sampling Techniques for Forest Inventories. Chapman \& Hall/CRC. Boca Raton, London, New York.

McRoberts, R. E., Ståhl, G., Vidal, C., Lawrence, M., Tomppo, E. O., Schadauer, K., Chirici, G., \& Bastrup-Birk, A. (2010a). National Forest Inventories. Pathways for Common Reporting, chapter National Forest Inventories: Prospects for Harmonised International Reporting, (pp. 33-43). Springer Heidelberg Dordrecht London New York.

McRoberts, R. E., Tomppo, E., Schadauer, K., Vidal, C., Ståhl, G., Chirici, G., Lanz, A., Cienciala, E., Winter, S., \& Smith, W. B. (2009). Harmonizing National Forest Inventories. Journal of Forestry, 107(4), 179-187.

McRoberts, R. E. \& Tomppo, E. O. (2007). Remote sensing support for national forest inventories. Remote Sensing of Environment, 110, 412-419.

McRoberts, R. E., Tomppo, E. O., \& Næsset, E. (2010b). Advances and emerging issues in national forest inventories. Scandinavian Journal of Forest Research, 25(4), $368-381$.

Metropolis, N., Rosenbluth, A. W., Rosenbluth, M. N., Teller, A. H., \& Teller, E. (1953). Equation of State Calculations by Fast Computing Machines. Journal of Chemical Physics, 21(6), 1087-1092.

Nagel, J. (1996). Anwendungsprogramm zur bestandesbewertung und zur prognose der bestandesentwicklung. Forst und Holz, 51(3), 76-78.

Nagel, J. (2004). Einsatz des Waldwachstumssimulators BWINPro in der Forsteinrichtung. In M. Hanewinkel \& K. von Teuffel (Eds.), Waldwachstumsmodelle für Prognosen in der Forsteinrichtung - Stand der Wissenschaft in Mitteleuropa, volume 50 of Berichte Freiburger Forstliche Forschung (pp. 85-94).: Forstliche Versuchs- und Forschungsanstalt Baden-Württemberg. 
Nagel, J., Albert, M., \& Schmidt, M. (2002). Das waldbauliche prognose- und entscheidungsmodell bwinpro 6.1. Forst und Holz, 57(15/16), 486-493.

Nagel, J., Duda, H., \& Hansen, J. (2006). Forest simulator bwinpro7. Forst und Holz, $61,427-429$.

Nagel, J. \& Schmidt, M. (2006). Sustainable Forest Management, Growth Models for Europe., chapter The Silvicultural Decision Support System BWINPro, (pp. 59-63). Springer-Verlag Berlin Heidelberg.

Neyman, J. (1938). Contribution to the Theory of Sampling Human Populations. Journal of the American Statistical Association, 33(201), 101-116.

Niedersächsisches Forstplanungamt (2001). Anweisung zur Betriebsinventur. Niedersächsisches Forstplanungamt, Wolfenbüttel.

Nothdurft, A., Borchers, J., Niggemeyer, P., Saborowski, J., \& Kändler, G. (2009). Eine Folgeaufnahme einer Betriebsinventur als zweiphasige Stichprobe zur Stratifizierung. Allgemeine Forst- und Jagdzeitung, 180, 133-140.

Overbeck, M. \& Schmidt, M. (2012). Modelling infestation risk of Norway spruce by Ips typographus (L.) in the Lower Saxon Harz Mountains (Germany). Forest Ecology and Management, 266, 115-125.

Polley, H., Schmitz, F., Hennig, P., \& Kroiher, F. (2010). National Forest Inventories. Pathways for Common Reporting, chapter Germany, (pp. 223-243). Springer Heidelberg Dordrecht London New York.

Pretzsch, H. (2002). Application and Evaluation of the Growth Simulator SILVA 2.2 for Forest Stands, Forest Estates and Large Regions. Forstwissenschaftliches Centralblatt, Supplement 1, 28-51.

Pretzsch, H. (2009). Forest Dynamics, Growth and Yield. Springer-Verlag Berlin Heidelberg.

Pretzsch, H., Biber, P., Ďurský, J., \& Sodtke, R. (2006). Sustainable Forest Management, Growth Models for Europe., chapter The Individual-Tree-Based Stand Simulator SILVA, (pp. 78-84). Springer-Verlag Berlin Heidelberg.

Pretzsch, H. \& Ďurský, J. (2001). Evaluierung von Waldwachstumssimulatoren auf Baum- und Bestandesebene. Allgemeine Forst- und Jagdzeitung, 172, 146-150.

R Core Team (2012). R: A Language and Environment for Statistical Computing. R Foundation for Statistical Computing, Vienna, Austria. ISBN 3-900051-07-0.

Rao, J. (1973). Double Sampling for Stratification and Analytical Surveys. Biometrika, $60(1), 125-133$.

Rao, J. (2003). Small area estimation. Wiley Series in Survey Methodology.Hoboken, New Jersey. 
Saborowski, J. (1994). Möglichkeiten zur Effektivitätssteigerung zweiphasiger Stichprobeninventuren. In Biometrische Beiträge zu statischen und dynamischen Modellansätzen in der Forstwissenschaft und der Praxis. Tagungsbericht der Sektion Forstliche Biometrie u. Informatik, Martin (CSFR) 1991 (pp. 28-44).

Saborowski, J., Marx, A., Nagel, J., \& Böckmann, T. (2010). Double sampling for stratification in periodic inventories - Infinite population approach. Forest Ecology and Management, 260, 1886-1895.

Schaible, W. L. (1978). Choosing weights for composite estimators for small area statistics. In Proceedings of the Section on Survey Research Methods, American Statistical Association (pp. 741-746).

Schanz, H. (1996). Forstliche Nachhaltigkeit, volume 4 of Schriften aus dem Institut für Forstökonomie der Universität Freiburg.

Scheaffer, R. L., Mendenhall, W., \& Ott, R. L. (2006). Elementary Survey Sampling. Thomson Brooks/Cole.

Schmid, S., Zingg, A., Biber, P., \& Bugmann, H. (2006). Evaluation of the forest growth model SILVA along an elevational gradient in Switzerland. European Journal of Forest Research, 125, 43-55.

Schmidt, M., Hanewinkel, M., Kändler, G., Kublin, E., \& Kohnle, U. (2010). An inventory-based approach for modeling single-tree storm damage - experiences with the winter storm of 1999 in southwestern Germany. Canadian Journal of Forest Research, 40, 1636-1652.

Schreuder, H. T., Gregoire, T. G., \& Wood, G. B. (1993). Sampling Methods for multiressource Forest Inventories. John Wiley \& Sons, Inc., New York - Chichester Brisbane - Toronto - Singapore.

Scott, C. T. (1984). A New Look at Sampling with Partial Replacement. Forest Science, 30(1), 157-166.

Scott, C. T. (1993). Optimal Design of a plot cluster for monitoring. In K. Rennolls \& G. Gertner (Eds.), The optimal design of forest experiments and forest surveys (pp. 233-242).

Scott, C. T. \& Köhl, M. (1994). Sampling with Partial Replacement and Stratification. Forest Science, 40(1), 30-46.

Scott, C. T., Köhl, M., \& Schnellbächer, H. J. (1999). A comparison of Periodic and Annual Forest Surveys. Forest Science, 45(3), 433-451.

Shiver, B. D. \& Borders, B. E. (1996). Sampling techniques for forest resource inventory. John Wiley \& Sons, Inc., New York - Chichester - Brisbane - Toronto - Singapore. 
Singh, D. \& Singh, B. D. (1965). Some remarks on double sampling for stratification. Biometrika, 52(3), 587-590.

Sloboda, B., Gaffrey, D., \& Matsumura, N. (1993). Regionale und lokale Systeme von Höhenkurven für gleichaltrige Waldbestände. Allgemeine Forst- und Jagdzeitung, $164,225-228$.

Speidel, G. (1984). Forstliche Betriebswirtschaftslehre. Paul Parey, Hamburg und Berlin, 2 edition.

Särndal, C.-E., Swensson, B., \& Wretman, J. (2003). Model Assisted Survey Sampling. Springer-Verlag Berlin Heidelberg New York London Paris Tokyo.

Stierlin, H. R. \& Zinggeler, J. (2001). Terrestrial Inventory. In P. Brassel \& H. Lischke (Eds.), Swiss National Forest Inventory: Methods and Models on the Second Assessment (pp. 65-87).

Thiele, J. C. (2008). Beispielhafte Anwendung von zwei heuristischen Methoden der Tourenplanung für ein imaginäres Zellstoffwerk. Allgemeine Forst- und Jagdzeitung, $179(2 / 3), 33-42$.

Tomppo, E. O., Gschwantner, T., Lawrence, M., \& McRoberts, R. E., Eds. (2010a). National Forest Inventories. Pathways for Common Reporting. Springer Heidelberg Dordrecht London New York.

Tomppo, E. O., Schadauer, K., McRoberts, R. E., Gschwantner, T., Gabler, K., \& Ståhl, G. (2010b). National Forest Inventories. Pathways for Common Reporting, chapter Introduction, (pp. 1-18). Springer Heidelberg Dordrecht London New York.

Tomppo, E. O. \& Tuomainen, T. (2010). National Forest Inventories. Pathways for Common Reporting, chapter Finland, (pp. 185-206). Springer Heidelberg Dordrecht London New York.

van Deusen, P. C. (1996). Incorporating predictions into an annual forest inventory. Canadian Journal of Forest Research, 26, 1709-1713.

von Carlowitz, H.-C. (1713). Sylvicvltvra Oeconomica, Oder Haußwirthliche Nachricht und Naturmäßige Anweisung Zur Wilden Baum-Zucht. Johann Friedrich Braun, Leipzig.

von Lüpke, N., Nagel, J., \& Saborowski, J. (2011). Zusammengesetzte Schätzer für periodische Waldinventuren. In Deutscher Verband Forstlicher Forschungsanstalten, Sektion Forstliche Biometrie und Informatik - 22. Tagung (pp. 13-21).

Vospernik, S., Monserud, R. A., \& Sterba, H. (2010). Do individual-tree growth models correctly represent height:diameter ratios of Norway spruce and Scots pine? Forest Ecology and Management, 260(10), 1735-1753. 
Walvoort, D. J. J., Brus, D. J., \& de Gruijter, J. J. (2010). An R package for spatial coverage sampling and random sampling from compact geographical strata by $\mathrm{k}$ means. Computers \& Geosciences, 36, 1261-1267.

Walvoort, D. J. J., Brus, D. J., \& de Gruijter, J. J. (2012). spcosa: Spatial Coverage Sampling and Random Sampling from Compact Geographical Strata. R package version $0.3-0$.

Ward, J. H. (1963). Hierarchical Grouping to Optimize an Objective Function. Journal of the American Statistical Association, 58(301), 236-244.

Ware, K. D. \& Cunia, T. (1962). Continuous forest inventory with partial replacement of samples. Forest Science-Monograph, 3, 1-40.

Williams, M. S. (2001). Comparison of Estimation Techniques for a Forest Inventory in which Double Sampling for Stratification Is Used. Forest Science, 47(4), 563-576.

Zinggeler, J. (2001). Expenditure of the Terrestrial Inventory. In P. Brassel \& H. Lischke (Eds.), Swiss National Forest Inventory: Methods and Models on the Second Assessment (pp. 88-92).

Zinggeler, J. \& Herold, A. (1997). Zeitlicher und finanzieller Aufwand für die terrestrische Probenahme im zweiten Schweizerischen Landesforstinventar (LFI). Schweiz. Z. Forstwes., 148, 939-959. 